Linköping Studies in Science and Technology

Dissertation No. 1922

\title{
Peptide-Liposome Model Systems for Triggered Release
}

\author{
Camilla Skyttner
}

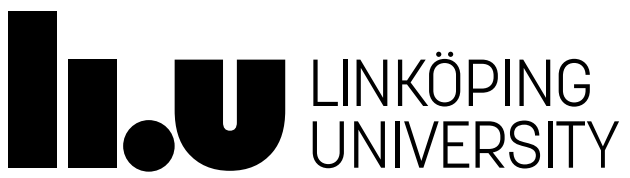

Division of Molecular Physics

Department of Physics, Chemistry and Biology

Linköping University, Sweden

Linköping 2018 
Cover: Artistic illustration of different modes of action of liposome-conjugated peptides (not to scale).

During the course of the research underlying this thesis, Camilla Skyttner was enrolled in Forum Scientium, a multidisciplinary doctoral programme at Linköping University, Sweden.

(C) Copyright 2018 Camilla Skyttner, unless otherwise noted

Skyttner, Camilla

Peptide-Liposome Model Systems for Triggered Release

ISBN: 978-91-7685-337-5

ISSN: 0345-7524

Linköping Studies in Science and Technology. Dissertation No. 1922

Electronic publication: http://www.ep.liu.se

Printed in Sweden by LiU-Tryck, Linköping 2018 
"Science is much more than a body of knowledge. It is a way of thinking. This is central to its success. Science invites us to let the facts in, even when they don't conform to our preconceptions."

Carl Edward Sagan 



\section{Abstract}

Liposomes are widely used in drug delivery to improve drug efficacy and to reduce side effects. For liposome-encapsulated drugs to become bioavailable and provide a therapeutic effect they must be released, which typically is a slow process that primarily relies on passive diffusion, liposome rupture or endocytotic uptake. Achieving drug concentrations within the therapeutic window can thus be challenging, resulting in poor efficacy and higher risks drug resistance. Finding means to modulate lipid membrane integrity and to trigger rapid and efficient release of liposomal cargo is thus critical to improve current and future liposomal drug delivery systems. The possibilities to tailor lipid composition and surface functionalization is vital for drug delivery applications but also make liposomes attractive model systems for studies of membrane active biomolecules.

The overall aim of this thesis work has been to develop new strategies for triggering and controlling changes in lipid membrane integrity and to study the interactions of membrane active peptides with model lipid membranes using both de novo designed and biologically derived synthetic amphipathic cationic peptides. Two different sets of designed peptides have been explored that can fold and heterodimerize into a coiled coil and helix-loop-helix fourhelix bundle, respectively. Conjugation of the cationic lysine rich peptides to liposomes triggered a rapid and concentration dependent release. The additions of their corresponding glutamic acid-rich complementary peptides inhibited the release of liposomal cargo. Possibilities to reduce the inhibitory effect by both proteolytic digestion of the inhibitory peptide and by means of heterodimer exchange have been investigated. Moreover, the effects of peptide size and composition and ability to fold have been studied in order to elucidate the factors that influence the membrane permeabilizing effects of the peptides.

In addition, the membrane activity of a the two-peptide bacteriocin PLNC8 $\alpha$ and PLNC8 $\beta$ has been explored using liposomes as a model system. PLNC8 $\alpha \beta$ are expressed by Lactobacillus plantarum and were shown to display pronounced membrane-partition folding coupling, leading to rapid release of liposome encapsulated carboxyfluorescein. PLNC8 $\alpha \beta$ also kill and suppressed growth of the gram-negative bacteria Porphyromonas gingivalis by efficiently damaging the bacterial membrane.

Although membrane active peptides are highly efficient in perturbing lipid membrane integrity, possibilities to trigger release using external stimuli are also of large interest for therapeutic applications. Light-induced heating of liposome encapsulated gold nanoparticles (AuNPs) has been shown by others as a potential strategy to trigger drug release. To facilitate fabrication of thermoplasmonic liposome systems we developed a simple method for synthesis of small AuNPs inside liposomes, using the liposomes as nanoscale reaction vessels. 
The work presented in this thesis provides new knowledge and techniques for future development of liposome-based drug delivery systems, peptide-based therapeutics and increase our understanding of peptide-lipid interactions. 


\section{Populärvetenskaplig sammanfattning}

Det finns många läkemedel som bryts ner för snabbt i kroppen, är giftiga eller svårlösliga men i övrigt fungerar bra. Ett sätt att göra dessa läkemedel mer effektiva och minimera svåra biverkningar är att kapsla in dem i mikroskopiska fettbubblor som kallas liposomer. Liposomer används därför med fördel tillsammans med olika läkemedel. Nya problem som kan uppstå är att läkemedlet läcker ut ur liposomen för långsamt vilket riskerar att göra läkemedlet verkningslöst. Därför kan en strategi för frisättning av läkemedlet från liposomen vara avgörande. Liposomernas sammansättning liknar den tunna hinna som omger kroppens alla celler, det så kallade cell-membranet, vilket gör dem väl lämpade för medicinska tillämpningar. Denna egenskap gör också att man kan använda liposomer som modellsystem för att studera hur naturligt förekommande proteiner och proteinfragment (peptider) påverkar cellmembranet.

Målet med arbete i den här avhandlingen är att utveckla nya strategier för att kontrollera frisättning av små molekyler från liposomer med hjälp av peptider som kan göra små hål i liposomernas yta (lipidmembran). Flera olika varianter av peptider har undersökts där några peptider gjorde hål i lipidmembranet och släppte ut de inkapslade molekylerna och några peptider blockerade denna process. Två strategier för att häva blockeringen undersöktes som ett led i utvecklingen av metoder för kontrollerad frisättning. En strategi som användes var att göra det möjligt för den blockerande peptiden att brytas ner i kroppen och den andra strategin var att plocka bort den blockerande peptiden med hjälp av ytterligare en peptid. Effekten av storlek och kemisk sammansättning på peptiderna samt deras förmåga att strukturera om sig som följd av interaktioner med liposomer studerades.

Därutöver har två naturligt förekommande peptider studerades med hjälp av ett liposommodellsystem. Dessa peptider utsöndras av en mjölksyrabakterie och kan förhindra tillväxten av och döda en sjukdomsframkallande bakterie genom att förstöra dess lipidmembran. Interaktionen med lipidmembranet i modellsystemet visade att interaktionen var snabb och resulterade i en strukturförändring hos peptiderna.

Ytterligare ett sätt att kontrollera frisättningen av molekyler från liposomer är att värma upp liposomerna, vilket gör lipidmembranet mer genomsläppligt. Genom att använda värmen som produceras när man lyser på nanometersmå partiklar av guld kan man öka frisättningen av molekyler genom att lysa på ställen på kroppen dit läkemedlet bör frisättas. Att effektivt kapsla in dessa nanopartiklar i liposomer kan dock vara komplicerat varför en ny metod har utvecklats som gör det möjligt att tillverka nanopartiklarna direkt i liposomerna,

Arbetet i denna avhandling har bidragit till ny kunskap som kan vara av stor nytta för fortsatt utveckling av system för kontrollerad frisättning av läkemedel från liposomer samt gett ökad 
förståelse för de interaktioner som är involverade i samspelet mellan peptider och lipidmembraner. 


\section{List of publications}

This thesis is based on the authors' contributions to the following five scientific papers:

\section{Paper I}

Seng Koon $\operatorname{Lim}^{\dagger}$, Camilla Sandén ${ }^{\dagger}$, Robert Selegård, Bo Liedberg, Daniel Aili

Tuning Liposome Membrane Permeability by Competitive Peptide Dimerization and Partitioning-Folding Interactions Regulated by Proteolytic Activity

Scientific Reports, 2016, 6:21123

\section{Paper II}

Camilla Skyttner, Karin Enander, Christopher Aronsson, Daniel Aili

Tuning Liposome Membrane Permeability by Competitive Peptide Heterodimerization and Heterodimer Exchange

Langmuir, 2018, 34(22):6529-6537

\section{Paper III}

Camilla Skyttner, Robert Selegård, Jakob Larsson, Christopher Aronsson, Karin Enander, Daniel Aili

Sequence and Length Optimization of Membrane Active Coiled Coils for Triggered Liposome Release

Submitted

${ }^{+}$These authors contributed equally to this work. 


\section{Paper IV}

Hazem Khalaf, Sravya Sowdamini Nakka, Camilla Sandén, Anna Svärd, Kjell Hultenby, Nikolai Scherbak, Daniel Aili, Torbjörn Bengtsson

Antibacterial Effects of Lactobacillus and Bacteriocin PLNC8 $\alpha \beta$ on the Periodontal Pathogen Porphyromonas Gingivalis

BMC Microbiology, 2016, 16:188

\section{Paper V}

Sushanth Gudlur, Camilla Sandén, Petra Matoušková, Chiara Fasciani, Daniel Aili Liposomes as Nanoreactors for the Photochemical Synthesis of Gold Nanoparticles Journal of Colloid Interface Science, 2015, 456:206-209. 


\section{Author contributions}

\section{Paper I}

Planned, conducted and analysed all experimental work together with Seng Koon Lim, with the exception that I conducted the MMP-7 experiments and Seng Koon Lim conducted the QCM-D experiments. The peptide synthesis was done by Robert Selegård. Wrote a minor part of the manuscript.

\section{Paper II}

Planned, conducted and analysed all experimental work apart from the peptide synthesis which was done by Christopher Aronsson. Wrote a major part of the manuscript.

\section{Paper III}

Planned, conducted and analysed all experimental work apart from the peptide synthesis which was done by Robert Selegård. Wrote a major part of the manuscript.

\section{Paper IV}

Planned and analysed all experimental work concerning the liposome model system, conducted the experiments together with Anna Svärd. Wrote the corresponding part of the manuscript.

\section{Paper V}

Conducted and analysed all experimental work together with co-authors. Wrote a minor part of the manuscript. 


\section{Conference contributions}

Camilla Skyttner, Karin Enander, Christopher Aronsson, Daniel Aili

Poster: Designed Coiled Coil Peptides that Tune Release of Liposomal Cargo

Annual Surface and Materials Chemistry Symposium, 2017, Stockholm, Sweden

Seng Koon Lim${ }^{\dagger}, \underline{\text { Camilla Sandén }}{ }^{\dagger}$, Bo Liedberg, Daniel Aili

Poster: Tuning Liposome Membrane Permeability, By Insertion and Folding of De Novo Designed Polypeptides

$4^{\text {th }}$ International Conference on Multifunctional, Hybrid and Nanomaterials, 2015, Sitges, Spain

Seng Koon $\operatorname{Lim}^{\dagger}$, $\underline{\text { Camilla Sandén }}^{\dagger}$, Bo Liedberg, Daniel Aili

Poster: Tunable Release from Liposomes, Mediated by Membrane Anchoring, Insertion and Folding of Synthetic Polypeptides

Conference on Advanced Functional Materials, 2014, Kolmården, Sweden

${ }^{\dagger}$ These authors contributed equally to this work. 


\section{Contents}

Acknowledgements $\quad 1$

1 Introduction $\quad 3$

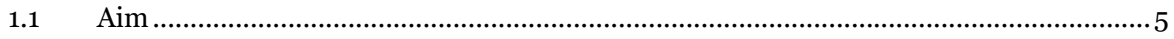

$1.2 \quad$ Thesis outline

2 Strategies for liposome-based drug delivery systems $\quad 7$

2.1 Encapsulation of drug molecules.................................................................................

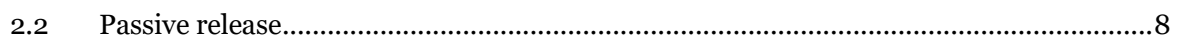

$2.3 \quad$ Targeted and triggered release …................................................................................

3 Lipids and liposome composition $\quad 11$

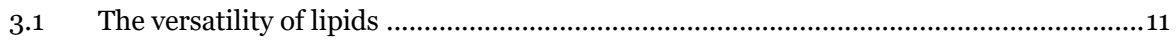

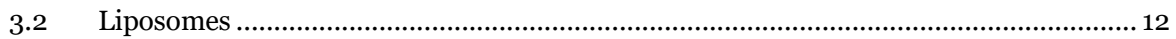

3.3 Liposome-models mimicking biological membranes .................................................. 16

4 The JR2, EKIV and PLNC8 $\alpha \beta$ peptides $\quad 19$

4.1 The primary and secondary structure of a peptide ……………………............................. 19

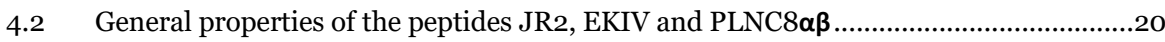

5 The interaction of JR2, EKIV and PLNC8 $\alpha \beta$ peptides with liposomes 25

5.1 Linear cationic amphipathic membrane active peptides .................................................. 25

5.2 Conjugation via maleimide-thiol Michael addition reaction ............................................ 27

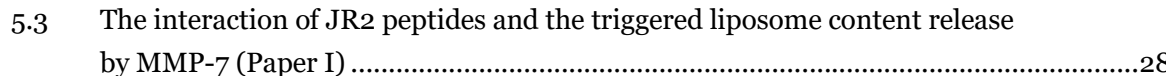

5.4 The interaction of EKIV peptides and the triggered liposome content release by heterodimer exchange (Paper II) ............................................................................... 31

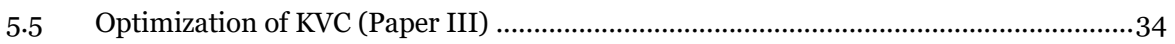

5.6 PLNC8 $\alpha \beta$ peptide-interactions with liposome-model system (Paper IV).........................38

6 Liposomes as nanoreactors for gold nanoparticle synthesis 41

6.1 The properties of gold nanoparticles ................................................................................ 41

6.2 Synthesis of spherical gold nanoparticles (Paper V) ..........................................................43

7 Characterization techniques $\quad 49$

7.1 Carboxyfluorescein (CF) release ...................................................................................49 


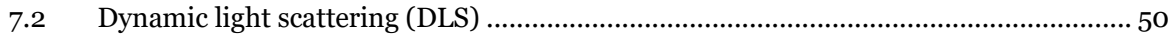

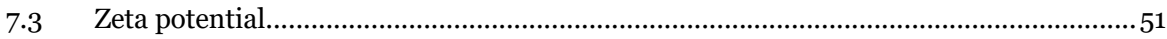

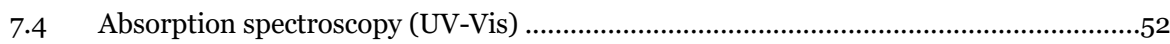

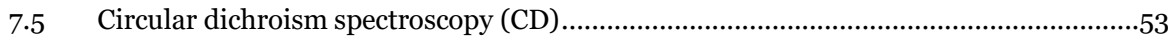

7.6 Quartz crystal microbalance with dissipation (QCM-D) ............................................... 54

7.7 Isothermal titration calorimetry (ITC) ………….......................................................... 54

7.8 Surface plasmon resonance (SPR) ..............................................................................5

7.9 Transmission electron microscopy (TEM) ……............................................................ 56

8 Summary of papers $\quad 57$

9 Conclusions and future outlook $\quad 63$

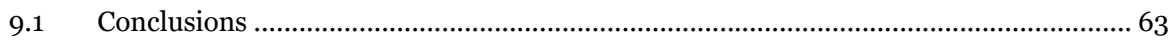

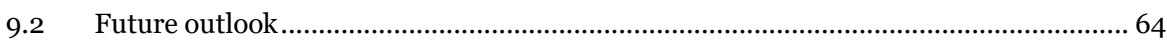

$\begin{array}{ll}\text { References } & 67\end{array}$ 


\section{Acknowledgements}

This thesis would not be possible without the people around me. I would like to extend a heartfelt thank you:

...to my supervisor Daniel Aili for always pushing me further, for the pure joy of brainstorming during our meetings and that you always seem to have space on your whiteboard for my sketches. Thank you for never doubting that I would one day write this thesis.

...to my co-supervisor Karin Enander for keeping me grounded and focused.

...to all my co-authors; Anna, Bo, Chiara, Christopher, Hazem, Jakob, Kjell, Nikolai, Petra, Robert, Seng-Koon, Sravya, Sushanth, and Torbjörn. Thank you for all the help making our projects possible!

...to all the current and alumni from Laboratory of Molecular Materials, thank you for the continuous support. Now, I leave it up to you to decide when to play (or not to play) the one and only $\mathrm{CD}$ in the lab.

...to all the current and alumni from Molecular Physics and Molecular Surface Physics and Nanoscience for broadening my knowledge and for giving me challenging questions during our joint meetings.

...to all current members and alumni of Forum Scientium that I have had the pleasure of spending time with. Thank you Stefan, Charlotte and Annette for working hard to keep Forum Scientium going. Thank you all for expanding my thinking about scientific research and personal development as well as all the good times filled with laughter.

...to all the incredibly brilliant women I have had the privilege to be around and learn from during these years. You are such an inspiration to me! Karin, Kajsa, Caroline, Abeni, Erica and many more.

...to my officemates during the years: Alina, Bela, Emma, Jing, Michael, Michal and Robert. Thank you all for the laughter, encouragement, sci-fi nerdiness and the occasional scientific discussion.

...to Kaffeklubben for fuelling my coffee addiction and for the lovely company during lunchtime. 
...to all my friend for taking my mind of work from time to time with dinners, board games, sewing circles and adventures.

...to my family, Sandén and Skyttner, who have patiently been there through all the ups and downs.

...to my husband Kristofer, I look forward to our future together!

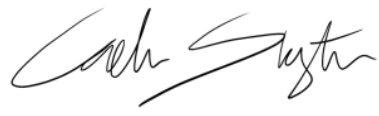

Linköping, August 2018 


\section{Chapter 1}

\section{Introduction}

Pharmaceutical development is not exclusively focused on finding a drug that has the desired effect on the target condition, but also on how to optimize the function of drugs that seem promising but might have non-desired effects. These problems may include poor solubility thus low bioavailability, rapid clearance of the drug in vivo, unfavorable pharmacokinetics or lack of selectivity thus increasing the risk of the drug having no effect in vivo or having harmful side-effects. The solution to these problems can be to apply various packaging, storage and delivery techniques, different formulations or systems for internal transportation and release. Any of these strategies can be referred to as a drug delivery systems (DDS). ${ }^{[1-3]}$

It is crucial that the drug delivered through any DDS becomes bioavailable for the target cells (illustrated in Figure 1-1). Depending on the properties of the drug and where it needs to be delivered, for example intracellularly or extracellularly, different release strategies can be used which is an area of great interest for research.[4,5] In addition to the release strategy also the rate of which the drug is released is very important to ensure drug concentrations within the therapeutic window. ${ }^{[6]}$ Development of methods to control drug release is thus central in DDS development.

Liposomes have, soon after their first description in $1965,{ }^{[7]}$ been popular to use as the basis of DDS as a delivery and release strategy. The simplicity in encapsulating the drug into a liposome, the liposome versatility in composition and biocompatibility[8] as well as the multitude of liposome surface functionalization strategies ${ }^{[9]}$ are important factors explaining their popularity throughout the years. One of the first demonstration of liposomes used as a DDS was heat-sensitive liposomes which released the encapsulated drug when local heating at the target site was applied. ${ }^{[10]}$ Today, there are at least 15 FDA approved products where the 
active drug is formulated with liposomes and many more are in clinical trials. ${ }^{[11,12]}$ The products on the market includes, among others, the chemotherapy drug doxorubicin encapsulated in stabilized liposomes to increase the systemic circulation time of the circulating drug ${ }^{\left[13^{-15}\right]}$ and the anti-fungal drug amphotericin $B$ which is incorporated in the lipid membrane increasing the solubility and decreasing the toxicity.[16,17] There is no doubt that the list will continue to grow. However, many liposome-based drug formulations have failed because of difficulties with releasing the drug at an appropriate rate.[18]

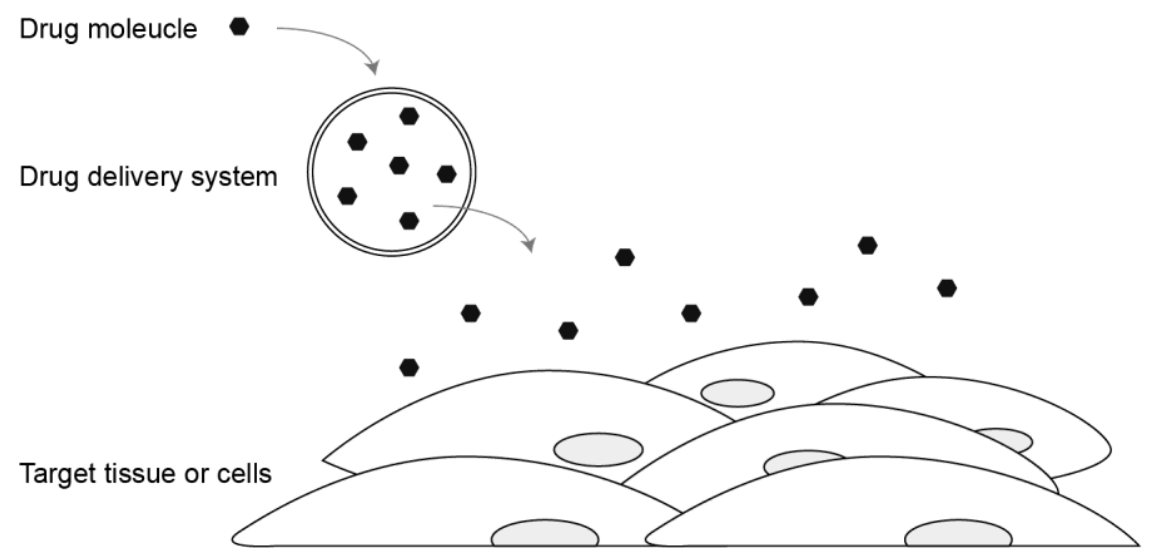

Figure 1-1: Schematic illustration showing the encapsulated drug in the drug delivery system (DDS) and the subsequent release of the drug at the target site.

Peptides are class of highly versatile molecules found in all biological systems and that also can be synthetically obtained.[19] Many peptides interact with lipid membranes and affect the properties of the membrane. Some membrane active peptides can traverse cell membranes, ${ }^{[20]}$ others form pores in lipid membranes ${ }^{[21]}$ and some kill bacteria by destroying their membrane. The latter are typically referred to as antimicrobial peptides (AMPs). ${ }^{[22]}$ Liposomes are widely used as model systems for investigating the interactions of membrane active peptides, including AMPs. ${ }^{[23]}$ Membrane active peptides can also potentially be utilized to control the drug release from DDS, which requires that the peptide-lipid interactions can be tightly controlled and tuned by external stimuli or endogenous factors.

An alternative release strategy for liposome-based DDS exploits heating of the liposomes. ${ }^{[10]}$ Local heating can be induced by incorporating gold nanoparticles (AuNPs) into the liposomes and utilizing the light-induced plasmonic heating to achieve a triggered release. ${ }^{[24]}$ In addition, liposome encapsulated AuNPs can enable systematic studies of, and potentially improve, the performance of AuNPs in vivo with respect to renal clearance and tissue accumulation, which depends on both the nanoparticle size and surface chemistry.[25,26] 


\subsection{Aim}

The main objective of this thesis was to develop and study new strategies that enable tunable and triggered changes in the permeability of the lipid membranes of liposomes.

For this purpose, the interactions of de novo designed membrane active peptides with liposomes were investigated (Paper I-III). The same evaluation process was also used to extract more information about the interactions of antimicrobial peptides with lipid membranes (Paper IV). This thesis further includes the development of a synthesis-strategy for ultra-small gold nanoparticles within liposomes, which has the potential to be used to modulate the lipid membrane integrity (Paper V).

\subsection{Thesis outline}

The thesis outline is summarized in Figure 1-2. The principles of a liposome-based DDS are described and reviewed in Chapter 2. The tailoring of liposomes for either peptide functionalization or as model membranes are described in Chapter 3. The membrane active peptides, both de novo designed and natural, that were studied are presented in Chapter 4 and their interactions with lipid membranes are described in Chapter 5. Chapter 6 addresses the usefulness of liposomes as nanoreactors for gold nanoparticle (AuNP) synthesis and how this nanosized vesicle changes the dynamics of the reaction. This chapter also includes a short review of the potential of AuNPs to trigger release from liposomes.

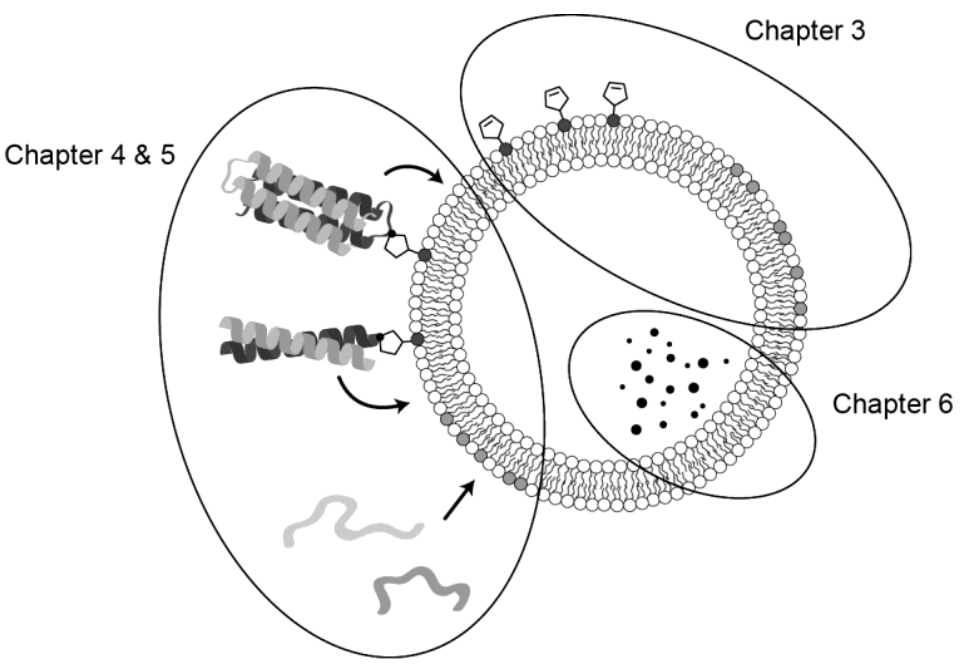

Figure 1-2: Schematic illustration of the outline of this thesis according to the thesis outline. 
Chapter 7 contains a short description of the characterization techniques used in this thesis. Chapter 8 provides a short summary of the papers included in this thesis and lastly Chapter 9 contains conclusions and future outlook. 


\section{Chapter 2}

\section{Strategies for liposome-based drug delivery systems}

\subsection{Encapsulation of drug molecules}

Liposome-based DDS are often used due to their simple encapsulation of drug molecules. The encapsulation of the drug serves as protection from degradation and can increase the solubility of drug molecules with low solubility in aqueous solutions. ${ }^{[1-3]}$ The drug molecules can either be encapsulated in the liposome interior or be incorporated into the membrane (Figure 2-1). The location of the drug molecules is determined by its solubility in the aqueous interior and hydrophobic membrane, respectively.[27]

Liposomes have been known and used since $1965,{ }^{[7]}$ and are further described in Chapter 3. Other biomolecules have been designed to offer the same basic principles of encapsulation and release of drug molecules such as peptide-based nanovesicles, ${ }^{[28,29]}$ block-co-polymer-based vesicles[30] as well as block-co-polymer and lipid mixed vesicles ${ }^{[31]}$ and peptide crosslinked layer-by-layer polymer vesicles.[32] Though there are many alternatives, the research in liposome-based DDS is extensive thanks to the many possibilities to tailor a liposome with respect to both various lipid compositions and surface modifications. These variations offer a multitude of passive or triggered release strategies to ensure that the drug molecules are distributed at a local concentration, rate or location that is therapeutically relevant.[6] 


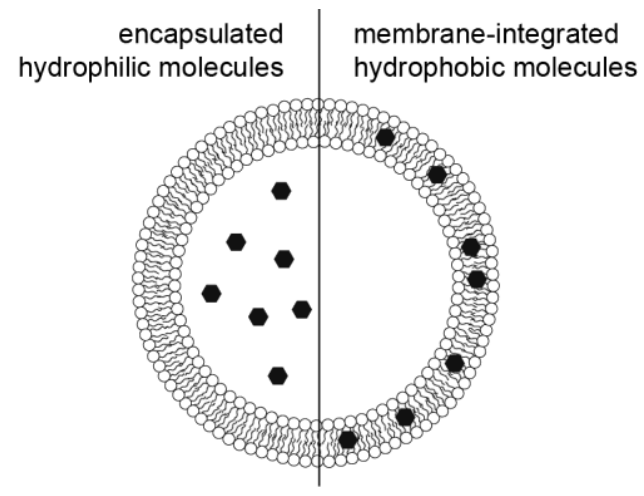

Figure 2-1: A schematic illustration of the localization of hydrophilic and hydrophobic drug molecules in a liposome. Left) Hydrophilic molecules are encapsulated in the aqueous interior of the liposome. Right) Hydrophobic molecules are integrated into the hydrophobic interior of lipid bilayer membrane.

The evaluation of passive and triggered release strategies is often done by analysing the release of an encapsulated fluorophore instead of the actual drug molecule. The release of a fluorophore, such as carboxyfluorescein (described in section 7.1), can easily be monitored and thus an initial estimation of the release strategy can be determined.[33] This model system for drug release facilitate inexpensive investigations and optimizations of new release strategies.

\subsection{Passive release}

The passive release from liposomes refers to the small leakage due to osmotic pressure and the release due to non-triggered extra- or intracellular liposome degradation. The release rate can be tuned by tailoring the lipid composition making up the liposomes. The lipid composition determine how the liposome permeability changes at increased temperatures at inflammatory sites. ${ }^{[6]}$

Liposome surface modifications by adding a polymer layer can drastically modulate the properties of the liposome (Figure 2-2). Decorating liposomes with hyaluronic acid proved to increase the flexibility of liposomes thus making them more suitable for cutaneous formulations. ${ }^{[34]}$ For applications in malignant tumor treatment, liposome-based DDS can accumulate in the tissue due to the enhanced permeability and retention of the local blood vessels and thus generating a high local concentration in relevant tissue.[35] To ensure that the liposome half-life is long enough to allow accumulation in the tumor tissue surface modifications with PEG are done to minimize degradation of circulating liposomes. ${ }^{[36,37]}$ 


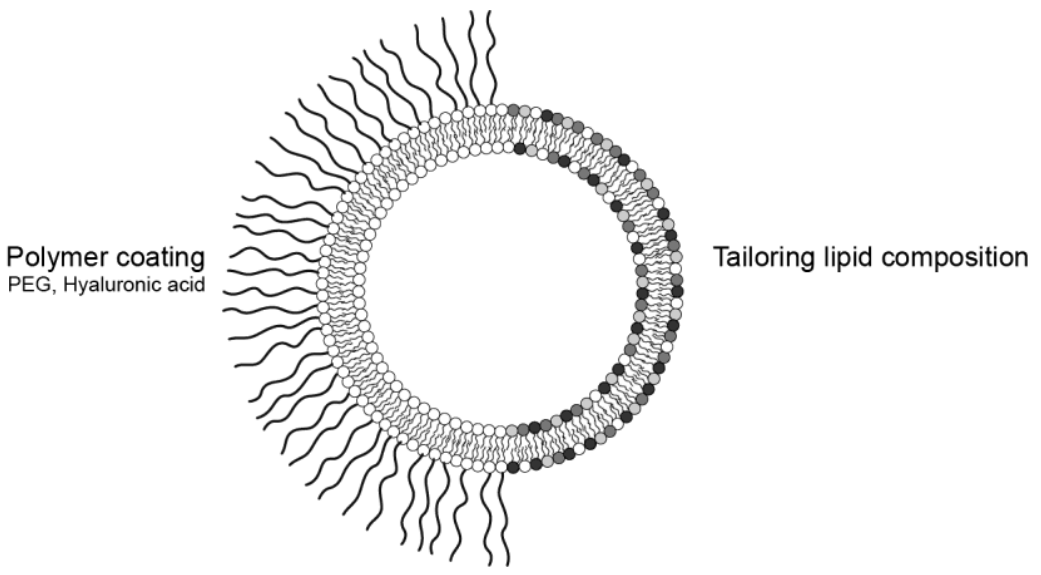

Figure 2-2: Schematic illustration of two main strategies, polymer surface coating and tailoring lipid composition, for tuning liposomes for passive release of encapsulated molecules.

\subsection{Targeted and triggered release}

Liposome-based drug delivery systems can be further sophisticated by adding functionality to the liposome surface to enable a targeted delivery of the liposomes or a triggered release of the encapsulated molecules. Eight strategies that have been widely investigated are summarized in Figure 2-3. As in passive release, the tailoring of lipid composition can be utilized to ensure a triggered release by externally applying the heat at predetermined areas instead of relying on smaller internal heat changes. Ever since the first reports using this strategy in the $19705^{[10,38]}$ the development continues to this day to find the optimum lipid compositions for different applications and to investigate the behaviour and accumulation of circulating liposomes ${ }^{[38-40]}$ as well as the use of non-traditional external heat sources such as high intensity focused ultrasound.[41]

Shortly after liposomes were gaining interest as DDS the idea of actively targeting the liposomes to the desired tissue and cells was investigated using surface functionalization with antibodies.[39] The ambition of such targeting strategies are to enable a controlled release upon antibody-antigen binding to the desired site. Additionally liposome surfaces can be modified using viral proteins to target specific cell types and to enable liposomes to fuse with cells thus the drug molecules are delivered intracellularly.[42]

The multiple possible designs of functionalized liposome-based DDS for triggered release enable a vast number of strategies to be explored. One strategy is to construct acoustically active liposomes where air is incorporated into the liposomes and by using ultrasound on the desired area the air in the liposomes will destabilize the membrane and thus release the encapsulated drug. ${ }^{[43]}$ Alternatively, the passageway for the drug molecule to move from the 
liposome interior to exterior can be pre-integrated with the lipid membrane. One example of this is a peptide, or protein, channel that opens and closes upon an added trigger. Specifically this has been achieved using a temperature sensitive leucine-zipper which spans the lipid membrane forming a folded closed structure and when heated changes into an unfolded open channel.[44] Moreover, nanoparticles can be encapsulated, incorporated into the lipid membrane or attached to the liposome surface. The nanoparticles can act as lipid membrane destabilising agents due to their heat generation upon light actuation of gold nanoparticles[45] or magnetic actuation of iron oxide nanoparticles. ${ }^{[46]}$ Another strategy for triggered release that relies on the surface functionalization of the liposomes is the addition of stabilizing moieties that include a cleavable linker. When the linker is cleaved due to the presence of a predesigned trigger, such as a change in $\mathrm{pH}^{[47]}$ or an enzyme like the matrix metalloproteinase 9 (MMP-9),[48-50] the resulting destabilized liposomes release their encapsulated drug molecules.

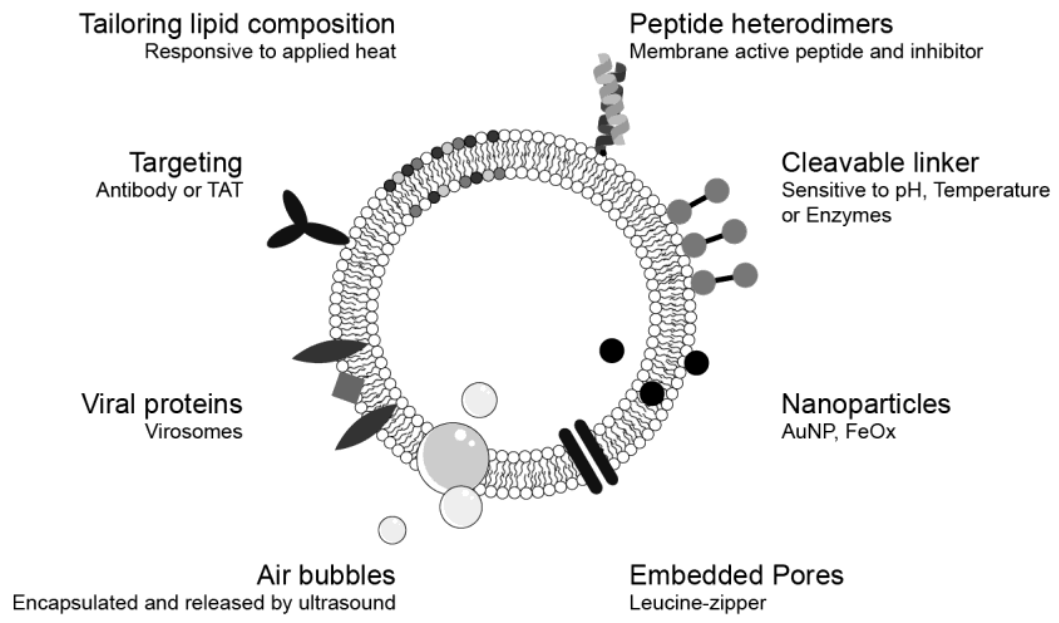

Figure 2-3: Schematic illustration of eight different strategies for targeted and triggered release.

The use of peptide heterodimers as means to tune and trigger the release of liposome encapsulated drug molecules was investigated in Paper I and II. The two peptide monomers used was one membrane active and one inhibitory peptide, thus enabling triggered release upon proteolytic digestion by MMP-7 of the inhibitory peptide in Paper I or by removal of the inhibitory peptide by a heterodimer exchange in Paper II. Paper III focused on the optimization of the membrane active peptide used in Paper II. 


\section{Chapter 3}

\section{Lipids and liposome composition}

\subsection{The versatility of lipids}

Lipids are a large group of naturally occurring biomolecules that are insoluble in polar and soluble in organic solvents. Lipids are divided into a multitude of subgroups with different properties and functions in living organisms. [51] There are thousands of different lipids with great diversity. ${ }^{[52]}$ The various membranes in cells are largely comprised of lipids, and the lipid composition may vary vastly between species, cell types and the different membranes and locations within the cell.[53]

Lipids are commonly divided into the subgroups: fatty acyls, glycerolipids, glycerophospholipids, sphingolipids, sterol lipids, prenol lipids, saccharolipids and polyketides.[52]

\subsubsection{Critical packing parameter}

Many lipids are amphipathic, which means that they typically have a hydrophilic or charged head group and one or more hydrophobic tails. The head group can contain various functionalities and the tail often contain hydrocarbon chains of different lengths and number of unsaturated bonds. As a result, a lipid can adopt a large number of apparent geometries, which can be described by the critical packing parameter (CPP). CPP gives an insight into the structures that the lipids will give rise to when they spontaneously self-assemble in polar solvents and is defined as: 


$$
C P P=\frac{v}{a_{0} l_{c}}
$$

where $v$ is the volume of the hydrocarbon chain, $l_{c}$ is the critical chain length and $a_{o}$ is the estimated head-group area.

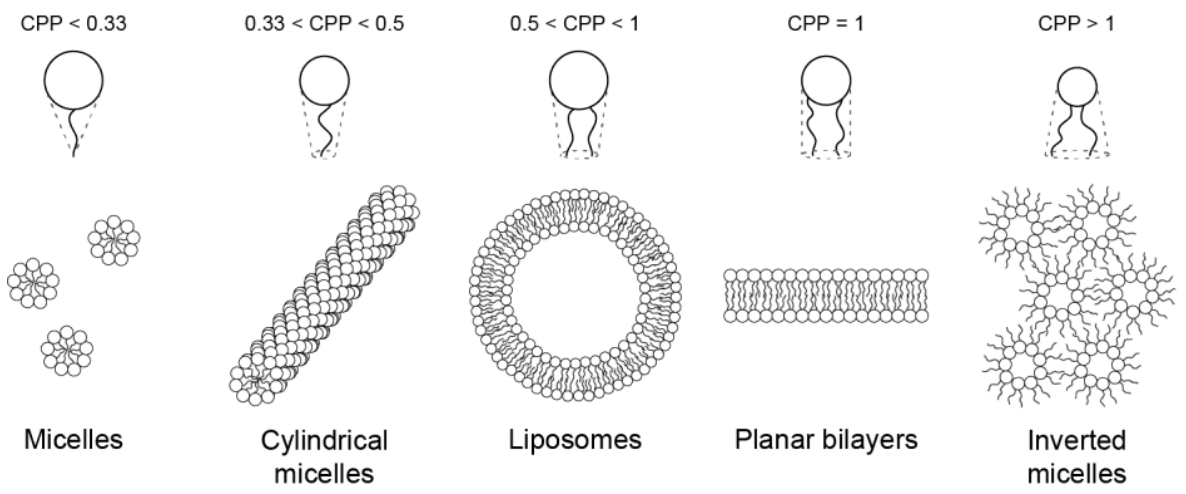

Figure 3-1: The difference in CPP for different lipids give rise to different structures such as spherical and cylindrical micelles, liposomes, planar bilayers and inverted micelles. The spheres represent the hydrophilic headgroup and the lines represent the hydrophobic tails.

The structures can vary from spherical to cylindrical micelles, liposomes (curved bilayer), planar bilayers and inverted micelles as determined by the CPP (Figure 3-1). The self-assembly process is primarily a result of the hydrophobic effect since it is thermodynamically favorable for the hydrophobic tails to aggregate to exclude the otherwise highly ordered water molecules around the lipid tails when the lipids are in aqueous solution.[27]

\subsection{Liposomes}

Liposomes are spherical membranes where the lipids have a CPP allowing for the assembly of curved lipid bilayers ( $0.5>$ CPP $>1$ ). Liposomes were first described by Bangham et al. in $1965^{[7]}$ A liposome can consist of one (unilamellar) or more (multilamellar) lipid bilayers layered like an onion. ${ }^{[54]}$

The inner compartment of liposomes is filled with water or other hydrophilic molecules or ions and inside the lipid bilayer the environment is hydrophobic. Additionally, liposomes can have sizes ranging from roughly 0.02 to $5 \mu \mathrm{M}$ in diameter. The size and number of bilayers is often used to describe a liposome (Figure 3-2), though there is only a rough consensus of the size limitations of when a liposome is small enough to be regarded as a SUV. ${ }^{[54]}$ The definitions in Figure 3-2 are used in this thesis. 


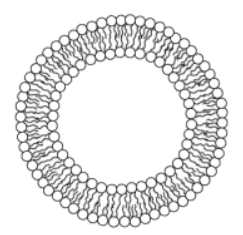

SUV

Small unilamellar vesicle

$20<\mathrm{d}<100 \mathrm{~nm}$ one bilayer

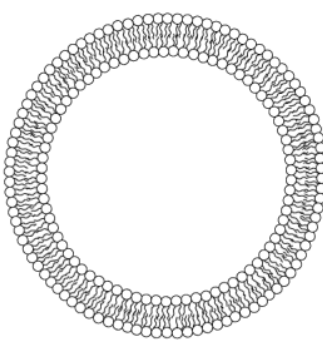

LUV

Large unilamellar vesicle

d $>100 \mathrm{~nm}$ one bilayer

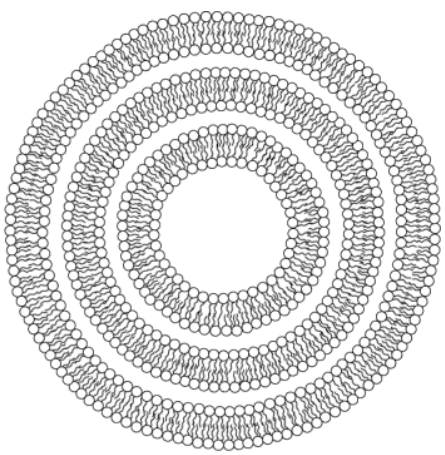

MLV

Multilamellar vesicle

$\mathrm{d}>300 \mathrm{~nm}$ multiple bilayers

Figure 3-2: Definitions of liposomes according to size and number of bilayers. The definitions may vary slightly with respect to size between sources.

\subsubsection{Lipid mobility}

Depending on lipid composition and temperature, lipids can diffuse within the membrane, allowing movement of the individual lipids both within the plane of the bilayer and between two leaflets. Compared to the lateral diffusion, the transverse diffusion or flip-flop is a much slower process (Figure 3-3).[51] Though the transverse diffusion for phospholipids is commonly considered to be slow, in the order of hours or days, some experiments show that it can actually be faster ( $\mathrm{t}_{1 / 2}$ of about $30 \mathrm{~min}$ ) and thus a more prominent feature of the lipid bilayer dynamics.[55]

a)

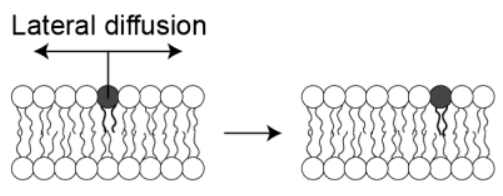

b) Transverse diffusion

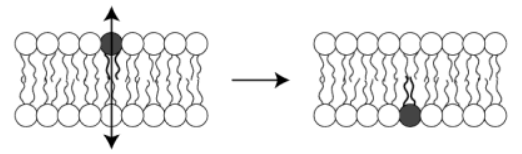

Figure 3-3: Lipid movements in bilayers, a) lateral and b) transverse diffusion.

\subsubsection{Phase transition temperature}

The diffusion of lipids depends on the temperature and strength of the interactions between the lipids, which in turn depend on lipid composition. Lipids can switch from a more ridged gel phase to a flexible liquid phase by increasing the temperature.[19] 


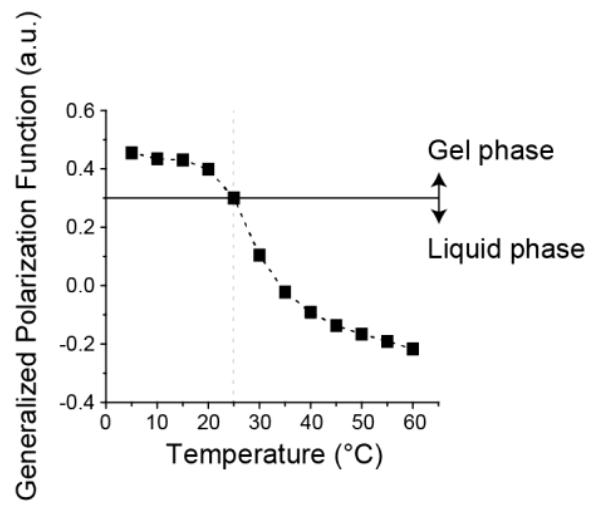

Figure 3-4: The transition from gel to liquid phase in liposomes containing 1,2-dimyristoyl-sn-glycero-3phosphocholine (DMPC) and 2 mol\% Laurdan. The fluorophore Laurdan is located in the lipid bilayer and susceptible to dipolar relaxation by water molecules entering the lipid bilayer as a consequence of increasing mobility of the lipids when temperature increases. The fluorescence is thus sensitive to the lipid phase through an emission peak shift of Laurdan from 440 to $490 \mathrm{~nm}\left(\mathrm{~F}_{440}\right.$ and $\mathrm{F}_{490}$ respectively), and a generalized polarization function (GP) is used to visualized this where $\mathrm{GP}=\left(\mathrm{F}_{440}-\mathrm{F}_{490}\right) /\left(\mathrm{F}_{440}+\mathrm{F}_{490}\right)$. The $\mathrm{T}_{\mathrm{m}}$ can be determined by using $\mathrm{GP}=0.3 \cdot{ }^{\left[{ }^{[56]}\right.}$ The experimentally obtained $\mathrm{T}_{\mathrm{m}}=25^{\circ} \mathrm{C}$ for DMPC is close to the literature value of $24{ }^{\circ} \mathrm{C} .{ }^{[57]}$

The phase transition temperature is described as the temperature where the switch from gel to liquid phase occurs and depends on the properties of the lipids (Figure 3-4). For instance, the longer the hydrocarbon tails the more pronounced the hydrophobic effect, which results in a higher phase transition temperature. The phase transition temperature is also highly effected by the number of unsaturated bonds in the lipid tail, as well as the double bond configuration (cis/trans) and the interactions between the lipid head groups.[58]

\subsubsection{Liposome formation through thin film hydration and extrusion}

There are a multitude of ways of forming liposomes of different sizes. To mention a few there are the reverse-phase evaporation, ${ }^{[59]}$ freeze-thaw technique, ${ }^{[60]}$ solvent injection, ${ }^{[61]}$ detergent dialysis, ${ }^{[62]}$ and thin film hydration ${ }^{[63]}$ with subsequent extrusion. ${ }^{[64,65]}$ The latter technique was used in this thesis due to its simplicity in yielding defined sizes of SUVs or LUVs. The technique is based on the evaporation of the organic solvent in which the lipids are dissolved in, thereby forming a lipid film. The lipid film is then gently rehydrated with a buffer which results in liposomes of varying sizes and lamellarity.[63] The liposomes are subsequently extruded through a polycarbonate membrane with defined pore size. The final size of the liposomes is defined by the choice of pore size of the membrane ${ }^{[64,65]}$ and can be measured by dynamic light scattering described in section 7.2. 


\subsubsection{Phospholipids and their use in liposomal drug delivery}

Glycerophospholipids (or phospholipids) consist of two long-chained hydrocarbon chains that may be saturated or unsaturated (for example palmitoyl and oleoyl respectively), and usually a nitrogen containing head group such as choline (in POPC) and the central part is always a glycerol (Figure 3-5a). The CPP of many phospholipids promote formation of a curved bilayer, and they are thus favorable in biological membranes. The phospholipids found in biological membranes have a vast overrepresentation of hydrocarbon chain lengths of 16 or 18 carbons. ${ }^{[66]}$

Due to their biocompatibility and CPP value allowing for formation of liposomes, phospholipids are attractive as the main material for DDS and are thus extensively researched and utilized for such purposes. The lipid composition can be tailored by mixing different lipids to change the overall liposome phase transition temperature ${ }^{[10,38,41]}$ and/or to enable functionalization with e.g. peptides and proteins.[39,44]

a)

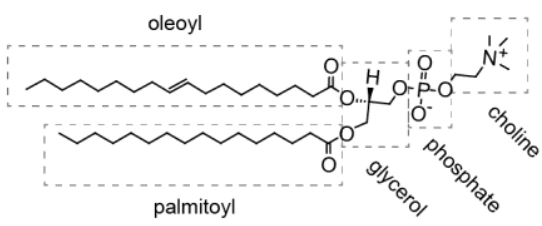

POPC

palmitoyl

1-palmitoyl-2-oleoyl-sn-glycero-3-phosphocholine

b)

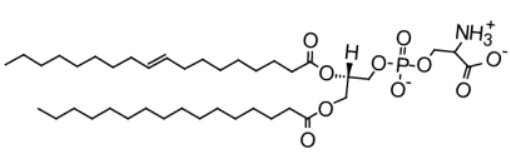

POPS

1-palmitoyl-2-oleoyl-sn-glycero-3-phospho-L-serine

c)

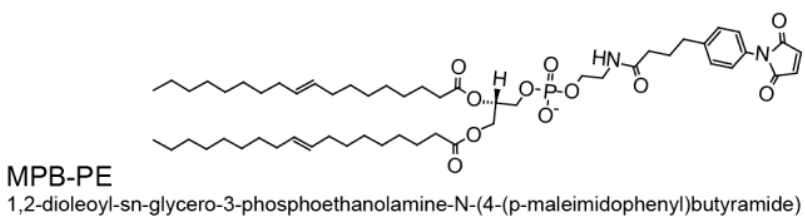

Figure 3-5: The chemical structure of phospholipids used in this thesis. a) POPC, b) POPS and c) the maleimide head-group functionalized MPB-PE.

In this thesis POPC was used as the main lipid for fabrication of liposomes. In Paper I-III MPB-PE was added to functionalize the surface with maleimide groups and in Paper IV POPS was used to add negative charge to the liposome surface (Figure 3-5). 


\subsection{Liposome-models mimicking biological membranes}

The complexity of biological membranes makes it difficult to analyse individual interactions in detail. To isolate the interaction of interest a model system can be created to mimic cell membranes. A model system is often highly simplistic and based on for example the main lipid component. Even though it cannot be as complex as the original cell membrane, relevant information can be extracted that can give clues into what may happen in more complex environments. Liposomes can be prepared to mimic a wide number of aspects of the cell membrane, such as lipid composition, net charge, phase transition temperature and much more depending on the interaction of interest.[67]

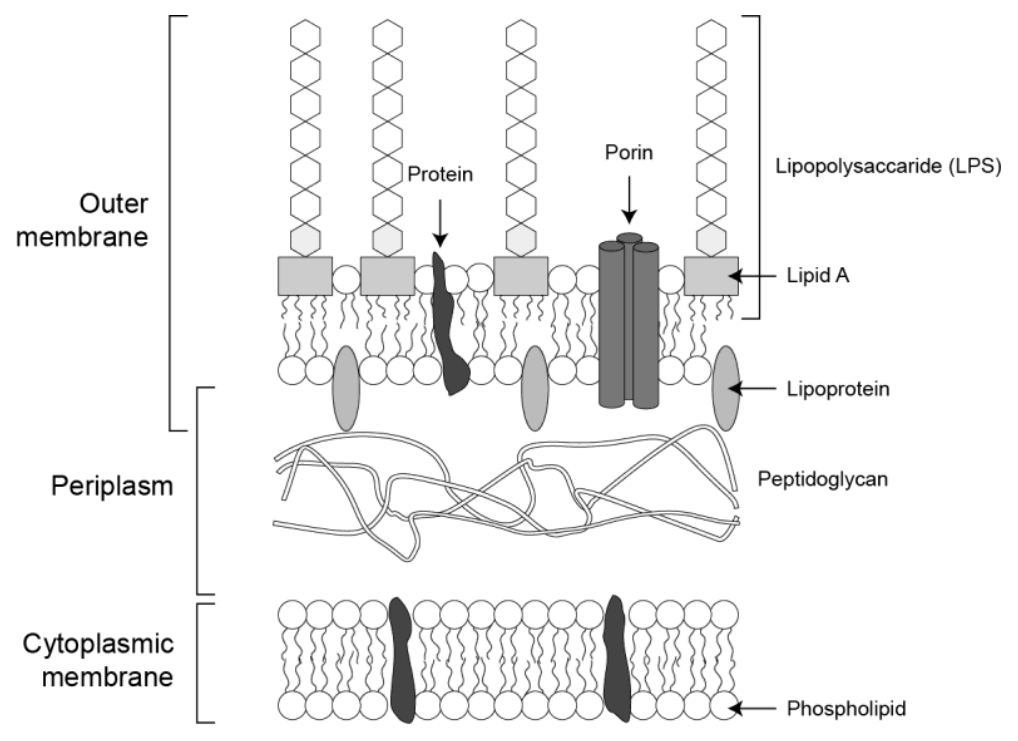

Figure 3-6: Schematic illustration of the cell wall of gram-negative bacteria.

An example of a very complex biological cell membrane is that of gram-negative bacteria, which is comprised of an outer membrane, a periplasm of peptidoglycans and a cytoplasmic membrane (Figure 3-6). The outer membrane is rich in polysaccharides (LPS), porins, and a vast numbers of membrane proteins and phospholipids. ${ }^{[68]}$ When designing a liposome-model system it is important to consider what interaction that should be studied. A liposome-based model system can be used to answer questions whether certain components in the outer membrane, such as LPS, would be of importance for interaction with a specific antimicrobial peptide. To address this liposomes can be used, one with LPS mixed with phospholipids and one with lipid A mixed with phospholipids ${ }^{[69]}$ or simply only phospholipids. ${ }^{[70]}$ A liposome- 
based model system may also be tuned to mimic the charge of a bacterium by mixing phospholipids with different head-group functionalities.[71]

A few examples of liposomal compositions utilized for mimicking gram-negative bacterial membrane are 1:4 DOPG:DOPC, ${ }^{[72]} 1: 3^{[70]}$ or $3: 7^{[71]}$ POPG:POPC, $1: 1^{[73]}$ or 2:1 ${ }^{[74]}$ POPS:POPC and 1:2:2 POPG:POPE:POPC.[75] There are hence both differences in the lipids used and the ratios between the lipid components, but all of the liposomes have a net negative charge, due to the PG or PS lipid-headgroup content, which is desired for creating a simple mimic of gramnegative bacteria. It is important to remember that the interactions between any component and a lipid membrane model will most likely be different from that of the interaction with an actual bacteria.[76]

\subsubsection{Design of a liposome-model system mimicking Porphyromonas gingivalis}

Surface charge mimetic liposomes are difficult to construct, but zeta potential mimics can be made by comparing measurements between the actual system and the liposome-model system. Zeta potential is described in section $7 \cdot 3$.

A liposome-model system for the gram-negative bacteria Porphyromonas gingivalis ( $P$. gingivalis) W50 strain was designed in Paper IV. The zeta potential of microvesicles extracted from $P$. gingivalis cultures was matched with liposomes having different molar ratios of zwitterionic POPC and negatively charged POPS phospholipids. The P. gingivalis microvesicles are formed by the bacteria as a result of the cell wall turnover.[77] The vesicles are essentially a representation of the outer membrane composition and small enough for zetapotential measurements. The liposome composition of 5:95 POPS:POPC proved to match the zeta potential of the P. gingivalis microvesicles as shown in Figure 3-7.

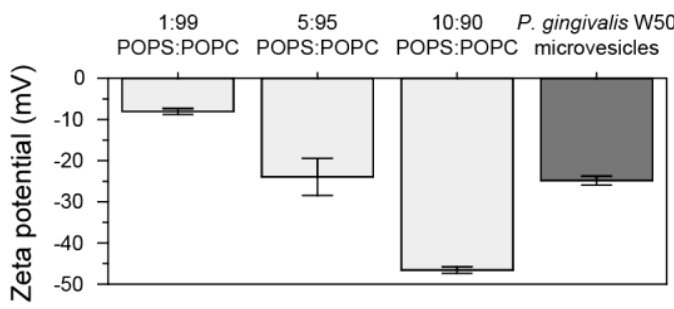

Figure 3-7: Zeta potential of liposomes with POPS:POPC molar ratio of 1:99, 5:95 and 10:90 and microvesicles extracted from $P$. gingivalis in $\mathrm{PB} \mathrm{pH} 7$. 


\section{Chapter 4}

\section{The JR2, EKIV and PLNC8 $\alpha \beta$ peptides}

\subsection{The primary and secondary structure of a peptide}

A number of de novo designed and naturally derived peptides have been utilized and studied in this thesis. A peptide is a polymer or oligomer of amino acids, formed as a result of covalently linking of two or more amino acids through amide bonds. The number of residues in a peptide i.e. the number of linked amino acids, can vary from two to several hundreds. The composition only varies due to the diversity of the side chains $\left(\mathrm{R}_{\mathrm{n}}\right)$ of each residue that has been linked into the peptide primary structure (Figure 4-1).[19]

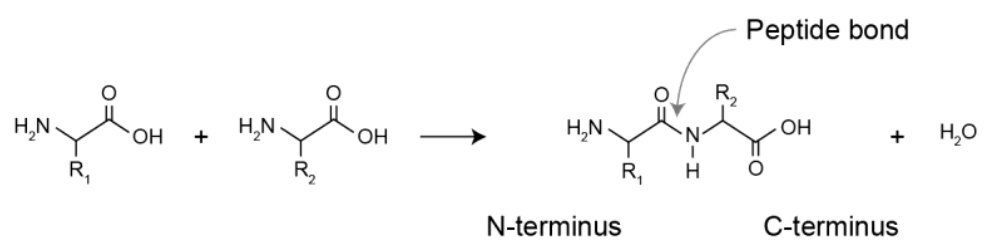

Figure 4-1: The condensation reaction of two amino acids to form a dipeptide where the N-terminus refers to the free amine $\left(-\mathrm{NH}_{2}\right)$ and C-terminus to the free carboxyl group $(-\mathrm{COOH})$ at each end of the peptide.

The presence of hydrophilic, hydrophobic and charged residues in the primary structure enables different intra- and intermolecular interactions such as hydrogen-bonds, hydrophobic interactions and electrostatic attraction and repulsion. In response to these interactions the 
peptide can fold into secondary structures, in full or in part, to minimize the Gibbs free energy of the system. There two most common secondary structures are the $\alpha$-helix and the $\beta$-sheet. The secondary structure of a peptide can be determined by circular dichroism described in section 7.5 .

An $\alpha$-helix is the structure adopted when the peptide backbone forms a spiral structure, regularly with 3.6 residues per turn, and the residue side chains directed outwards from the rotation axis of the helix. Many other different helices have been identified, such as the $31^{-}$ and $\pi$-helix, differing in number of residues per turn and helix diameter due to difference in composition and environment. The $\alpha$-helix is usually stabilized through intramolecular hydrogen bonding of the carbonyl (residue $i$ ) and amide (residue $i+4$ ) groups in the peptide backbone. The $\alpha$-helix is often visualized in a top-down manner with the rotation axis in the center and the residues in positions around. This representation is the helical wheel diagram and since it takes about 7 residues to return to the starting position helix-containing sequences are often described as heptad repeats ( $a b c d e f g)$.

In contrast to the $\alpha$-helix, $\beta$-strands are stabilized through intermolecular hydrogen bonding between other parallel or antiparallel $\beta$-strands. The residue arrangement in a $\beta$-strand is linear where the residue sidechains are directed outwards in on plane. Due to the intermolecular stabilization $\beta$-strands are often found in multiples forming $\beta$-sheets.

The absence of a defined secondary structure is referred to as random coil.[19]

Changes in secondary structures can occur due to changes in various physicochemical factors such as temperature, ${ }^{[78]} \mathrm{pH},{ }^{[79]}$, ionic strength, ${ }^{[80]}$ metal ion coordination ${ }^{[81]}$ and through specific or unspecific interactions with other small molecules ${ }^{[82]}$ or peptides. ${ }^{\left[{ }^{83}-{ }^{85}\right]}$ The interaction of peptides with interfaces, such as nanoparticle surfaces ${ }^{[86]}$ and lipid bilayers, ${ }^{[87]}$ can also induce changes in secondary structure.

\subsection{General properties of the peptides JR2, EKIV and PLNC8 $\alpha \beta$}

The peptides used in this thesis are all synthetic and have been produced using solid phase peptide synthesis.[88] The JR2 and EKIV peptides are de novo designed peptides and the primary structures can hence not be found in any naturally occurring proteins. In contrast, PLNC8 $\alpha \beta$ are naturally occurring peptides normally produced by bacteria.

\subsubsection{Four-helix bundles and the JR2-peptides}

The four-helix bundle is a motif consisting of four amphipathic $\alpha$-helices aligned to form a structure where the hydrophobic faces of helices make up a hydrophobic core.[19] The formation of this hydrophobic core is the main driving force behind the folding of the peptides 
and additional hydrogen bonding and electrostatic interactions between helices increase the stability of the motif.[83] The four $\alpha$-helices in the motif may either all be part of the same unit, connected via loops or other secondary structures, or be assembled from two or more subunits. The four-helix bundle is frequently found in nature and a few examples can be found in the RNA-binding Rop protein (Figure 4-2a), ${ }^{[89]}$ the electron-carrier cytochrome $b_{562,}{ }^{[90]}$ the cytokine interleukin-2,[91] and as a part of the hepatitis B virus capsid.[92]

The JR2-peptides are a pair of helix-loop-helix peptides, the lysine-rich JR2K and the glutamic acid-rich JR2E, that were de novo designed by Rydberg and Sarojini..[83] Both peptides contains 42 residues and are random coil at neutral $\mathrm{pH}$, but when mixed together they fold into a helix-loop-helix motif and heterodimerize into a four-helix bundle (Figure 4-2b,c), $\left.{ }^{8} 3\right]$ with a dissociation constant of about $20 \mu \mathrm{M}$.[93] The hydrophobic core is mainly made up of alanine (A) and leucine (L) with the residues positioned at $a$ and $d$. The arrows in Figure 4-2b indicate the electrostatic interactions between the charged residues in the $b$ and $e$ positions. ${ }^{\left[{ }_{3}\right]}$ The substitution valine $\rightarrow$ cysteine, JR2K $\rightarrow \mathrm{JR} 2 \mathrm{KC}$, in the loop region by Aili and Enander enabled immobilization of the peptides on for example gold substrates ${ }^{[93,94]}$ and maleimidefunctionalized materials such as the liposomes used in Paper I.

a)

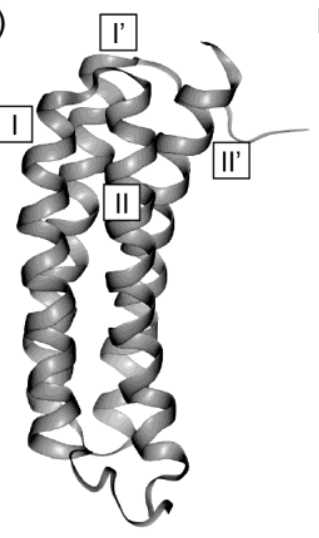

b)

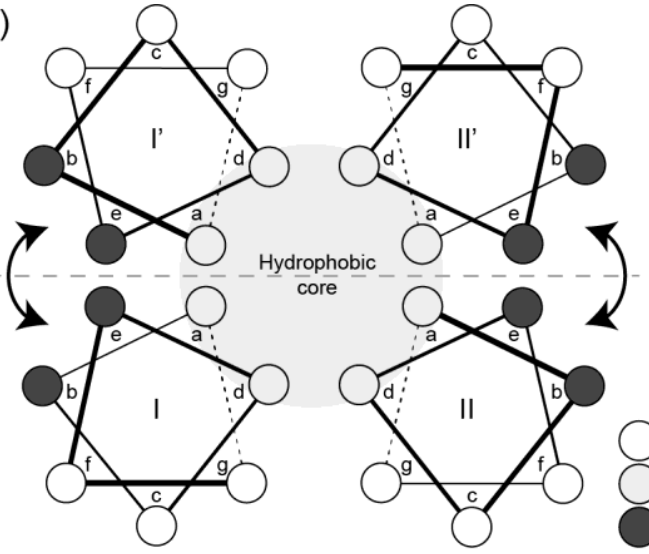

Hydrophilic Hydrophobic Charged c)

\begin{tabular}{|c|c|c|c|}
\hline \multirow{4}{*}{$\begin{array}{l}\text { JR2KC } \\
\text { JR2E }\end{array}$} & \multicolumn{3}{|l|}{ Primary structure } \\
\hline & $a b c d e f g \quad a b c d e f g a b c d$ & $a b c d e f g$ & $a b c d e f g \quad a b c d e$ \\
\hline & N AADLKKA IKALKKH LKAK GPCD & AAQLKKQ & LKQAFKA FKRAG \\
\hline & N AADLEKA IEALEKH LEAK GPVD & AAQLEKQ & LEQAFEA FERAG \\
\hline & I & & II \\
\hline
\end{tabular}

Figure 4-2: a) The four-helix bundle of the RNA-binding Rop protein (PDB ID: $1 \mathrm{RPR}^{[95]}$ ) acquired from the protein data bank (PDB) ${ }^{[96]}$ and visualized using the NGL viewer. ${ }^{[97,98]}$ b) Helical wheel diagram showing the topdown view of the helices of the lysine (K)-rich JR2KC and the glutamic acid (E)-rich JR2E when folded and heterodimerized into a four-helix bundle. c) The primary sequence of the JR2KC and JR2E peptides. 


\subsubsection{Coiled coils and the EKIV-peptides}

The coiled coil motif is comprised of amphipathic $\alpha$-helices which are slightly wrapped around one another to optimize the packing of residue side chains in the hydrophobic core. This additional twisting causes each individual $\alpha$-helix to be slightly distorted with 3.5 instead of 3.6 residues per turn. ${ }^{[19]}$ The primary structure of coiled coil peptides often follows the repeating pattern of HPPHPPP, where hydrophobic residues $(\mathrm{H})$ are located at the $a$ and $d$ positions in the helical wheel and the rest are hydrophilic residues (P).[99] This motif is common in proteins and can e.g. be found in tropomyosin in the cytoskeleton (Figure $4-3 a),{ }^{[100]}$ laminin in the extra-cellular matrix ${ }^{[101]}$ and in the staphylococcal protein A. ${ }^{[102]}$

a)

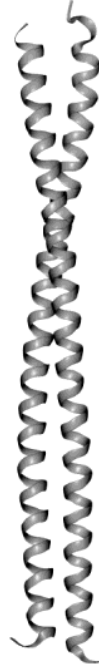

b)

\begin{tabular}{|c|c|}
\hline & $\begin{array}{c}\text { Primary structure } \\
g a b c d e f \quad g a b c d e f \quad g a b c d e f \quad g a b c d e f\end{array}$ \\
\hline $\mathrm{KV}(\mathrm{C})$ & (C) KVSALKE KVSALKE KNSALKW KVSALKE \\
$\mathrm{KI}(\mathrm{C})$ & (C) KIAALKE KIAALKE KNAALKW KIAALKE \\
$\mathrm{EV}$ & EVSALEK EVSALEK ENSALEW EVSALEK \\
$\mathrm{EI}$ & EIAALEK EIAALEK ENAALEW EIAALEK \\
\hline
\end{tabular}

c)

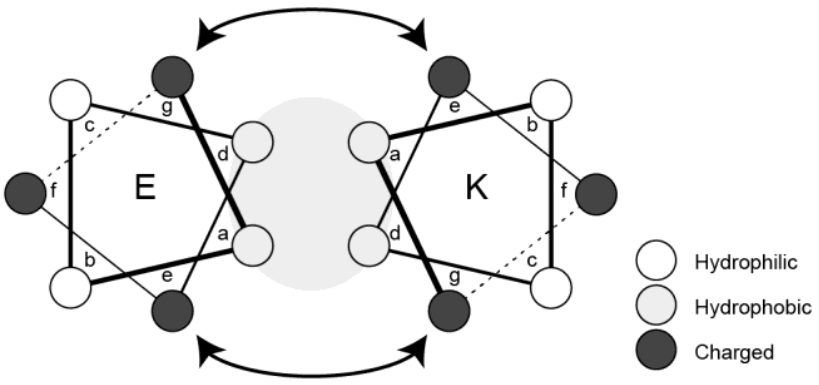

Figure 4-3: a) The coiled coil 81-residue $\mathrm{N}$-terminal fragment of tropomyosin (PDB ID: $1 \mathrm{IC2}^{\left[{ }^{[103]}\right)}$ acquired from the protein data bank (PDB) ${ }^{[96]}$ and visualized using the NGL viewer. ${ }^{[97,98]} \mathrm{b}$ ) The primary structure of the EKIV peptides: KV, KVC, KI, KVC, EV and EI peptides. c) Helical wheel diagram showing the top-down view of the helices of the lysine (K)-rich and the glutamic acid (E)-rich variants of the EKIV peptides when folded into a coiled coil.

The EKIV-peptides are a set of four de novo designed 28 residue amphipathic $\alpha$-helices designed to heterodimerize and fold into coiled coils. The design was inspired by coiled coil sequences from Hodges ${ }^{[104]}$ and Woolfson ${ }^{[85]}$ and further refined and expanded into the four EKIV-peptides by Aronsson et al. ${ }^{[84]}$. The name of each peptide reflects major residue content and the primary structure is shown in Figure 4-3b. The residues making up the hydrophobic core are leucine (L) at the $d$ position and isoleucine (I) for $\mathrm{KI}$ and $\mathrm{EI}$, and valine (V) for $\mathrm{KV}$ and EV in the $a$ position. To further stabilize the coiled coil, charged residues are located in the $e$ and $g$ positions; glutamic acid (E) for EI and EV and lysine (K) for KI and KV. The 
asparagine $(\mathrm{N})$ at the third repeat at the $a$ position enables the formation of a hydrogen bond with the corresponding asparagine in another peptide which locks the $\alpha$-helices in position and facilitate a parallel and in-register orientation of the two monomers. The tryptophan (W) in the third heptad at the $f$ position enables determination of peptide concentration through absorbance spectroscopy at $280 \mathrm{~nm}$. ${ }^{[84]}$ The addition of a $\mathrm{N}$-terminal cysteine in $\mathrm{KI} \rightarrow \mathrm{KIC}$ and $\mathrm{KV} \rightarrow \mathrm{KVC}$ further enabled conjugation of the peptide to maleimide-functionalized materials such as polymers ${ }^{[105]}$ and liposomes used in Paper II-III.

As a consequence of the charge complementary design, heterodimerization is favoured at neutral $\mathrm{pH}$. Any combination of two charge complementary peptides, out of the four EKIVpeptides, heterodimerize and fold into coiled coils (Figure 4-3c) with different dissociation constants ranging from less than $0.1 \mathrm{nM}$ (EVKV) to about $1 \mu \mathrm{M}$ (EIKI) (Figure 4-4) ${ }^{[84]}$ due to the difference in the hydrophobic core composition and the helical propensity of the serine (S) and alanine (A) ${ }^{[106]}$ in the $b$ position.

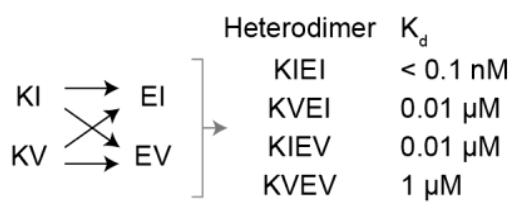

Figure 4-4: The heterodimerization of the EKIV peptides and the $\mathrm{K}_{\mathrm{d}}$ for each heterodimer respectively.

To further study the interactions of KVC with lipid membranes, a small redesign of the peptide sequence was made for Paper III. Adjustments were made to make each heptad repeat identical (KVSALKE) to enable comparison of peptides of different lengths and also to study the influence of the $\mathrm{N}$ and $\mathrm{W}$ in positions 17 and 22, respectively, on the membrane activity. Peptides with 2-5 heptad repeats were synthesised (Figure 4-5). The cysteine was kept at the $\mathrm{N}$-terminal for all KVC variants.

\begin{tabular}{|c|c|c|c|c|}
\hline & $\begin{array}{l}\text { Primary structure } \\
\qquad g \text { a } b c d e f \quad g a b c d e f\end{array}$ & $g a b c d e f$ & $g a b c d e f$ & $g a b c d e f$ \\
\hline $\begin{array}{l}\mathrm{KVC}_{2} \\
\mathrm{KVC}_{3} \\
\mathrm{KVC}_{4} \\
\mathrm{KVC}_{5}\end{array}$ & $\begin{array}{ll}\text { C } & \text { KVSALKE KVSALKE } \\
\text { C } & \text { KVSALKE KVSALKE } \\
\text { C } & \text { KVSALKE KVSALKE } \\
\text { C } & \text { KVSALKE KVSALKE }\end{array}$ & $\begin{array}{l}\text { KVSALKE } \\
\text { KVSALKE } \\
\text { KVSALKE }\end{array}$ & $\begin{array}{l}\text { KVSALKE } \\
\text { KVSALKE }\end{array}$ & KVSALKE \\
\hline
\end{tabular}

Figure 4-5: Primary structure of $\mathrm{KVC}_{2}-\mathrm{KVC}_{5}$ peptides. 


\subsubsection{Bacteriocins and the PLNC8 $\alpha \beta$ peptides}

Bacteriocins are a class of peptide toxins produced by bacteria in order to inhibit growth or kill other strains of bacteria. The vast variety of bacteriocin sequences and mechanisms of action make them attractive as possible "new antibiotics".[107] This class of peptides have not yet been extensively used clinically and there is thus a very low evolutionary pressure on the target bacteria to evolve resistance, which is a major problem with current antibiotics. ${ }^{[108]}$ Bacteria have, however, evolved multiple strategies to resist the effects of bacteriocins, such as secretion of enzymes to digest the peptides, active transport of any bacteriocin that enter the cell out again and changing the charge of the bacterium membrane in order to repel the bacteriocins. ${ }^{[109]}$ Bacteriocins and other antimicrobial peptides still may provide hope for new treatments if used with more care than current antibiotics have been.

PLNC8 $\alpha \beta$ is a two-peptide bacteriocin produced by the bacterium Lactobacillus plantarum which is part of the human natural flora of the oral cavity amongst other. ${ }^{[110]}$ The PLNC8 $\alpha \beta$ has proven effective in inhibiting the growth of Porphyromonas gingivalis, a key pathogen in periodontitis.[111]

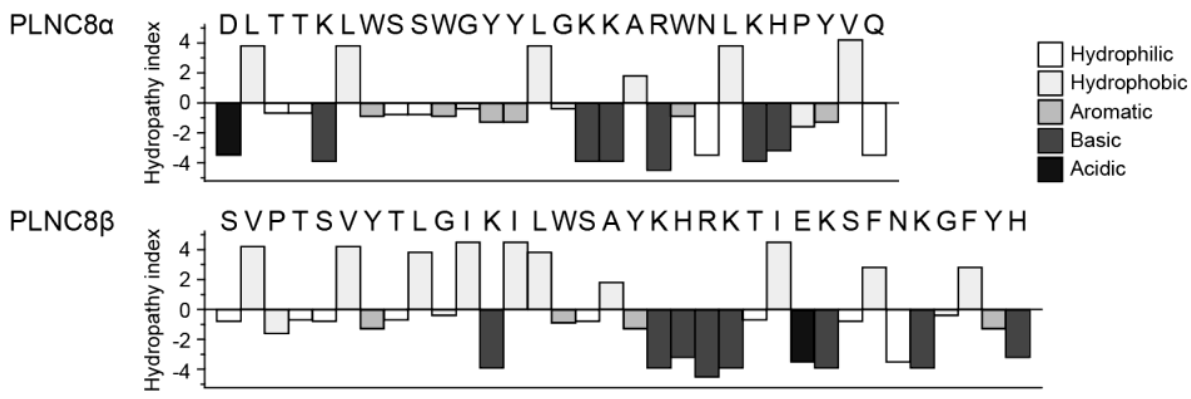

Figure 4-6: The primary structure and its hydropathy index for each residue of the two bacteriocins PLNC8 a and PLNC8 $\beta$.

Synthetic peptides with the same primary structure as PLNC8 $\alpha \beta$ where used in Paper IV. The primary sequence of the two peptides PLNC8 $\alpha$ and PLNC8 $\beta^{[111]}$ are presented in Figure 4-6 showing the hydropathy index of each residue. The hydropathy index provide a simple overview of the residue-properties in the primary structure. ${ }^{[112]}$ 


\section{Chapter 5}

\section{The interaction of JR2, EKIV and PLNC8 $\alpha \beta$ peptides with liposomes}

\subsection{Linear cationic amphipathic membrane active peptides}

Membrane active peptides are a very broad class of functional biomolecules that can be found in practically all organisms. These peptides include the antimicrobial peptides (AMP) that can kill or inhibit bacterial growth by disrupting the integrity of the bacterial cell membrane, ${ }^{[113]}$ naturally occurring cell penetrating peptides (CPPs) that traverse the cellular membrane ${ }^{[20]}$ and essentially all de novo designed peptides that interact with any lipid membranes ${ }^{[14]}$ (Figure 5-1). The primary structure of de novo designed membrane active peptides are often inspired by natural peptides in order mimic function of AMPs ${ }^{[15]}$ or $\mathrm{CPPS}^{[116]}$ but membrane activity in designed peptide may also be a result of serendipity.

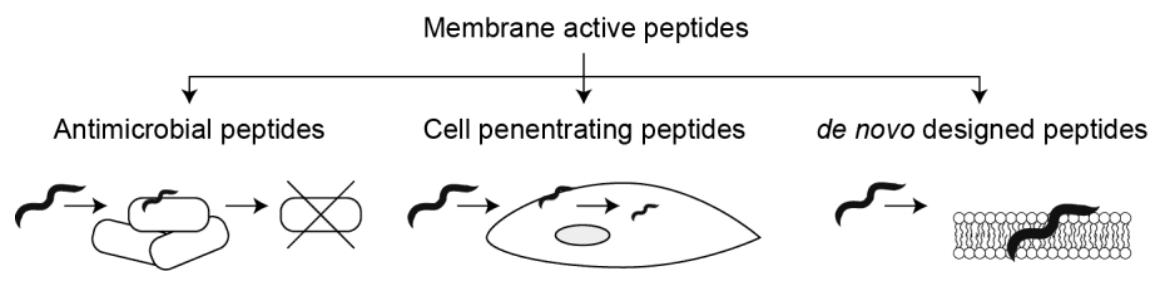

Figure 5-1: Illustration of the different categories of membrane active peptides. 
The vast numbers of different membrane active peptides interact with lipid membranes through many different interactions and mechanisms. AMPs are usually divided into subgroups based on their charge, specific residue content or secondary structure content. ${ }^{[22]}$ One subclass of membrane active peptides comprises the linear amphipathic cationic peptides. These peptides are often random coil in solution but adopt a defined $\alpha$-helical secondary structure upon interaction with lipid membranes. The $\alpha$-helix propensity of individual amino acids differs between aqueous and lipid environments. ${ }^{[117]}$ The initial electrostatic interaction between the cationic peptide and anionic lipid membranes enables the subsequent folding of the peptide. ${ }^{[118]}$

The folding of these peptides is energetically favourable because of the amphipathic characteristics of the peptide in the folded $\alpha$-helical state where the hydrophobic residues are largely concentrated on once face of the $\alpha$-helix. Hydrophobic interactions thus appears to be the main driving force behind the folding of the peptide and their affinity to lipid bilayers. ${ }^{[117,118]}$ However, Van der Waals interactions and electrostatic interactions are also often very important. In addition, the $\alpha$-helix is stabilized through internal $\mathrm{H}$-bonds between the amide and carbonyl groups in the peptide backbone. ${ }^{[119]}$ Although the folding increases the entropy of the peptide, the entropy change for the entire system is typically negative due to the loss of the highly organized water previously associated with the hydrophobic sidechains. ${ }^{[19]}$ Linear amphipathic cationic peptides interact with lipid bilayers differently depending on their primary structure and the specific composition of the lipid bilayer. ${ }^{[120]}$ The peptide-lipid modes of action can be mainly described by the detergent-like, carpet, toroidal pore or barrel stave pore model (Figure 5-2). ${ }^{[121]}$

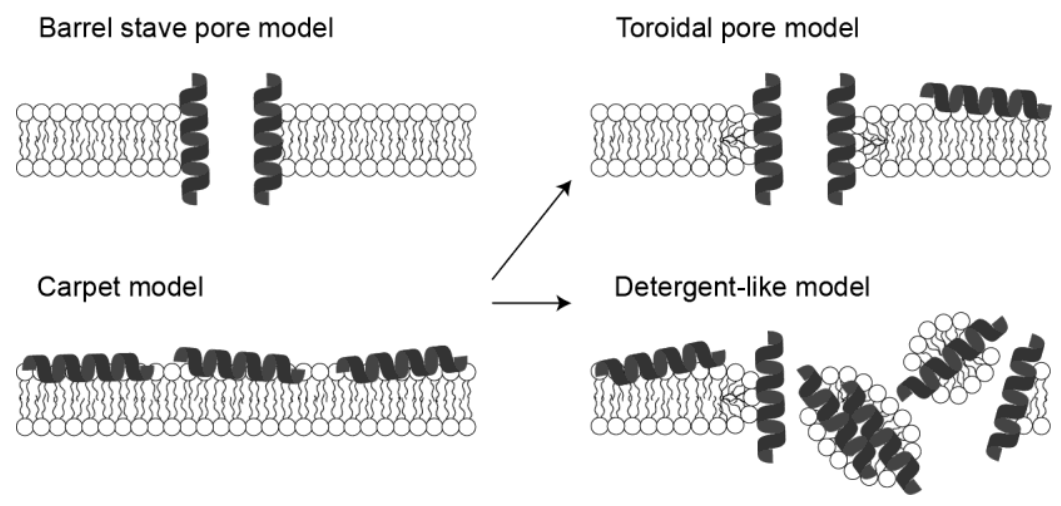

Figure 5-2: Schematic illustration of the main different modes of action by peptide interacting with lipid bilayers. Adapted with permission from Kumar et al.[121]

Irrespectively of the mechanisms by which the linear amphipathic cationic peptides interact with the lipid bilayer, the association tends to trigger changes in secondary structure of the 
peptide, from random coil to $\alpha$-helical. In the carpet model the peptides reside in the outer leaflet of the lipid bilayer. The detergent-like model describes the removal of peptide-lipid complexes upon peptide interaction with the lipid bilayer due to the mismatch in sterical properties. ${ }^{[122]}$ The detergent-like model is the only one that include lipid removal, although the carpet model is sometimes a precursor to both the detergent-like and toroidal pore model. The two pore models (toroidal and barrel stave) differ only in how the lipids are arranged around the pore. In the toroidal pore model, the peptide lipid head-groups interact with the peptides all through the cross-section of the pore. In the barrel stave pore, the lipid headgroups only resides on the lipid bilayer surfaces and the peptide thus interact more intimately with the hydrophobic tails of the lipids. ${ }^{[121]}$ Pore forming peptides include melittin found in bee-venom, ${ }^{[123,124]}$ magainin 2 secreted from frog $\operatorname{skin}^{[125,126]}$ and LL-37 secreted from epithelial cells in the human lung. ${ }^{[127,128]}$

Membrane active de novo designed linear amphipathic cationic peptides and their interaction with liposomes have been extensively investigated, such as the KLAL peptide, ${ }^{[118]}$ the K peptide (KIAALKE) ${ }_{3}{ }^{[129]}$ and short collagen-mimetic peptides. ${ }^{[48]}$ The interaction in these studies were characterized, among others, by monitoring the change in lipid membrane permeability using the release of an encapsulated fluorophore (described in section 7.1) and by measuring the changes in secondary structure using circular dichroism (described in section 7.5).

In Paper I-III different de novo designed linear amphipathic cationic peptides and their interactions with lipid bilayers were investigated. In Paper IV naturally occurring linear cationic peptides and their interactions with a very simplistic bacterial lipid bilayer model systems were investigated.

\subsection{Conjugation via maleimide-thiol Michael addition reaction}

Peptides with no or low lipid membrane affinity can be modified in order to promote membrane association and lipid interactions by increasing their hydrophobicity through conjugation to phospholipids, cholesterols or fatty acids. ${ }^{\left[{ }^{130-132]}\right.}$ Two main types of strategies are used; pre- and post-modification. In the pre-modified strategy, also known as lipidation, the peptide is conjugated to a hydrophobic moiety and purified before allowing any interaction with the lipid membranes. During post-modifications the peptide is allowed to covalently bind to a moiety in the already formed lipid membrane. Pre-modifications has been thoroughly investigated to improve the properties of antimicrobial peptides ${ }^{[133]}$ and to develop model systems for studies of e.g. membrane fusion. ${ }^{[130,131]}$

In this thesis, the conjugation of peptides to liposomes in Paper I-III, regarding the JR2 and EKIV peptides, was done using the maleimide-thiol Michael addition reaction (Figure 5-3). The conjugation was performed after formation of liposomes, and thus this conjugation strategy could also be referred to as a post-modification lipidation. Conjugation of the lysine- 
rich and N-terminal cysteine containing JR2KC, KIC and all versions of KVC peptides to MPB$\mathrm{PE}$ containing liposomes was done by utilizing the maleimide in MPB-PE and the thiol in the cysteine.

a)

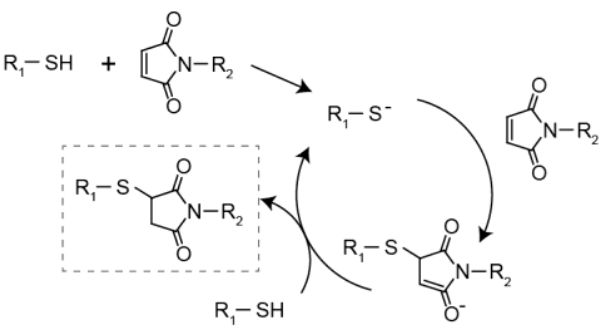

b)

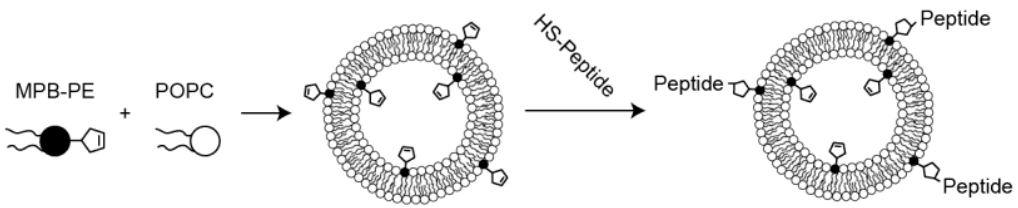

Figure 5-3: a) Schematic over the maleimide-thiol Michael addition reaction adapted from Northrop et al. ${ }^{[134]}$ b) Conjugation of peptide with cysteine to MPB-PE containing liposomes.

The Michael addition of the maleimide-thiol reaction relies on a nucleophilic attack of the $\pi$ bond of the maleimide by the nucleophilic thiolate anion. The enolate intermediate deprotonates another thiol group resulting in additional maleimide-thiol reactions and the final product is the result of the protonated enolate intermediate. The main driving force due to the withdrawing effects of the two activating carbonyls groups and the resulting release of ring strain. ${ }^{[134]}$

\subsection{The interaction of JR2 peptides and the triggered liposome content release by MMP-7 (Paper I)}

The interactions of the amphipathic cationic JR2KC and the amphipathic anionic JR2E (peptides described in section 4.2.1) with liposomes containing MPB-PE and POPC (described in section 3.2.4) was investigated to evaluate the potential of this four-helix bundle peptide system as a tunable and enzymatically triggered liposomal cargo release system. 


\section{a)}
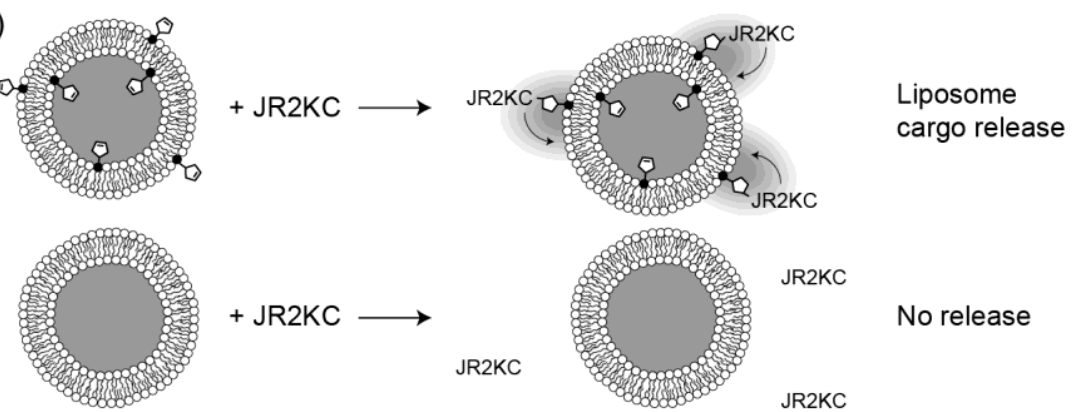

b)

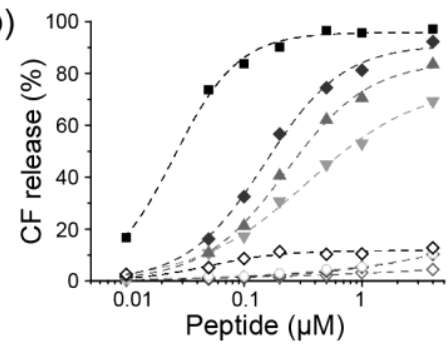

JR2KC

No release c)

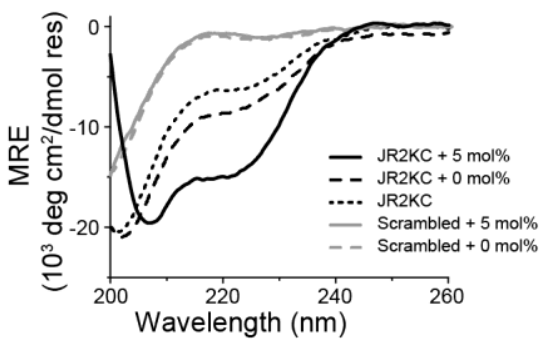

d)

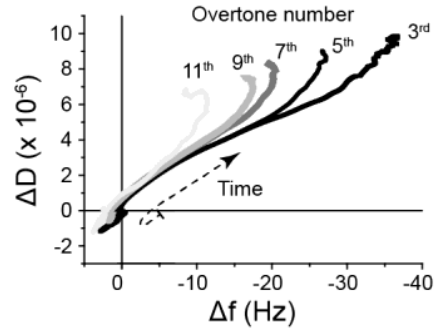

Figure 5-4: a) Schematic illustration of the conjugation of JR2KC with and without MPB-PE lipids mixed into the POPC liposomes. b) The CF release after 30 min interaction between o, 1, 3, 5 and 10 mol\% MPB-PE liposomes with JR2KC, oxidized JR2KC, scrambled JR2KC and JR2K (se legend). c) CD spectra of JR2KC and scrambled JR2KC with o and 5 mol\% MPB-PE liposomes in $10 \mu \mathrm{M}$ PBS pH 7.4 (se legend). d) $\Delta$ D vs $\Delta$ f plot from QCM-D measurement with $4 \mu \mathrm{M}$ JR2KC added to SLB made from 5 mol\% MPB-PE liposomes. The addition of peptide started at $\mathrm{t}=\mathrm{o}$ and the final time point in this graph is just before buffer rinsing.

As previously described, the cysteine-containing JR2 KC was conjugated to the maleimide moiety in MPB-PE-containing POPC liposomes (Figure 5-4a). It was evident that JR2KC was membrane active only after this conjugation, which caused a change in permeability of the lipid membrane to release the encapsulated fluorophore carboxyfluorescein (CF) (the method is described in section 7.1). The CF release after $30 \mathrm{~min}$ from liposomes (with total lipid concentration of $40 \mu \mathrm{M}$ ) containing 1, 3, 5 and 10 mol\% MPB-PE with $4 \mu \mathrm{M}$ JR2KC was 69 , 84, 92 and $97 \%$ indicating that an increase in MPB-PE content increased the release rate. The same trend was noted with increasing peptide concentration (Figure $5-4 \mathrm{~b}$ ). The CF releases after 30 min when either the cysteine in the peptide was removed (JR2K) or when liposomes did not contain MPB-PE (o mol\% MPE-PE liposomes) were all below $11 \%$. The drastic 
difference in permeability change of the lipid membrane demonstrated the importance of conjugation of this specific peptide. The conjugation can be considered as a prerequisite to the peptide-lipid interaction that modulate the liposome permeability and the $\mathrm{CF}$ release rate can be finely tuned by tailoring the MPB-PE and JR2KC content.

The interaction of JR2 KC with the lipid membrane containing MPB-PE also triggered a change in secondary structure of the peptide from random coil to $\alpha$-helical (Figure $5-4 \mathrm{~b}$ ). The folding was only observed when JR2KC was allowed to conjugate to the liposome. The primary structure of the peptide was shown to be of importance since a peptide with a scrambled primary structure did neither fold nor cause any significant increase in CF release. A similar change in secondary structure as a consequence of partitioning into the lipid bilayer have also been seen in the pore forming helix-loop-helix peptide melittin ${ }^{[123,135]}$ and commonly seen for other amphipathic cationic peptides. ${ }^{[129,136,137]}$ The folding enables the hydrophobic residues to bury their sidechains in the hydrophobic interior of the lipid bilayer. The total Gibbs free energy of the system is thus reduced trough the release of highly organized water around the hydrophobic residues. ${ }^{[118]}$ The interaction of JR2KC with 5 mol\% MPB-PE supported lipid bilayers evaluated by QCM-D showed that the initial interaction resulted in the partitioning of peptides and likely pore formation as indicated by the increase in mass and change in viscoelastic properties. At equilibrium the majority of peptides were, however, mainly localized on the bilayer surface (Figure 5 -4d). ${ }^{[138-140]}$

Additionally, it was observed that the CF release could be further tuned by the addition of the charge complementary peptide JR2E which heterodimerize with JR2KC forming four-helix bundles (Figure $5-5 \mathrm{a}$ ). ${ }^{\left[{ }^{3}\right]}$ The $\mathrm{CF}$ release could be inhibited from 81 to $10 \%$ by allowing conjugation of the heterodimer to 5 mol\% MPB-PE liposomes instead of JR2 KC alone (Figure $5-5 b)$. The competitive interaction offered by JR2E inhibits the otherwise faster interaction of JR2KC with the lipid membrane.

A triggered CF release was achieved by the proteolytic digestion of the inhibitory peptide JR2E by the matrix metalloproteinase MMP-7 (Figure 5-5a). The upregulation of MMP-7 in vivo is associated with the progression of various malignant tumours and inflammatory processes. ${ }^{[141]}$ JR2E contains two cleavage sites for MMP-7; 11-A-|-L-12 and 26-A-|-Q-27, and the JR2E fragments have a drastically reduced ability to associate with JR2E. ${ }^{[142]}$ The presence of MMP7 enabled JR2KC to interact with the lipid membrane and, as shown in the beginning of this section, increase the permeability of the lipid membrane and release the encapsulated $\mathrm{CF}$ (Figure 5-5c). The MMP-7 concentrations used here $(0.5-10 \mu \mathrm{g} / \mathrm{mL}$ ), are higher than clinically relevant concentrations (on the order of $\mathrm{ng} / \mathrm{mL}$ ), ${ }^{[143]}$ but demonstrate the concept of MMPtriggered release and can likely be improved by further optimization of the system. 

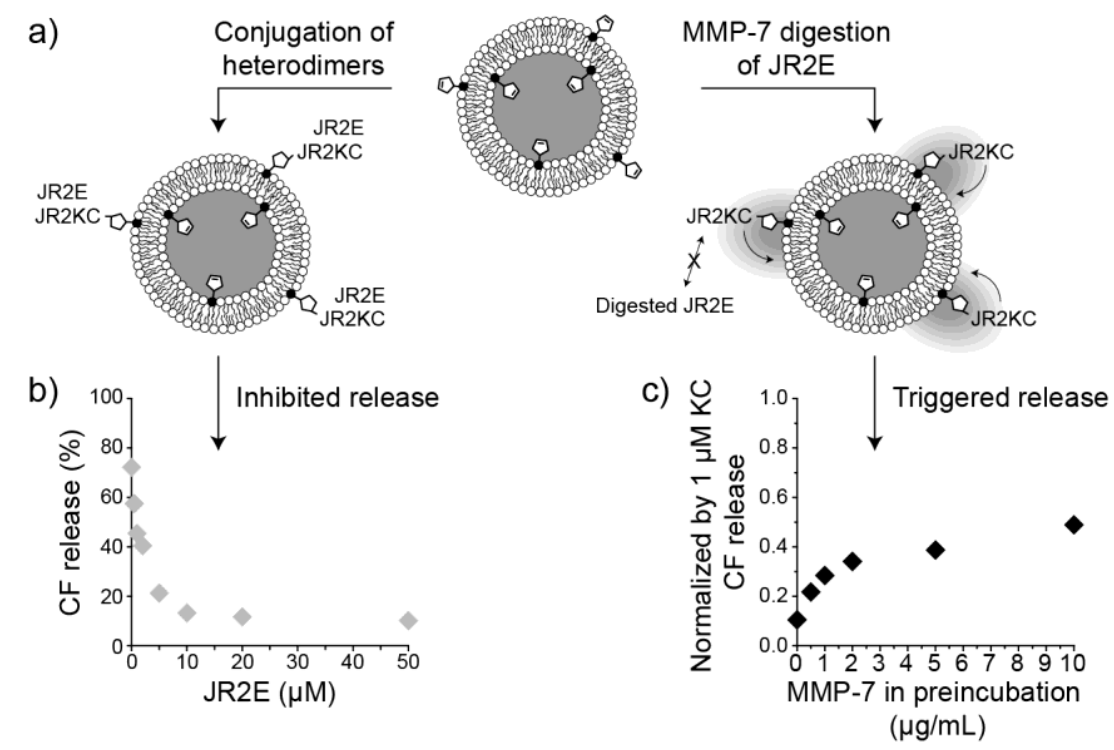

Figure 5-5: a) Schematic illustration of the inhibition of CF release by the conjugation of JR2KC- to 5 mol\% MPB$\mathrm{PE}$ liposomes in the presence of the complementary peptide JR2E and the triggered release by MMP-7 digestion of JR2E. b) The CF release after $2 \mathrm{~h}$ when conjugation pre-incubated JR2E $1 \mu \mathrm{M}$ and JR2KC. c) CF release after 2 $\mathrm{h}$ after degradation of JR2E ( $50 \mu \mathrm{M})$ with MMP-7. The CF release was due to reactivated JR2KC and the result was normalized according to the release from $1 \mu \mathrm{M}$ JR2KC after $2 \mathrm{~h}$.

Similar liposome-based DDS have been developed for triggered release by MMP-9 exploiting the proteolytic digestion of liposome-conjugated triple helical peptides derived from collagen type I. In contrast to JR2KC that trigger release when intact, the collagen derived peptides unfolds when digested causing a strain on the lipid membrane resulting in a release of the liposomal content.[48-50] This strategy, however, required significantly higher peptide concentrations (30 mol\%) compared to the concept developed in Paper I based on JR2KC and showed a relatively slow and inefficient release with a substantial background leakage.

\subsection{The interaction of EKIV peptides and the triggered liposome content release by heterodimer exchange (Paper II)}

Inspired by the findings that JR2KC was membrane active when conjugated to liposomes the interactions of the amphipathic coiled coil peptides KIC, KVC, EI and EV (peptides described in section 4.2.2) with liposomes containing MPB-PE and POPC (described in section 3.2.4) were investigated. The potential to use this coiled coil peptide system in design of tunable and triggered liposomal cargo release system was evaluated. 

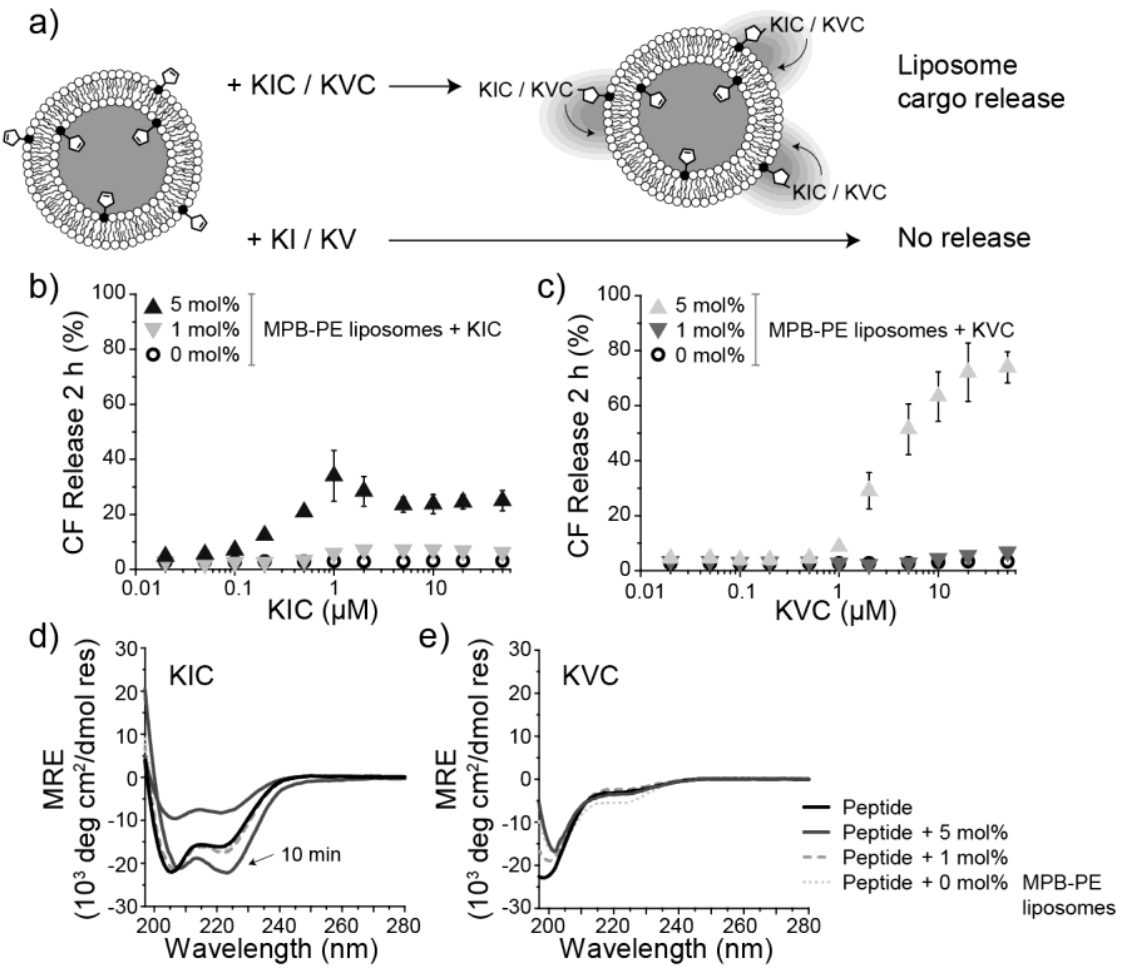

Figure 5-6: a) Schematic illustration of the conjugation of KIC and KVC to MPB-PE containing liposomes and the non-conjugated KI / KV. b-c) The CF release after $2 \mathrm{~h}$ from o, 1 and 5 mol\% MPB-PE liposomes upon interaction with KIC (b) and KVC (c). d-e) CD spectra of $50 \mu \mathrm{M}$ peptide KIC and KVC (d and e, respectively), with o mol\%, 1 mol\% and 5 mol\% MPB-PE liposomes in PBS after $8 \mathrm{~h}$, except for an extra measurement on the KIC + 5 mol\% MPB-PE liposomes after 10 min as indicated by the arrow, legend in (e).

The peptide-lipid interactions of KIC and KVC proved to be highly dependent on the conjugation of the peptide to the liposome through the maleimide-thiol reaction, as was the case with JR2KC in Paper I. The dependence of the conjugation was determined from the lack of $\mathrm{CF}$ release upon peptide interaction with o mol\% MPB-PE liposomes in combination with the extensive CF release from 5 mol\% MPB-PE liposomes. The CF release from 1 mol\% MPBPE liposomes never reached over $10 \%$ after addition of any of the two peptides (Figure 5-6ac). The critical peptide surface concentration was hence likely not reached at this MPB-PE concentration. The conjugated KIC caused a CF release from 5 mol\% MPB-PE liposomes which peaked at a peptide:maleimide ratio of about 1:2 (1 $\mu \mathrm{M} \mathrm{KIC),} \mathrm{but} \mathrm{never} \mathrm{reached} \mathrm{a} \mathrm{higher}$ release than about $40 \%$. KVC on the other hand was observed to have an increased CF release with increasing concentration of the peptide. Comparing the two peptides KVC did release more of the encapsulated CF whereas KIC released CF at lower peptide concentrations but never came near an extensive release. KIC likely folded into homodimers as the peptide surface concentration increased. The folding into homodimers was further supported by both the 
increased coiled coil secondary structure $\left(\mathrm{MRE}_{222}<\mathrm{MRE}_{208}\right.$, Figure 5-6d) and the extensive aggregation of KIC-functionalized liposomes. ${ }^{\text {a }}$ The higher propensity of KI as compared to KV to form homodimers in PBS was previously observed by Aronsson et al.,[84] although in peptides without the $\mathrm{N}$-terminal cysteine modification, and can be explained by the higher packing efficiency of isoleucine (I) compared to valine (V). ${ }^{[144]}$ Interestingly, even though it was expected that KVC would fold when interacting with a lipid bilayer lipid bilayer no defined secondary structure was observed (Figure 5-6e). Either the mechanism of action does not require a change in secondary structure or only a small fraction of the conjugated KVC was folded and responsible for the $\mathrm{CF}$ release.

Since a reproducible and efficient $\mathrm{CF}$ release, as well as a discrete (i.e. non-aggregated) system was desired, KIC was excluded as a candidate and the inhibition and triggered release using $\mathrm{KVC}$ was further investigated. As a means to inhibit the CF release by conjugated KVC, the effect of heterodimerization was explored. The two peptides EI and EV are both capable of heterodimerizing with $\mathrm{KVC}$ and fold to form coiled coils with different dissociation constants $\left(\mathrm{K}_{\mathrm{d}}=0.01 \mu \mathrm{M}\right.$ and $\mathrm{K}_{\mathrm{d}}=1 \mu \mathrm{M}$ for EIKV and EVKV, respectively).[84] The CF release was significantly lower when conjugating the heterodimeric coiled coils instead of KVC and the efficiency of the inhibition was reflected by their affinities for heterodimerization (Figure 5-7a,b). The formation of heterodimeric coiled coils before conjugation was crucial, since already conjugated KVC did not significantly interact with neither EI nor EV due to the competing peptide-lipid interactions (Figure 5-7c). This observation further confirmed that KVC interacted extensively with the lipid bilayer.

a)

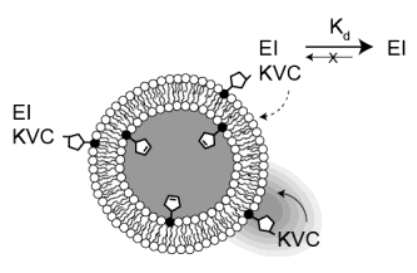

b)

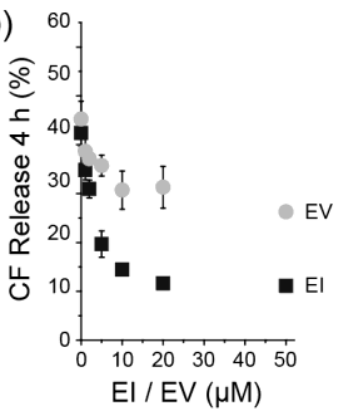

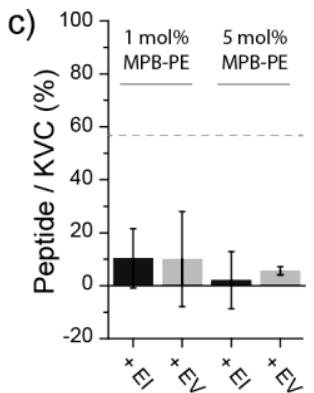

Figure 5-7: a) Schematic illustration of the inhibition of release by EI (or EV) through conjugation of heterodimers. b) The CF release after $4 \mathrm{~h}$ by conjugation of the heterodimers EIKVC and EVKVC ( $5 \mu \mathrm{M} \mathrm{KVC}+\mathrm{o}$, 1, 2, 5, 10, 20 and $50 \mu \mathrm{M}$ EI or EV). C) Degree of EI and EV which could heterodimerize with KVC already conjugated to $5 \mathrm{~mol} \% \mathrm{MPB}-\mathrm{PE}$ liposomes calculated from surface plasmon resonance sensorgrams.

\footnotetext{
a Figure 2 in Paper II
} 
a)

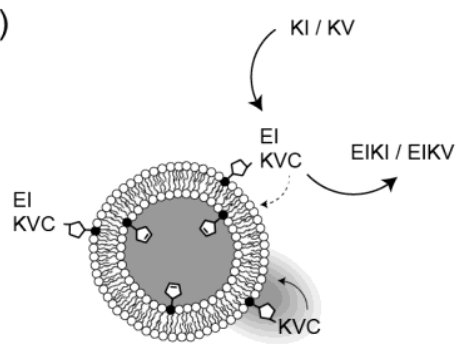

b)

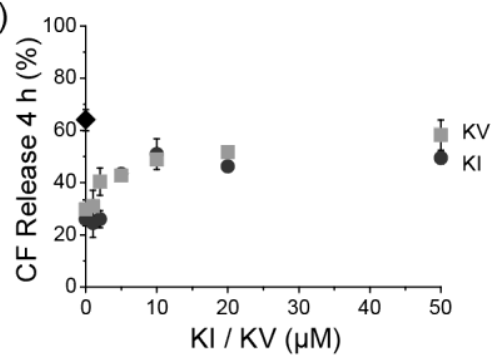

Figure 5-8: a) Schematic illustration of the heterodimer exchange. b) The CF release after $4 \mathrm{~h}$ from KVC (5 $\mu \mathrm{M})$ $+\mathrm{EI}(10 \mu \mathrm{M})+\mathrm{KI}$ (dark grey) or KV (light grey) and the control KVC (5 $\mu \mathrm{M})$ (black).

The triggered release was achieved by exploiting the heterodimer exchange, which was previously demonstrated by Dånmark et al.[105] to control the crosslinking density in peptidebased hydrogels. The additions of KI or KV to EI inhibited KVC-conjugated liposomes resulted in a heterodimer exchange removal of inhibitory peptide, rendering the conjugated KVC free to interact with the lipid bilayer. The heterodimeric exchange was slightly more efficient with the addition of KV even though $\mathrm{KI}$ has a higher affinity for EI heterodimerization $\left(\mathrm{K}_{\mathrm{d}}=<0.1\right.$ $\mathrm{nM}$ and $\mathrm{K}_{\mathrm{d}}=0.01 \mu \mathrm{M}$ for EIKI and EVKI, respectively[84]), likely a result of the tendency of KI to homodimerize (Figure 5-8).

The prospect of using KVC for a tunable and triggered liposome cargo release strategy seems promising. There are still some questions regarding the interactions and mechanism involved, in particular the lack of secondary structure seems puzzling. Peptides with similar primary structure tend to fold into $\alpha$-helices when interacting with lipid membranes, ${ }^{[118,129]}$ although it has been suggested that increased permeability can be an effect of electrostatic interactions between the peptide and the lipid headgroups solely. ${ }^{[118]}$ In order to further characterize and optimize the peptides for controlled the release, the influence of peptide length and were investigated.

\subsection{Optimization of KVC (Paper III)}

The interactions of the $\mathrm{KVC}$-derived peptides $\mathrm{KVC}_{2}-\mathrm{KVC}_{5}$ (described in section 4.2.2) with liposomes containing MPB-PE and POPC (described in section 3.2.4) was evaluated to investigate if there was an optimal $\mathrm{KVC}_{\mathrm{n}}$ length that could be used in future designs for triggered liposome cargo release. In Paper II it was shown that KVC could be used as the membrane active peptide in a peptide heterodimer system for tunable and triggered release. For future designs based on this peptide, detailed knowledge of the optimal composition and number of heptad repeats ( $\mathrm{n}$ ) of $\mathrm{KVC}_{\mathrm{n}}$ will be beneficial. 
The KVC peptide was originally designed to heterodimerize and fold into parallel coiled coils with a complementary peptide. To promote in-register dimerization (i.e. no overhanging ends) an asparagine (N) was included asymmetrically in the hydrophobic core in all peptides. Efficient dimerization thus required alignment of the $\mathrm{N}$ residues in the two peptides to form a hydrogen bond when the two peptides interacted. ${ }^{[84]}$ The presence of a polar residue on the hydrophobic face, however, reduced the amphipathic characteristics of the peptide which was thought to negatively influence the interaction of KVC with lipid membranes. In addition, KVC has a $\mathrm{W}$ in $\mathrm{f}$ position to facilitate purification and determination of concentration, but which further compromised the amphipathic properties of the peptide.

A redesign of $\mathrm{KVC}$ by introducing the substitutions $17-\mathrm{W} \rightarrow \mathrm{E}$ and $22-\mathrm{N} \rightarrow \mathrm{V}$ was hence carried out, resulting in the peptide $\mathrm{KVC}_{4}$ with the repetitive primary sequence (KVSALKE) 4 . The changes in liposome permeability triggered by $\mathrm{KVC}_{4}$ was dependent on the peptide-lipid conjugation as previously observed in Paper I and II. This dependency was shown both as an absence of $\mathrm{CF}$ release and lack of interaction observed by isothermal titration calorimetry (ITC) (Figure 5-9) unless conjugated.

a)
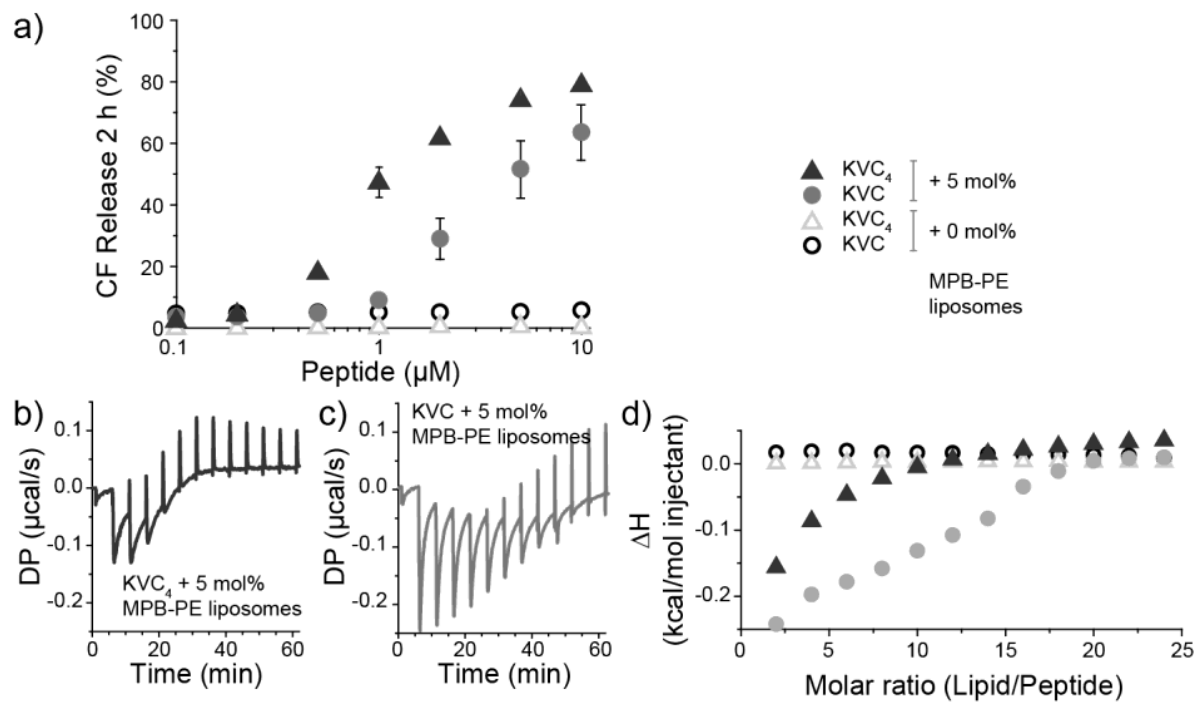

Figure 5-9: a) The CF release after $2 \mathrm{~h}$ with o, $5 \mathrm{~mol} \% \mathrm{MPB}-\mathrm{PE}$ liposomes and $\mathrm{KVC}, \mathrm{KVC}_{4}$ (see legend). b-c) ITC heat traces of 5 mol\% MPB-PE liposomes (30 mM) titrated into $150 \mu \mathrm{M} \mathrm{KVC}_{4}$ (b) and $\mathrm{KVC}$ (c). d) Enthalpy changes for the interactions in b-c and for interactions of o mol\% MPB-PE liposomes with $\mathrm{KVC}_{4}$ and $\mathrm{KVC}$. Legend as in a.

When comparing the lipid-peptide interactions of $\mathrm{KVC}$ and $\mathrm{KVC}_{4}$ it was observed that $\mathrm{KVC}_{4^{-}}$ liposome interaction increased the permeability substantially more than KVC did, despite the rather minor differences in primary sequence between the two peptides. The unfavourable 
localization of $\mathrm{W}$ and $\mathrm{N}$ at the hydrophobic-hydrophilic interface of the lipid bilayer ${ }^{[145]}$ may thus contribute to the large difference in peptide-lipid interaction between $\mathrm{KVC}_{4}$ and the $\mathrm{W} / \mathrm{N}$ containing KVC. When conjugated to the 5 mol\% MPB-PE liposomes $\mathrm{KVC}_{4}$ caused a $\mathrm{CF}$ release at lower peptide concentrations than KVC and a small but consistent increase in helicity. The thermodynamics of the interactions of the two peptides with liposomes was investigated using ITC but interpretation was complicated by the negative contribution from the maleimide-thiol conjugation $(\Delta \mathrm{H}=-0.57 \mathrm{kcal} / \mathrm{mol})$. The interaction between $5 \mathrm{~mol} \% \mathrm{MPB}-\mathrm{PE}$ liposomes and $\mathrm{KVC}$ and $\mathrm{KVC}_{4}(\Delta \mathrm{H}=-0.24$ and $-0.16 \mathrm{kcal} / \mathrm{mol}$, respectively) reflected the combined peptidelipid conjugation and the resulting non-covalent interactions. Subtracting the contribution from the conjugation indicates that the peptide-lipid interactions was entropy driven.

The peptides $\mathrm{KVC}_{2}, \mathrm{KVC}_{3}, \mathrm{KVC}_{4}$ and $\mathrm{KVC}_{5}$ were evaluated to study the effects of peptide length on the release efficiency. The CF release after 20 min with $10 \mu \mathrm{M}$ peptide and 5 mol\% MPB$\mathrm{PE}$ liposomes was 1.4, 25.2, 65.1 and $35.7 \%$ for $\mathrm{KVC}_{2}-\mathrm{KVC}_{5}$, respectively (Figure 5-10a-d). The difference in the $\mathrm{CF}$ release could be related to the length of the peptides in relation to the thickness of the POPC lipid bilayer (4 nm). ${ }^{[146]}$ The unfolded contour length of the peptides were $5.5,8,10.6$ and $13.1 \mathrm{~nm}$, for $\mathrm{KVC}_{2}-\mathrm{KVC}_{5}$ respectively, assuming $0.356 \mathrm{~nm} /$ residue $^{[147]}$ and the folded $\alpha$-helix contour length 2.25, 3.3, 4.4 and $5.4 \mathrm{~nm}$, respectively, assuming 0.15 $\mathrm{nm} /$ residue. ${ }^{[148]}$ The low $\mathrm{CF}$ release from $\mathrm{KVC}_{2}$ was on par with the short contour length suggesting the peptide was not long enough to efficiently span the lipid membrane. The peptides $\mathrm{KVC}_{3}-\mathrm{KVC}_{5}$ were all sufficiently long enough and the $\mathrm{CF}$ release was extensive. $\mathrm{KVC}_{3}$ was observed by dynamic light scattering (DLS) to cause liposome aggregation at high peptide surface concentration which is not considered as an attractive property from a DDS perspective. ${ }^{\mathrm{b}}$

The changes in secondary structure when the peptides interact with o mol\% MPB-PE liposomes were minimal and all peptides remained as random coils. ${ }^{c}$ When the peptides could interact with 5 mol\% MPB-PE liposomes, the $\alpha$-helical content increased as the peptide length increased (Figure 5-10e-h). $\mathrm{KVC}_{2}$ barely changed secondary structure, which correlated with the low $\mathrm{CF}$ release. $\mathrm{KVC}_{3}$ was observed to have drastically lower signal intensity when folded which can be an indicator of increased scattering in the sample which was confirmed by the aggregation seen in the DLS measurements. $\mathrm{KVC}_{4}$ and $\mathrm{KVC}_{5}$ were both observed to increase their $\alpha$-helical content when conjugated to $5 \mathrm{~mol} \%$ MPB-PE liposomes, although the folding of $\mathrm{KVC}_{5}$ was much faster, the $\mathrm{CF}$ release of $\mathrm{KVC}_{4}$ was faster and without any trace of aggregation.

b Figure 4 in Paper III

c Figure 5i-l in Paper III 

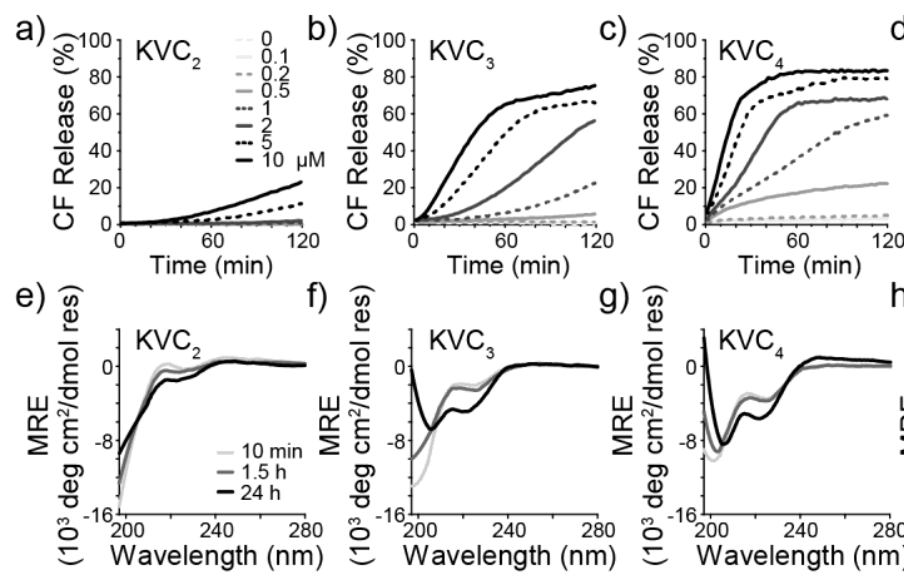

g) $\widehat{y}$
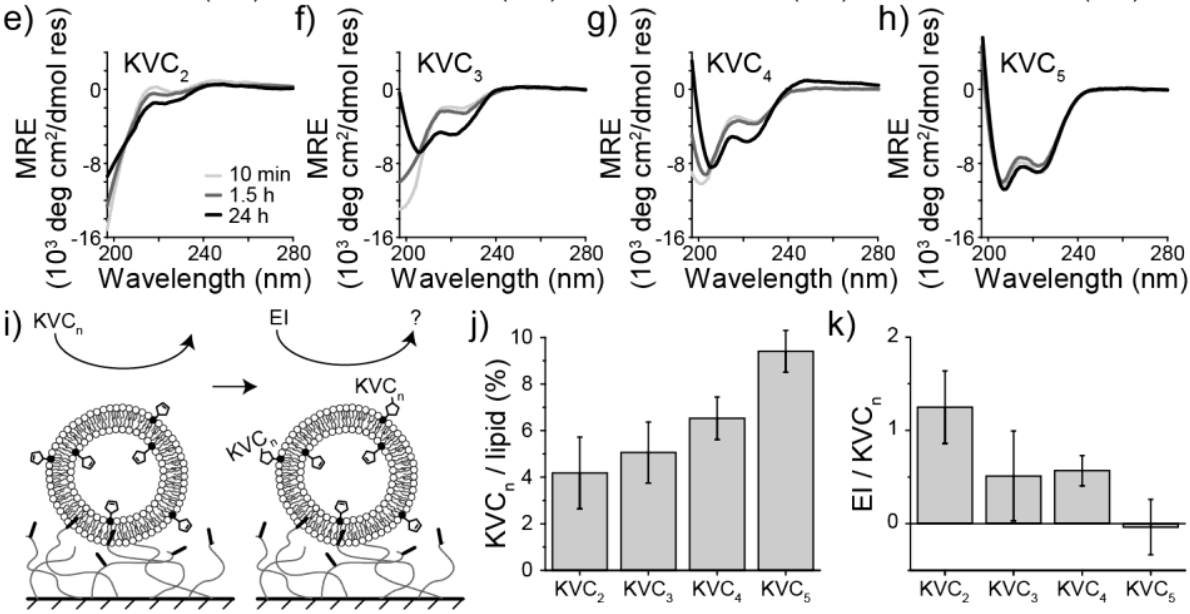

Figure 5-10: a-d) The CF release of $\mathrm{KVC}_{2}-\mathrm{KVC}_{5}$ respectively over $2 \mathrm{~h}$, legend in (a). e-h) CD spectra of $\mathrm{KVC}_{2}-\mathrm{KVC}_{5}$ +5 mol\% MPB-PE liposomes, legend in (e). i) Schematic illustration of the setup for SPR measurements generating data to calculate $\mathrm{j}$ ) the conjugation-degree of $\mathrm{KVC}_{2}-\mathrm{KVC}_{5}$ per lipid (5 mol\% MPB-PE liposomes) and $\mathrm{k}$ ) the heterodimerization-degree of $\mathrm{EI}$ to $\mathrm{KVC}_{2}-\mathrm{KVC}_{5}$-functionalized 5 mol\% MPE-PE liposomes.

To further investigate the interactions of the peptides with the lipid membrane, surface plasmon reference (SPR) was used to estimate the degree of conjugation $\mathrm{KVC}_{\mathrm{n}} / \mathrm{lipid}$ (Figure 5-10i,j). $\mathrm{KVC}_{5}$ showed a surface concentration that was higher than the MPB-PE-content, indicating that either homodimerization between conjugated and non-conjugated peptides on the liposome surface occurred or that the initial interaction promoted defect formation in the lipid bilayer, as seen with similar peptides, ${ }^{[149]}$ allowing unconjugated peptide to bind to these defects without being conjugated.

The availability of the conjugated $\mathrm{KVC}_{\mathrm{n}}$ to bind to the complementary peptide EI was used to determine the amount of conjugated $\mathrm{KVC}_{\mathrm{n}}$ that did not interact with the lipid membrane and thus was available for heterodimerization (Figure 5-10k). It was observed that more EI was able to bind to the peptides in reverse order of length $\left(\mathrm{EI} / \mathrm{KVC}_{5}<\mathrm{EI} / \mathrm{KVC}_{4} \approx \mathrm{EI} / \mathrm{KVC}_{3}<\right.$ $\mathrm{EI} / \mathrm{KVC}_{2}$ ), even though the longer peptides had a higher conjugation degree as well as higher charge per peptide. The electrostatic attraction between the $\mathrm{EI}$ and $\mathrm{KVC}_{\mathrm{n}}$ thus did not explain these results but rather the availability of the $\mathrm{KVC}_{\mathrm{n}}$ hydrophobic residues to form a hydrophobic core when folded with EI was crucial. The high availability for heterodimerization and the low $\mathrm{CF}$ release by $\mathrm{KVC}_{2}$ was interpreted as a low degree of interaction with the lipid 
membrane, where for $\mathrm{KVC}_{3}$ and $\mathrm{KVC}_{4}$ the opposite was observed. The low availability for heterodimerization and the slightly lower $\mathrm{CF}$ release by $\mathrm{KVC}_{5}$ compared to $\mathrm{KVC}_{4}$ was explained by the homodimerization of $\mathrm{KVC}_{5}$ thus rendering the peptide unavailable for heterodimerization.

\begin{tabular}{|c|c|c|c|c|c|c|}
\hline \multirow{2}{*}{\multicolumn{3}{|c|}{ Conjugation-dependent peptide-lipid interaction }} & \multirow{2}{*}{$\frac{\mathrm{KVC}_{2}}{+++}$} & \multirow{2}{*}{$\frac{\mathrm{KVC}_{3}}{+++}$} & \multirow{2}{*}{$\frac{\mathrm{KVC}_{4}}{+++}$} & $\mathrm{KVC}_{5}$ \\
\hline & & & & & & +++ \\
\hline \multirow[t]{2}{*}{$\mathrm{CF}$ release } & \multicolumn{2}{|c|}{ - Total release after $2 \mathrm{~h}$} & + & ++ & +++ & +++ \\
\hline & \multicolumn{2}{|l|}{ - Rate } & + & ++ & +++ & ++ \\
\hline \multicolumn{3}{|c|}{ Discrete system (no aggregation) } & +++ & - & +++ & ++ \\
\hline \multicolumn{3}{|c|}{ Folding upon conjugation } & - & + & ++ & +++ \\
\hline \multicolumn{2}{|c|}{ Conjugation efficiancy } & $\left(\mathrm{KVC}_{\mathrm{n}} / \mathrm{MPB}-\mathrm{PE}\right)$ & $0.8 \pm 0.3$ & $1.0 \pm 0.3$ & $1.3 \pm 0.2$ & $1.8 \pm 0.2$ \\
\hline \multicolumn{2}{|c|}{ Heterodimerization } & $\left(E I / K V C_{n}\right)$ & $1.2 \pm 0.4$ & $0.5 \pm 0.5$ & $0.6 \pm 0.2$ & $0.0 \pm 0.3$ \\
\hline
\end{tabular}

Figure 5-11: Table summarizing the main results thus facilitating the comparison of $\mathrm{KVC}_{2}-\mathrm{KVC}_{5}$.

In conclusion (summarized in Figure $5^{-11}$ ), $\mathrm{KVC}_{4}$ was able to trigger the most rapid and efficient release without causing aggregation of the system and was thus considered to be the best candidate for future work on designed bioresponsive peptide-liposome based DDS.

\subsection{PLNC8 $\alpha \beta$ peptide-interactions with liposome-model system (Paper IV]}

The interactions of the bacteriocins PLNC8 $\alpha$ and PLNC8 $\beta$ (described in section 4.2.3) with the Porphyromonas gingivalis charge mimetic liposome model system 5:95 POPS:POPC (described in section 3.3.1) was investigated in order to improve our understanding of the mechanisms involved.

It is assumed that PLNC8 $\alpha \beta$ belongs to a class of two peptide bacteriocins that show no, or very low, antimicrobial effect if only one of the two peptides are present. ${ }^{[150]}$ Previous studies of the antimicrobial effect of PLNC8 $\alpha \beta$ on gram-positive bacteria strains were done by cocultures with Lactobacillus plantarum and detecting its increase in PLNC8 $\alpha \beta$ production as a response to the presence of the gram-positive bacteria. ${ }^{[151]}$ Since the genes for the two peptides are in close proximity to each other, it further strengthens the theory of the twopeptide system. ${ }^{[111]}$ Though these studies were based around the effect of PLNC8 $\alpha \beta$ on grampositive bacteria and not gram-negative bacteria such as $P$. gingivalis.

Co-cultures between $P$. gingivalis and $L$. plantarum, as well as additions of synthetic 1:2 ratio PLNC8 $\alpha \beta$ proved to supress the growth of the gram-positive $P$. gingivalis. The PLNC8 $\alpha \beta$ 
bound to the cell membrane of $P$. gingivalis and thus increased the permeability which was shown by DNA staining with Sytox Green. ${ }^{\mathrm{d}}$

The peptide-lipid interaction was evaluated by utilizing a liposome model system comprising 5:95 POPS:POPC and observing the CF release kinetics during 30 min for both a 1:2 mix of PLNC8 $\alpha \beta$ as well as each peptide separately. The CF release from liposomes proved to be as extensive for PLNC8 $\beta$ alone as for the 1:2 PLNC8 $\alpha \beta$ (Figure 5-12a). The initial CF release also proved to be very fast (a few minutes) followed by a slower plateau phase (Figure $5-12 b, c$ ).
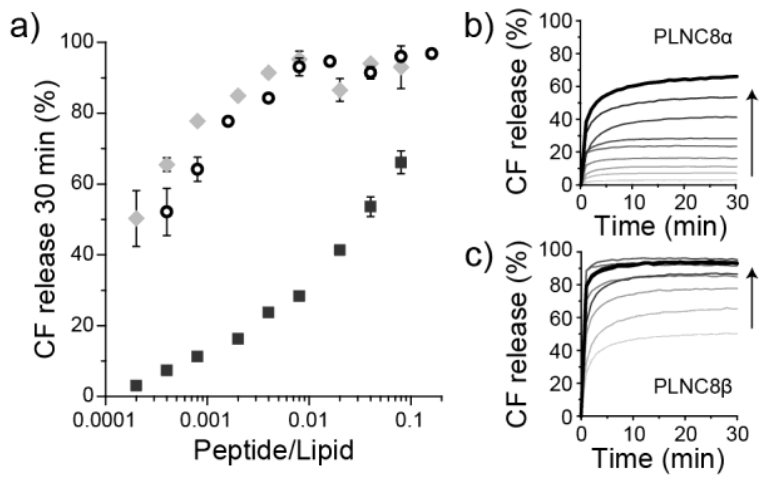

Figure 5-12: a) Release of encapsulated CF after 30 min from 5:95 POPS:POPC liposomes upon incubation with PLNC8 $\alpha$, PLNC8 $\beta$ or PLNC8 $\alpha$. The total bacteriocin concentration was varied from $0.0005-4 \mu \mathrm{M}$ and the total lipid concentration was $25 \mu \mathrm{M}$ in all samples. b-c) The interaction kinetic for PLNC8 $\alpha$ and PLNC8 $\beta$, the arrow indicates increasing peptide/lipid ratio and the black line represents the highest ratio of o.o8 peptides per lipid.

a)

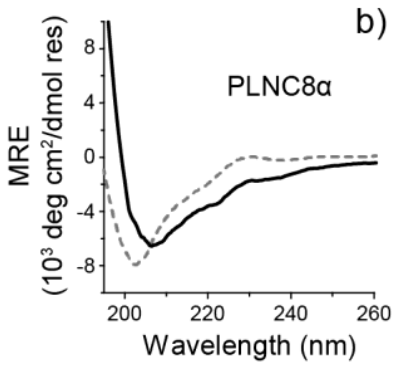

b)

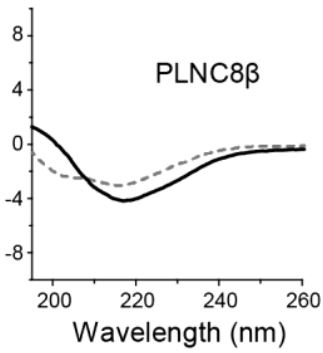

Figure 5-13: CD spectra of $100 \mu \mathrm{M}$ a) PLNC8 $\alpha$ and b) PLNC8 $\beta$ without (dashed line) and with $1 \mathrm{mM}$ total lipid concentration of 5:95 POPS:POPC liposomes in $10 \mathrm{mM} \mathrm{PB} \mathrm{pH} \mathrm{7,} 20^{\circ} \mathrm{C}$.

\footnotetext{
d Figure 1 and 2 in Paper IV
} 
Additionally, the interactions of PLNC8 $\alpha$ with the 5:95 POPS:POPC resulted in a slight change in the peptide secondary structure with an increase in $\alpha$-helicity whereas PLNC8 $\beta$ showed a slight increase in $\beta$-strand content (Figure 5 -13). These changes in secondary structure when allowed to interact with liposomes further confirmed that both peptides did interact with the lipid bilayer, although resulting in different effects on the $\mathrm{CF}$ release kinetics.

The investigation of the interactions of PLNC8 $\alpha \beta$ with the 5:95 POPS:POPC liposome model system suggest that both peptides may interact with $P$. gingivalis without a specific target epitope. The initial electrostatic attraction between the cationic peptides $(+4.1$ and +5.2 at $\mathrm{pH}$ 7 for PLNC8 $\alpha$ and PLNC8 $\beta$, respectively) and the anionic liposomes is most likely the driving force for the interaction, though this is more pronounced for PLNC8 $\beta$. This non-specific interaction strategy is common for many other antimicrobial peptides.[22] 


\section{Chapter 6}

\section{Liposomes as nanoreactors for gold nanoparticle synthesis}

\subsection{The properties of gold nanoparticles}

The characteristics of gold nanoparticles (AuNPs) differ from gold in bulk. The difference between the macro- and nanoscale is not unique for gold, but can be found in many metals for example silver. ${ }^{[152]}$ Where the gold in bulk is a soft yellow, electrically conducting metal with a melting temperature slightly above $1000{ }^{\circ} \mathrm{C}$, all this changes at the nanoscale. ${ }^{[153]}$

\subsubsection{Localized surface plasmon resonance}

Gold can interact with electromagnetic radiation (i.e. light) under certain conditions and create a propagating electron density wave at a metal-dielectric interface at a specific frequency. This resonance condition is called surface plasmon resonance (SPR). Surface electrons in gold nanoparticles can also interact with light and resonantly induce collective electron oscillations, a phenomena known as localized surface plasmon resonance (LSPR).[154] The small size of AuNPs compared to the wavelength of the incident light results in the charge polarization due to displacement of conduction electrons from the equilibrium distribution. At resonance, the displacement of the conducting electrons oscillates with the frequency of the incident electromagnetic field. In this process some of the energy is scattered and dissipated as heat giving rise to a distinct absorption band. For spherical AuNPs with a diameter of about 
$20 \mathrm{~nm}$ the absorption peak, or plasmon peak, is typically seen at $520 \mathrm{~nm} .{ }^{[155]}$ Depending on particle size and geometry, the plasmon peak can have different positions and hence, give rise to different colors for dispersed AuNPs. ${ }^{[155,156]}$ A suspension of AuNPs appear red since the particles absorb light in the blue/green region of the spectrum. ${ }^{[157]}$ The plasmon peak position can undergo a significant red-shift due to plasmonic coupling between individual particles when the interparticle distance is less than 3 times the radius of the particles. ${ }^{[157]}$ This color change, induced by the aggregation of particles, is detectable by the naked eye or by UV-Vis spectroscopy (Figure 6-1), which can be utilized in biosensing applications. ${ }^{[158-161]}$

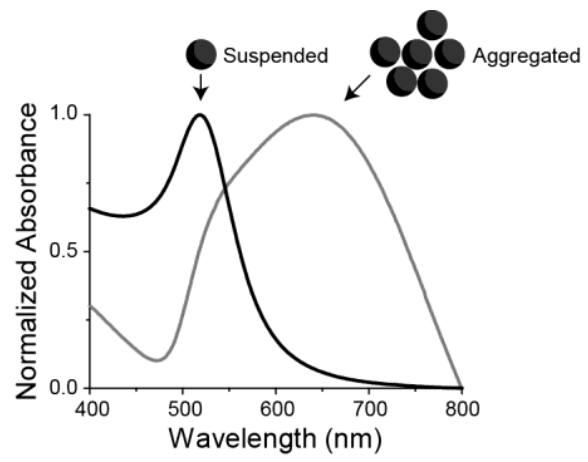

Figure 6-1: UV-Vis absorbance spectra of citrate-stabilized $13 \mathrm{~nm}$ AuNPs, before and after addition of NaCl (black and grey, respectively) causing aggregation through charge screening (unpublished data).

\subsubsection{Plasmonic heating of lipid membranes}

Due to the low optical quantum yield for gold nanoparticles the absorbed energy is forced into a non-irradiative route generating heat. The heat from the particle warms the surrounding media, which is referred to plasmonic heating. ${ }^{[162]}$

The heat generated by AuNPs can be utilized to induce local phase transitions in lipid membranes which can increase the membrane permeability, and thus enable triggered release from liposomes. ${ }^{[24]}$ The extent of heating of the lipid membrane depends on AuNP size and shape as well as on the distance between AuNPs and the membrane. The AuNPs can be associated to a liposome either by anchoring to the surface, encapsulation or by insertion into the hydrophobic interior of the lipid bilayer. ${ }^{[45]}$ Plasmonic heating has been investigated for delivery and triggered release of cancer drugs using drug delivery systems based on thermosensitive liposomes combined with AuNPs. Plasmonic heating has also been explored for cancer treatment by photothermal ablation. ${ }^{[163,164]}$ 


\subsection{Synthesis of spherical gold nanoparticles (Paper V)}

The chemical synthesis of AuNPs is often based on the starting material hydrogen tetrachloroaurate $\left(\mathrm{HAuCl}_{4}\right)$ dissolved in water. The formation of nanoparticles is realized through the reduction of $\mathrm{Au}^{\mathrm{III}}$ to $\mathrm{Au}^{\mathrm{O}}$ by a variety of reducing agents. The nanoparticles must be stabilized so that the result from the synthesis is discrete particles and not a few large assemblies. The nucleation step is the first stage in the formation of the nanoparticles, where a few $\mathrm{Au}^{\circ}$ atoms cluster together. The growth in the nucleation stage is chaotic and rapid, which explains the lack of an ordered face centered cubic crystal structure in ultra-small nanoparticles. At a critical size the particle growth may be described as linearly proportional to the particle surface area. ${ }^{[165]}$ Since larger particles have larger surface area they will continue to grow faster than smaller particles. Even after depletion of the $\mathrm{HAuCl}_{4}$ the growth of larger particles continues at the expense of smaller particles. This in known as Ostwald ripening and is important to consider when designing and evaluating synthesis strategies.[156]

\subsubsection{Photochemical synthesis of AuNPs}

One of the more popular strategies for chemical synthesis of AuNPs is the citrate reduction synthesis, developed by Turkevich et al, which exploits citrate both as the reducing and stabilizing agent. ${ }^{[166]}$ In this synthesis strategy the ratio between citrate and $\mathrm{HAuCl}_{4}$ can be altered in order to tailor the size of the resulting AuNPs. ${ }^{[167]}$ The popularity of the citrate reduction is not only due to the simplicity of the synthesis, but also because of the possibility to easily functionalize the resulting AuNPs by substitution of the adsorbed citrate with other molecules. ${ }^{[168]}$

a)

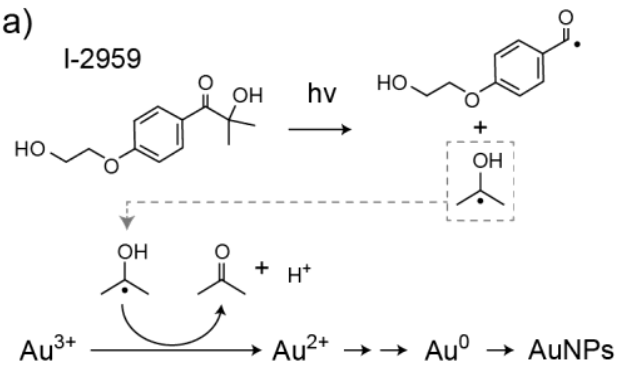

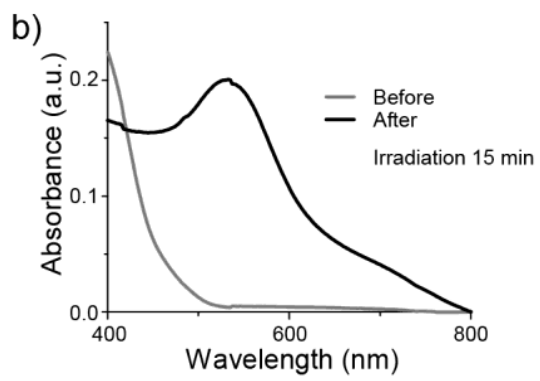

Figure 6-2: a) Activation scheme of the photoinitiator I-2959 and the subsequent stepwise reduction of $\mathrm{Au}^{3^{+}} \rightarrow$ $\mathrm{Au}^{2+} \rightarrow \mathrm{Au}^{+} \rightarrow \mathrm{Au}^{\circ}$ forming AuNPs. Adapted with permission from McGilvray et al., copyright (2006) American Chemical Society. ${ }^{[169]}$ b) UV-Vis absorbance spectra identifying the plasmon peak of AuNPs after 15 min UV irradiation (black) but not before (grey). The absorption below $500 \mathrm{~nm}$ before UV irradiation is due to the I-2959. 
In Paper V, a photochemical synthesis strategy developed by McGilvray et al. ${ }^{[169]}$ was explored, which exploited the photoinitiator I-2959 (Irgacure-2959, 1-[4-(2-hydroxyethoxy)phenyl]-2hydroxy-2-methyl-1-propane-1-one) and $\mathrm{HAuCl}_{4}$ dissolved in water. The reduction of the gold ions require that the solution is irradiated by UV light. Upon UV irradiation the carbonyl group in I-2959 accepts a photon which induces the cleavage into two radicals through a Norrish type I $\alpha$-cleavage, as can be seen in Figure 6-2. The free ketyl radical reduces the $\mathrm{Au}^{3+}$ to $\mathrm{Au}^{\circ}$ and AuNPs are formed.[169]

The resulting AuNPs were quite polydisperse with diameters spanning from 3-32 nm with the most common sizes being around $10.5 \pm 5.2 \mathrm{~nm}$ (Figure 6-3).

Through these synthesis strategies, it is inherently difficult to synthesize ultra-small AuNPs with a diameter of less than $2 \mathrm{~nm}$. The small size is attractive because of their high catalytic activity in many organic reactions ${ }^{[170]}$ and for the theoretically improved clearance from the body when used in drug delivery systems. ${ }^{[171]}$ There is consequently an interest in development of new synthesis strategies of ultra-small AuNPs by using for example microfluidic devices, ${ }^{[172]}$ or by introducing different ligands during the reaction or by etching of larger particles.[173]

a)

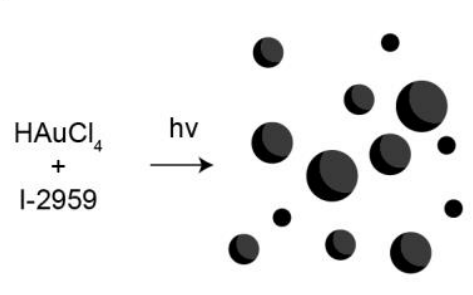

b)

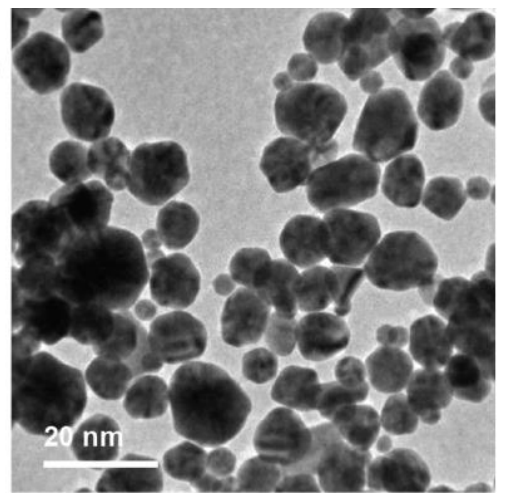

Figure 6-3: a) The photochemical synthesis of AuNPs. b) TEM image of the AuNPs obtained using $\mathrm{HAuCl}_{4}$ (0.1 $\mathrm{mg} / \mathrm{mL}$ ) and I-2959 (1 mM).

\subsubsection{Liposome-confined synthesis of AuNPs}

In order to explore the possibility to fabricate liposome encapsulated small-sized AuNPs, the photoinitiator I-2959 and $\mathrm{HAuCl}_{4}$ were encapsulate in liposomes. Liposomes made from POPC were prepared through thin film hydration (as described in subsection 3.2.3) using an aqueous solution of I-2959 and $\mathrm{HAuCl}_{4}$. After hydration of the lipid thin film and after extrusion through a $100 \mathrm{~nm}$ polycarbonate membrane the liposomes were purified on a G-25 sephadex column. This ensured that non-encapsulated I-2959 and $\mathrm{HAuCl}_{4}$ were removed. 
Upon UV irradiation for 15 min the appearance of a characteristic plasmon peak of AuNPs verified that AuNPs were forming (Figure 6-4).

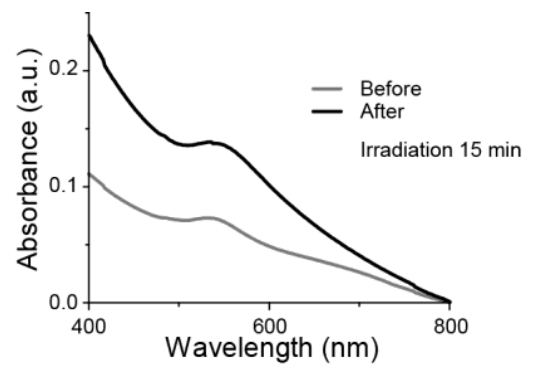

Figure 6-4: UV-Vis absorbance spectra showing the plasmon peak of AuNPs after 15 min UV irradiation (black) and a slight presence of AuNPs prior to irradiation (grey).

The position of the plasmon peak was centered around $530 \mathrm{~nm}$ which is a little higher than expected for small AuNPs. This is compared to citrate stabilized AuNPs where the plasmon peaks for 9,15 and $22 \mathrm{~nm}$ particles is positioned at 517,520 and $521 \mathrm{~nm}$ respectively. ${ }^{[174]}$ The position of the plasmon peak indicates that AuNPs larger than $20 \mathrm{~nm}$ was found but, the extinction coefficient for smaller sized particles are much lower than for larger ones which in turn could mean that not all particles contribute equally to the final intensity of the signal. ${ }^{[175]}$ For AuNPs smaller than about $2 \mathrm{~nm}$, a plasmon peak may not be possible to detect. ${ }^{[176]}$ In total, a few larger AuNPs may contribute to the majority of the plasmon peak and its position may not reflect the true content of the sample. The detection of the plasmon peak in itself confirmed that AuNPs were formed through the UV irradiation of the liposomes containing I-2959 and $\mathrm{HAuCl}_{4}$.

TEM bright field imaging (Figure 6-5) verified the success of the liposome-confined synthesis in producing ultra-small AuNPs with a size ranging from 0.5-12 $\mathrm{nm}$ with the majority of the particles having a diameter of $2.8 \pm 1.6 \mathrm{~nm}$. Liposomes are typically not expected to be visualized by TEM due to very low contrast of the lipids. The location of the AuNPs were clustered in a confined area about the size of liposomes which further confirmed that the majority of the particles were produced inside the liposomes. A few AuNPs can be found outside this clustered area (Figure 6-5b), which was likely due to residual reaction components in the sample due to a less than $100 \%$ efficiency in the G-25 sephadex separation. 
a)

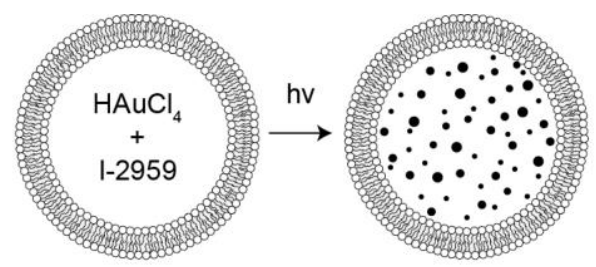

b)

c)

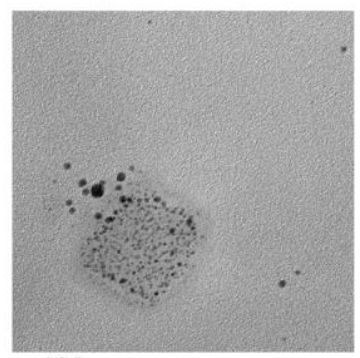

$100 \mathrm{~nm}$

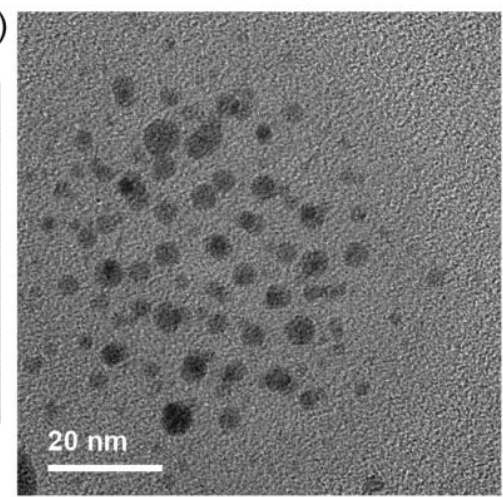

Figure 6-5: a) The AuNP synthesis inside liposomes, with a $2 \mathrm{mg} / \mathrm{mL}$ lipid concentration, using encapsulated $\mathrm{HAuCl}_{4}(0.1 \mathrm{mg} / \mathrm{mL})$ and I-2959 (1 mM). b-c) TEM image of the obtained AuNPs.

Before UV irradiation a low intensity plasmon peak can be observed (Figure 6-4) which probably is due to some minor reduction of $\mathrm{HAuCl}_{4}$ by lipids. There was no indication that this process damaged the liposomes as they retained their size.e

\subsubsection{Comparing confined and non-confined AuNP synthesis}

In conclusion the same synthesis strategy using the same concentrations of $\mathrm{HAuCl}_{4}$ and the photoinitiator I-2959, activated by UV irradiation, produced spherical AuNPs of vastly different sizes when conducted confined in liposomes as compared in bulk solution. Counts of the particles from multiple TEM bright field images was made to visualize this difference in a more inclusive way than a few selections of images (Figure 6-6).

e Figure $4 \mathrm{~b}$ in Paper V 


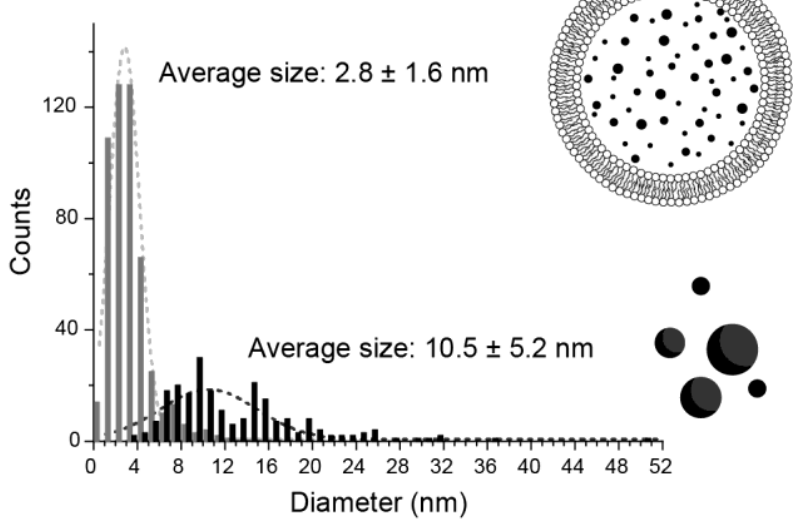

Figure 6-6: Size distribution analysis of AuNPs synthesized in bulk (black) and encapsulated in liposomes (grey).

The significantly smaller sizes of AuNPs produced inside liposomes is likely due to do the adsorption of gold nuclei on, or in, the lipid membrane which restricts diffusion and thus growth. The small size of the AuNPs and the fact that they are efficiently entrapped in the liposomes make this strategy highly interesting for further development of systems for photothermal drug delivery. 


\section{Chapter 7}

\section{Characterization techniques}

In this chapter the main characterization techniques used in this thesis are presented in short. The characterization techniques are presented in the order by which they appear in the thesis.

\subsection{Carboxyfluorescein (CF) release}

The ability of molecules to diffuse trough the membrane is defined by its permeability. It is difficult for ions and any hydrophilic molecule, with the exception for water, to diffuse through a lipid bilayer. The permeability of a lipid bilayer is therefor considered to be very low, and liposome encapsulated molecules are thus typically retained.[51] Interactions of membrane active molecules with the lipid bilayer can increase the permeability by disrupting the organization of the lipids. ${ }^{[23]}$ The permeability changes of a liposome can be analyzed by encapsulating a fluorophore at self-quenching concentrations and register the release by fluorescence spectroscopy.[33]

The principle of fluorescence spectroscopy is based on the ability of fluorophores to absorb a photon and emit another photon with lower energy. This occurs trough excitation, nonirradiative relaxation to the lowest vibrational level of the excited state and finally irradiative relaxation returning the fluorophore to the ground state. The irradiative relaxation trough the emitting of a photon is referred to as the fluorescence emission of the fluorophore. The measurement relies on selecting a wavelength for excitation $\left(\lambda_{\text {ex }}\right)$ of the fluorophore and detecting the spectrum of emitted light $\left(\lambda_{\mathrm{em}}\right)$. The fluorescence emission intensity can be decreased by offering a non-irradiative relaxation all the way back to the ground state through 
interactions with surrounding molecules, this process is called quenching.[177] The fluorophore carboxyfluorescein (CF) has a $\lambda_{\mathrm{ex}}=495 \mathrm{~nm}$ and maximum $\lambda_{\mathrm{em}}=517 \mathrm{~nm}$ and it is selfquenching at concentrations above $50 \mathrm{mM}$. The self-quenching mechanism of $\mathrm{CF}$ is caused by both the formation of non-fluorescent dimers and energy transfer from monomers to dimers. ${ }^{[178]}$ Encapsulation of self-quenching concentrations of $\mathrm{CF}$ in liposomes and detecting emission of $\mathrm{CF}$ from leaking liposomes have been done for decades. ${ }^{[33]}$ It is used in many studies investigating the integrity of lipid membranes for example upon storage, ${ }^{[179]}$ heating ${ }^{[38]}$ or interaction with surfactants ${ }^{[180]}$ or peptides. ${ }^{[23,49]}$ The change in CF release from liposomes due to peptide interactions was studied in Paper I-IV.

\subsection{Dynamic light scattering (DLS)}

The size of liposomes can be determined by dynamic light scattering (DLS), which is a technique that measures the scattering of light by small particles in suspension. DLS exploits a monochromatic light source to irradiate the sample and the scattering caused by particles in the sample is detected at a fixed angle, typically $90^{\circ}$. Fast sequential measurements are done to record fluctuations in the scattered light due to the Brownian motion of particles. Different sized particles have distinct differences in their movement patterns, where smaller particles move faster than larger particles. The measured count rate is the scattered intensity or simply the number of photons recorded per second. From this the normalized intensity time correlation function is derived:

$$
g^{(2)}(\tau)-1=\frac{\langle I(t) \cdot I(t+\tau)\rangle}{\langle I(t)\rangle^{2}}
$$

where the intensity of the scattered light is $I(t)$ and $I(t+\tau)$ at times $t$ and $t+\tau$, respectively. From the $\mathrm{g}^{(2)}(\tau)$ the translational diffusion coefficient (D) of the particle, and thus its hydrodynamic diameter $\mathrm{R}_{\mathrm{H}}$, can be obtained:

$$
\begin{gathered}
g^{(2)}(\tau)-1=\beta^{2} e^{-2 D q^{2} \tau} \\
R_{H}=\frac{k_{B} T}{3 \pi \eta D}
\end{gathered}
$$

where $\beta$ is an instrument constant ideally calibrated to $1, q$ is the magnitude of wave vector, $k_{B}$ is the Boltzmann's constant, $\mathrm{T}$ is the absolute temperature and $\eta$ is the viscosity of the sample. ${ }^{[181]}$ The CONTIN analysis method can be used to identify multiple translational diffusion coefficients and thus multiple hydrodynamic diameters from the correlation function for polydisperse samples.[182] 
a)

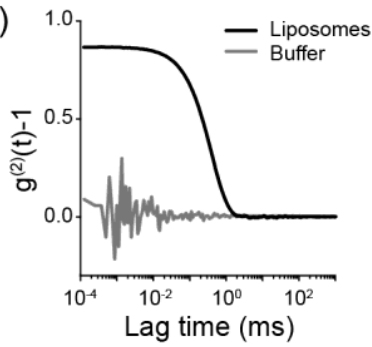

b)

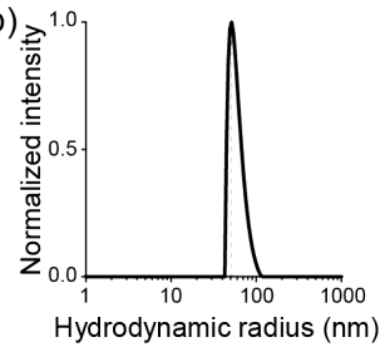

Figure 7-1: a) The normalized intensity time correlation function for POPC liposomes in PBS buffer extruded through a polycarbonate membrane with $100 \mathrm{~nm}$ pore size using a total lipid concentration of $40 \mu \mathrm{M}$. b) The resulting size distribution of liposomes by fitting the data in a using the CONTIN method. There is no detectable decay time for the PBS sample and thus no particles could be detected.

The determination of liposome size with DLS have been shown to be comparable to more resource-demanding techniques such as freeze-fracture electron microscopy (EM).[183] Liposomes extruded 21 times through a $100 \mathrm{~nm}$ in diameter pore size polycarbonate membrane will have a hydrodynamic radius of about 60-75 $\mathrm{nm}$ (Figure 7-1) and are thus suitable for measuring with DLS. The hydrodynamic radius of liposomes was measured by DLS in Paper I-V.

\subsection{Zeta potential}

The zeta potential $(\zeta)$ of a particle is the potential at the distance from the particle called the slipping plane. Any charged particle in solution will attract oppositely charged ion from the solution towards the particle surface, this first layer of counter ions is the Stern layer. Beyond the Stern layer, counter ions and their counter ions are highly organized (electric double layer) until the effect wears off with increased distance. The slipping plane is defined as the maximum distance from the particle where the associated counter ions move with the particle.[27]

The zeta potential cannot be directly measured but can be derived from the electrophoretic mobility $\left(\mu_{e}\right)$ of charged particles under an applied electric field $(E)$. During a measurement, the particle suspension is subjected to an applied electric field and the particle scatter the light from an incident laser. When the laser light is scattered by the particles the frequency shifts. To compare it to the original beam frequency, the beam is split allowing only one beam to pass through the sample and in the end combining the two beams to detect the shift (Doppler shift). The particle velocity $(V)$ is can be deduced from the Doppler shift. Thus, the electrophoretic mobility can be described by:

$$
\mu_{e}=\frac{V}{E}
$$


The electrophoretic mobility of large particles where the thickness of the electric double layer is much smaller than the particle itself (approximations for particles larger than $100 \mathrm{~nm}$ in diameter) can in turn be described by the Helmholtz-Smoluchowski equation:

$$
\mu_{e}=\frac{\varepsilon_{r} \varepsilon_{o} \zeta}{\eta}
$$

where $\varepsilon_{r}$ is the relative permittivity, $\varepsilon_{o}$ is the permittivity of vacuum and $\eta$ is the viscosity of the solution. The zeta potential can thus be calculated using the combined information in the two equations above. ${ }^{[184]}$ In Paper IV, zeta potential was used to tailor the lipid composition of the liposome model system to mimic the zeta potential of the bacterial cell membrane.

\subsection{Absorption spectroscopy (UV-Vis)}

Absorbance spectroscopy is based on measuring the difference in intensity of monochromatic (single wavelength) light before $\left(I_{o}\right)$ and after $(I)$ passing through a sample. To generate an absorption spectrum the wavelength of the incident light is stepwise changed over a desired range. The absorbance $(A)$ is determined by:

$$
A=\log \left(\frac{I_{O}}{I}\right)
$$

Depending on the molecule, it may absorb light of different wavelength (photon energy) and to a different extent, this is referred to the molar absorptivity or extinction coefficient $(\varepsilon)$. The absorbance is directly proportional to the concentration (c) of the light absorbing molecule in the sample trough the Beer-Lambert law:

$$
A=l \cdot c \cdot \varepsilon
$$

where $l$ is the pathlength. ${ }^{[185]}$

To determine peptide concentration the presence of the residues tryptophan (W), tyrosine (Y) or cysteine (C), which absorb light in the UV-range and have maxima around $280 \mathrm{~nm}$, can be used. A total extinction coefficient for the peptide must be calculated based on the primary structure content in order to use the Beer-Lambert law to determine peptide concentration.

$$
\varepsilon=n_{W} \varepsilon_{W} \cdot n_{Y} \varepsilon_{Y} \cdot n_{C} \varepsilon_{C}
$$

where $n_{W}, n_{Y}$ and $n_{C}$ are the number of tryptophans, tyrosines and cysteines in the peptide primary structure respectively. The extinction coefficient for the residues at $280 \mathrm{~nm}$ are $\varepsilon_{W}=$ $5960, \varepsilon_{Y}=1280$ and $\varepsilon_{C}=120 \mathrm{M}^{-1} \mathrm{~cm}^{-1}{ }^{1}{ }^{[186]}$ The peptide concentration was estimated through these calculations in Paper I-V. 


\subsection{Circular dichroism spectroscopy (CD)}

The secondary structure of peptides and proteins can be determined by circular dichroism (CD) spectroscopy. The technique relies on irradiating the sample with circularly polarized light and detecting the difference in absorbance of left- and righthanded circularly polarized light $(\Delta A)$ caused by the presence of optical active or chiral entities in the sample.

$$
\Delta A=l \cdot c \cdot \Delta \varepsilon
$$

where $l$ is the optical path length, $c$ is the molar concentration of the sample and $\Delta \varepsilon$ is the difference in the molar extinction coefficient of left- and righthanded circularly polarized light. The $\Delta A$ is converted to degrees of ellipticity $(\theta)$ to reflect the distortion of the circularly polarized light after passing through an optical active sample.

$$
\theta=\Delta A\left(\frac{\ln 1 O}{4}\right)\left(\frac{180}{\pi}\right)=32.98 \Delta A
$$

In peptides, the amide bond absorbs in the far-UV and give rise to the characteristic spectrums (Figure 7-2) due to the difference in the angles $\varphi$ and $\psi$ that can be found in each secondary structure.

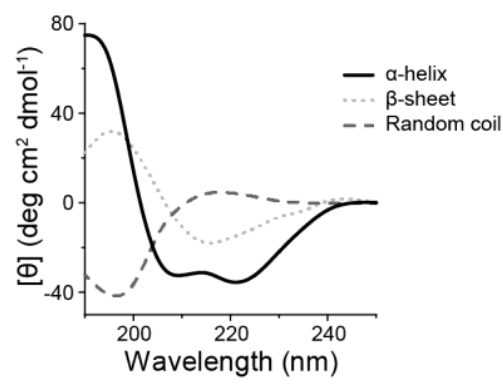

Figure 7-2: CD-spectra showing the characteristics of the $\alpha$-helix, $\beta$-sheet and random coil adapted from the Fasman standard curves of poly-Lysine. ${ }^{[187]}$

In order to facilitate comparisons of CD results from peptides with different lengths, or more precise the number of residues $(n)$, the data may be converted to mean residue molar ellipticity (MRE).[188]

$$
M R E=\frac{1 O O \cdot \theta}{c \cdot n \cdot l}
$$

In Paper I-IV the secondary structure of peptides interacting with liposomes was observed through CD spectroscopy. 


\subsection{Quartz crystal microbalance with dissipation (QCM-D)}

The QCM-D technique is based on the acoustic waves generated by an oscillating piezoelectric crystal quartz sensor. The oscillation arises when an alternating electric field is applied which causes the sensor to expand and contract. The resonance frequency depends on the mass of the sensor and any adhering material. The change in frequency $(\Delta f)$ is recorded and can be related to the change in adsorbed mass $(\Delta m)$ :

$$
\Delta f=\frac{\Delta m \cdot n}{C}
$$

where $n$ is the overtone number and $C$ is a constant derived from the thickness, density and resonance frequency of the dry sensor. Any odd number overtones are simultaneously recorded and the higher number overtone, the shorter the penetration depth of the acoustic wave. Thus, each overtone gives a different perspective of what happens at the sensor surface. ${ }^{[189]}$

The viscoelasticity of the adsorbed material on the sensor is measured through the dissipation (D) determined by monitoring the decay of the sensor oscillation.[190]

$$
D=\frac{E_{\text {dissipated }}}{2 \pi \cdot E_{\text {stored }}}
$$

where $E_{\text {dissipated }}$ is the dissipated energy during one oscillation period and $E_{\text {stored }}$ is the stored energy in the oscillating system.

Peptide-lipid interactions can be investigated using quartz crystal microbalance with dissipation (QCM-D). A supported lipid bilayer (SLB) can be formed on a silicon dioxide coated sensor surface by liposome adsorption and subsequent rupture. ${ }^{[191,192]}$ In Paper I, QCMD was used to observe peptide-lipid interactions and to evaluate its mechanism of action.

\subsection{Isothermal titration calorimetry (ITC)}

Isothermal titration calorimetry (ITC) offers a label-free technique to study the thermodynamics of biomolecule interactions such as peptide-liposome interactions. ${ }^{[193]}$ The technique relies on the detection of changes in heat of the reaction cell compared to the reference cell. The measurement is carried out by small titrations of the ligand into the sample cell containing the analyte and the changes in heat $(q)$ for each titration is recorded. In welldefined experiments with only one interaction it is possible to determine the association constant $\left(K_{a}\right)$, the enthalpy of binding $(\Delta H)$ and the stoichiometry $(n)$ of the interaction. ${ }^{[194]}$

$$
q=V \cdot \Delta H \cdot \Delta\left[L_{B}\right]
$$




$$
Q=V \cdot \sum_{i} \Delta H_{i} \cdot\left[L_{B, i}\right]=V \cdot \sum_{i} \frac{n_{i} \cdot \Delta H_{i} \cdot K_{a, i} \cdot[L]}{1+K_{a, i} \cdot[L]}
$$

where $\Delta L_{B}$ is the change in bound ligand concentration, $V$ is the reaction volume, $Q$ is the cumulative heat and $[L]$ is the concentration of free ligand.

In Paper II-III, ITC was used to evaluate the characteristics of the peptide-lipid interaction and the effect of conjugated and non-conjugated peptide respectively.

\subsection{Surface plasmon resonance (SPR]}

Surface plasmon resonance (SPR) is commonly used to characterize biomolecular interactions, first reported by Liedberg et al.[195] in 1983. It relies on the excitation of surface plasmons which propagate along a metal surface. The excitation is achieved by a light source which is reflected at the backside of the sample surface. At a specific incident angle of the light source, energy is transferred to the surface plasmon and at the detector this is recorded as an intensity minimum $\left(\theta_{\mathrm{sp}}\right)$. Any change in refractive index in the sample will affect the surface plasmon and thus the angle of incident light that is transferred to it $\left(\Delta \theta_{\mathrm{sp}}\right)$. The surface plasmon evanescent field probes the sample up to about a few hundred nm (from gold surfaces).[196]

The ligand immobilization can be made on different sensor surfaces depending on the characteristics of the system of interest. When analysing peptide-peptide interactions it is often preferred to use a $3 \mathrm{D}$ carboxymethylated dextran matrix (the $\mathrm{CM}_{5}$ sensor) where immobilization of ligand per sensor surface area can be maximized to increase the sensitivity. ${ }^{[197]}$ The interaction between the ligand and analyte is measured in response units (1 RU corresponds to $\Delta \theta_{\mathrm{sp}}=0.0001^{\circ}$ ) and the analyte per ligand bound can be calculated by using the respective $\Delta R U$ and their molecular weight $(M W)$ :

$$
\text { analyte per ligand }=\frac{\Delta R U_{\text {analyte }} / \Delta R U_{\text {ligand }}}{M W_{\text {analyte }} / M W_{\text {ligand }}}
$$

The $3 \mathrm{D}$ carboxymethylated dextran matrix was modified by incorporating hydrophobic alkyl chains to act as anchors to capture liposomes (the L1 sensor). ${ }^{[198]}$ The captured liposomes are generally regarded to be intact on the sensor, ${ }^{[198,199]}$ but there have been a few observations of liposome rupture and the subsequent formation of a supported lipid bilayer (SLB). ${ }^{[200]}$ The liposome-functionalized sensor enable measurements of the interaction between peptides and liposomes.[201] In Paper II-III, SPR was used to determine the conjugation efficiency of peptides to liposomes, the subsequent ability to heterodimerize as well as the isolated heterodimerization of peptides. 


\subsection{Transmission electron microscopy (TEM)}

Transmission electron microscopy (TEM) can be utilized to enable imaging of structures smaller than the wavelength of light, such as gold nanoparticles. The electrons are usually accelerated by an applied potential of about $70-300 \mathrm{keV}$ and can enable imaging resolutions below $1 \AA$. The higher the accelerating voltage the higher the resolution, although electrons with high energy may interact and destroy sensitive samples.

In bright field imaging the electrons going through the sample without scattering (transmitted) are detected by a CCD camera. In the resulting image, dark areas are thus areas where high electron dense material is located such as AuNPs. Low electron density materials such as liposomes do not scatter electrons to the same extent and the contrast to the background (typically carbon coated formvar) is low if no staining procedure is performed.[202]

In Paper V, TEM was used to image the AuNPs and measure the particle size. 


\section{Chapter 8}

\section{Summary of papers}

This thesis is based on five scientific papers where Papers I, II, IV and V are published in peerreview journals, and Paper III is submitted.

This chapter provides a short summary of each paper, their main results and discussion. 


\section{Paper I}

\section{Tuning Liposome Membrane Permeability by Competitive Peptide Dimerization and Partitioning-Folding Interactions Regulated by Proteolytic Activity}

Seng Koon $\operatorname{Lim}^{\dagger}$, Camilla Sandén ${ }^{\dagger}$, Robert Selegård, Bo Liedberg, Daniel Aili

Scientific Reports, 2016, 6:21123

The paper describes how the liposomal content release kinetics can be tuned by varying the degree of JR2KC peptide modification on liposomes as well as the inhibitory effects of heterodimerization of JR2KC with the charge complementary JR2E. The interaction and subsequent pore formation of $\mathrm{JR} 2 \mathrm{KC}$ in the lipid membrane is dependent on the peptide-lipid conjugation through a maleimide-thiol reaction. The liposomal content release can be triggered by proteolytic digestion of the inhibitory JR2E by the matrix metalloproteinase MMP-7 which is upregulated in many malignant tumors.

${ }^{\dagger}$ These authors contributed equally to this work. 


\section{Paper II}

\section{Tuning Liposome Membrane Permeability by Competitive Peptide Heterodimerization and Heterodimer Exchange}

Camilla Skyttner, Karin Enander, Christopher Aronsson, Daniel Aili

Langmuir, 2018, 34(22):6529-6537

The paper describes how the liposomal content release kinetics can be tuned using the de novo designed coiled coil peptides KIC and KVC. Relatively small differences in peptide primary structures resulted in large differences in membrane activity. The homodimerization of the isoleucine-rich KIC was extensive when conjugated to liposomes resulting in just a minor increase in membrane permeability. In contrast, conjugation of the valine-containing KVC lead to a dramatic increase in the permeability of the lipid membranes thus releasing the liposomal content. Moreover, the potential to inhibit the release using heterodimerization with the complementary peptides EI and EV resulting in folding into coiled coils was investigated. The differences in $\mathrm{K}_{\mathrm{d}}$ for heterodimerization (EIKVC $<\mathrm{EVKVC}$ ) was reflected in the inhibition efficiency, where EI inhibited KVC at lower concentrations than EV. The liposomal content release was reactivated upon addition of $\mathrm{KI}$ or $\mathrm{KV}$ to enable a heterodimer exchange resulting in a free liposome-conjugated KVC and a new heterodimer not associated with the liposomes (EIKI or EIKC). 


\section{Paper III}

\section{Sequence and Length Optimization of Membrane Active Coiled Coils for Triggered Liposome Release}

Camilla Skyttner, Robert Selegård, Jakob Larsson, Christopher Aronsson, Karin Enander, Daniel Aili

Submitted

The paper investigates the optimization of the membrane active 29 residue peptide KVC used in Paper II. By single amino acid substitutions in the hydrophobic $(\mathrm{N} \rightarrow \mathrm{V})$ and hydrophilic face $(\mathrm{W} \rightarrow \mathrm{E})$ of this amphipathic coiled coil the original KVC was modified to have a repeated heptad of (KVSALKE) $)_{n}$ but keeping the N-terminal C. This enabled the optimization of peptide length without the influence of single residue deviations. When comparing the original KVC to the equally long $\mathrm{KVC}_{4}, \mathrm{KVC}_{4}$ caused a more efficient release of liposomal content.

The number of heptad repeats investigated generated the peptides $\mathrm{KVC}_{2}, \mathrm{KVC}_{3}, \mathrm{KVC}_{4}$ and $\mathrm{KVC}_{5}$. The shorter peptides $\mathrm{KVC}_{2}$ and $\mathrm{KVC}_{3}$ proved to cause lower $\mathrm{CF}$ release due to the peptide length barely spanning the lipid bilayer for $\mathrm{KVC}_{2}$ and liposome aggregation was observed for $\mathrm{KVC}_{3}$. The longest peptide $\mathrm{KVC}_{5}$, although showing promising $\mathrm{CF}$ release kinetics the conjugation degree was about 1.8 peptides/conjugation site which indicate difficulties in having a highly controlled system. The optimal length proved to be $\mathrm{KVC}_{4}$ where the total $\mathrm{CF}$ release was high but also tunable in regard to the degree of peptide conjugation. $\mathrm{KVC}_{4}$ also proved to have a strong interaction with the lipid membrane without causing liposome aggregation. A future design including these components may also benefit from using the shortest peptide sequence that still results in an efficient release. 


\section{Paper IV}

\section{Antibacterial Effects of Lactobacillus and Bacteriocin PLNC8 $\alpha \beta$ on the Periodontal Pathogen Porphyromonas Gingivalis}

Hazem Khalaf, Sravya Sowdamini Nakka, Camilla Sandén, Anna Svärd, Kjell Hultenby, Nikolai Scherbak, Daniel Aili, Torbjörn Bengtsson

BMC Microbiology, 2016, 16:188

The paper investigates the antimicrobial effects of a few Lactobacillus species, as well as the L. plantarum NC8 produced bacteriocins PLNC8 $\alpha \beta$, on $P$. gingivalis identified as a key pathogen in periodontitis. It was shown that L. plantarum NC8 and 44048 as well as the bacteriocins PLNC8 $\alpha \beta$ alone could inhibit the growth of $P$. gingivalis. PLNC $8 \alpha \beta$ bound to the cell membrane of $P$. gingivalis and thus increased the permeability which was shown by DNA staining with Sytox Green.

The effect of the two bacteriocins PLNC8 $\alpha \beta$ on a liposome-model system using a 5:95 molar ratio of POPS:POPC to mimic the zeta potential of $P$. gingivalis membrane microvesicles was investigated. Upon liposome-membrane interaction the PLNC8 $\alpha \beta$ underwent changes in secondary structure where PLNC8 $\alpha$ showed an increase in $\alpha$-helicity and PLNC8 $\beta$ showed an increase in $\beta$-strand content. The rapid interaction and permeabilization of the $P$. gingivalis membrane by PLNC8 $\alpha \beta$ was also shown in the liposome-model system where the encapsulated fluorophore $\mathrm{CF}$ was released. It was indicated by the results from the liposomemodel system that PLNC8 $\beta$ was more efficient in membrane permeabilization then PLNC8 $\alpha$, and comparable with PLNC8 $\alpha \beta$ together at the double concentration. This suggests a new approach moving forward where the previously perceived pair of PLNC8 $\alpha \beta$ could be used individually or that their mechanism of action in killing the bacteria differs between the two. 


\section{Paper V}

\section{Liposomes as Nanoreactors for the Photochemical Synthesis of Gold Nanoparticles}

Sushanth Gudlur, Camilla Sandén, Petra Matoušková, Chiara Fasciani, Daniel Aili

Journal of Colloid Interface Science, 2015, 456:206-209

The paper describes the photochemical synthesis of gold nanoparticles (AuNPs) within liposomes. This synthesis was performed within minutes and the resulting AuNPs showed the characteristic plasmon peak. The AuNPs produced through this confined synthesis was observed to have a size of $2.8 \pm 1.6 \mathrm{~nm}$ in diameter, which was much smaller compared to the non-confined synthesis $(10.5 \pm 5.2 \mathrm{~nm})$. 


\section{Chapter 9}

\section{Conclusions and future outlook}

\subsection{Conclusions}

The main objective was to develop and study new strategies for tunable and triggered changes in the permeability of the lipid membranes of liposomes. To this end, the potential of using specific folding mediated interactions of liposome conjugated de novo designed helix-loophelix and coiled coil peptides to control the release of encapsulated species was investigated. Liposome-model systems was also used to elucidate information about the interactions of bacteriocins with lipid bilayers and their effect on membrane integrity. Finally, a novel procedure for synthesis of liposomes encapsulated gold nanoparticle was developed.

\subsubsection{Peptide-liposome systems for triggered drug delivery (Paper I-III]}

The tunable and triggered release of encapsulated molecules by peptide-functionalized liposomes proved successful. The JR2 and EKIV peptides could both be used to tune the release of a small fluorophore (CF) by the conjugation of the lysine-rich peptide (JR2KC, KIC and $\mathrm{KVC}$ ) and inhibit the release trough heterodimerization with a glutamic acid-rich inhibitory peptide (JR2E, EI and EV). A triggered release was achieved by MMP-7 digestion for the JR2 system and a heterodimer exchange for the EKIV system.

The membrane active KVC peptide was optimized in regard to sequence and length. Four different peptides $\left(\mathrm{KVC}_{2}, \mathrm{KVC}_{3}, \mathrm{KVC}_{4}\right.$, and $\left.\mathrm{KVC}_{5}\right)$ were investigated where the heptad repeat was optimized to $(\mathrm{KVSALKE})_{\mathrm{n}}$ where $\mathrm{n}=2,3,4$ and 5 . The $\mathrm{KVC}_{4}$ peptide had an efficient 
release of liposome-encapsulated molecules and did not induce aggregation and was suggested to be a good candidate for further development of peptide-liposome-based drug delivery systems.

\subsubsection{Liposome model systems for investigating antimicrobial peptides (Paper IV]}

The $P$. gingivalis charge mimetic liposome-model system was successfully used to elucidate information of the bacteriocins PLNC8 $\alpha \beta$ interaction with lipid bilayers. The peptide-lipid interactions of both PLNC8 $\alpha \beta$ increased the permeability of the liposomes, although the effect was more pronounced for PLNC8 $\beta$. These results indicate that PLNC8 $\alpha$ and $\beta$ could be used individually in treatment of $P$. gingivalis infections and that the mechanism of action of the two peptides likely are different.

\subsubsection{Gold nanoparticle synthesis in liposome confinement (Paper V)}

The comparison of a one-pot photochemical AuNP synthesis in a confined and non-confined reaction showed that differently sized AuNPs were generated. The resulting AuNP in the confined reaction and in the non-confined reaction was $2.8 \pm 1.6 \mathrm{~nm}$ in diameter $10.5 \pm 5.2$ $\mathrm{nm}$ in diameter, respectively. The smaller size resulting from the confined reaction is likely a result of a constrained diffusion of the gold nuclei initially in the growth process.

\subsection{Future outlook}

To this day, a couple of liposome-based drug delivery systems have been approved for clinical use and several are in clinical trials. All of them are based on the passive release of the encapsulated drug molecules but further development of these systems can enable tunable and triggered release in order to improve drug efficacy. As shown in this thesis, membrane active peptides are potentially interesting components in the design liposome-based drug delivery systems. Triggered release of encapsulated molecules was demonstrated using a number of different amphipathic peptides and means to control the release by both highly specific peptide mediated interactions and the hydrolytic activity of a cancer related enzyme were developed. The detailed interactions and structure of the peptides in the membranes are yet not fully understood and it would hence be of interest to characterize these systems further to e.g. find out if the release is caused by pore formation or some other mode of action. Another question not answered in this thesis is what type of molecules can be released. The only molecule used for release-studies so far is a small charged fluorophore. It would hence be of interest to repeat the experiments with a greater variety of encapsulated molecules with respect to size and charge to better predict which drug molecules could be release using these strategies. So far, the lipids and peptides have not been optimized to fully address the multitude of obstacles, such as degradation, that will arise when used in a biologically more 
relevant context. It would thus be interesting to investigate if the proposed release strategy can be combined with e.g. PEGylated liposomes that have been proven to not initiate an immune response. In addition, the peptides may be subjected to proteolytic degradation, and more stable versions obtained by including D-amino acids would be interesting candidates to consider. The tailoring of release to also include other triggers, such as enzymes related to specific disorders, is also of great interest. The results in Paper I-III can thus be regarded as a proof-of-concept and optimization of the materials in the system will be necessary.

The investigation of PLNC8 $\alpha \beta$ showed that a liposome model system also could be used to elucidate relevant information about the peptide-lipid interactions for this clinically potentially relevant bacteriocin. The work with these peptides is ongoing and it is my hope that the results from the liposome model system in Paper IV can facilitate the future development of therapeutic applications of the peptides. Because of the decrease in $\mathrm{pH}$ in the gingival pockets where the target pathogen $P$. gingivalis normally reside, it would be interesting to further investigate how the characteristics of the peptide-liposome interactions could differ at different $\mathrm{pH}$. In this thesis, the interactions were investigated at neutral $\mathrm{pH}$ and PLNC $\beta$ was found to have a more pronounced interaction with the model liposome than PLNCa. This suggests that PLNC $\beta$ might have a more prominent non-specific interaction with the $P$. gingivalis membrane and PLNC8 $\alpha$ might have a different target. These results may also provide ideas on how these peptides may be incorporated as antimicrobial agents into future functional materials, where perhaps PLNC8 $\beta$ can be functionalized on the material to be available for membrane interactions whereas PLNC8 $\alpha$ might need to be released. The development of a zeta potential mimicking liposomes might also be step forward in improving liposome model systems for fast screening of potential antimicrobial peptides.

To obtain liposome encapsulated AuNP systems, AuNPs are usually synthesized, stabilized by various surface functionalization strategies and then encapsulated into liposomes. The onepot synthesis described in Paper V showed a different strategy where the synthesis was achieved within the confinement of liposomes. In this paper only one concentration and ratio of the components was used, and it would be interesting to study further how the size of the synthesized AuNPs changes due to changes in concentration and ratio of the reactants and if this difference then would be the same for the confined and non-confined synthesis. If this confined synthesis strategy will be used to generate a triggered drug delivery system, then the effect of simultaneously encapsulating the drug molecule together with the reactants must be investigated.

It is my hope that some of the results presented in this thesis will be beneficial not only for my current group, which will continue to work in this direction, but also for other researchers around the world. In my mind, this is how true scientific progress works since each of us has a different perspective and therefor notices something different when studying the results of others. It is in the nature of scientific research that you never really now the impact of your work, since it might take many years before you can evaluate any change in the overall progress 
in the field. I hope that the work presented in this thesis will be a piece of the much larger puzzle moving forward. 


\section{References}

[1] Allen, T. M.; Cullis, P. R. Drug Delivery Systems: Entering the Mainstream. Science 2oo4, 303 (5665), 1818-1822.

[2] Al-Jamal, W. T.; Kostarelos, K. Liposomes: From a Clinically Established Drug Delivery System to a Nanoparticle Platform for Theranostic Nanomedicine. Accounts of Chemical Research 2011, 44 (10), 1094-1104.

[3] Pattni, B. S.; Chupin, V. V.; Torchilin, V. P. New Developments in Liposomal Drug Delivery. Chemical Reviews 2015, 115 (19), 10938-10966.

[4] Mura, S.; Nicolas, J.; Couvreur, P. Stimuli-Responsive Nanocarriers for Drug Delivery. Nature Materials 2013, 12 (11), 991-1003.

[5] Torchilin, V. P. Multifunctional, Stimuli-Sensitive Nanoparticulate Systems for Drug Delivery. Nature Reviews Drug Discovery 2014, 13 (11), 813-827.

[6] Charrois, G. J. R.; Allen, T. M. Drug Release Rate Influences the Pharmacokinetics, Biodistribution, Therapeutic Activity, and Toxicity of Pegylated Liposomal Doxorubicin Formulations in Murine Breast Cancer. Biochimica et Biophysica Acta 2004, 1663 (1-2), 167-177.

[7] Banghamm, A. D.; Standish, M. M.; Watkins, J. C. Diffusion of Univalent Ions across the Lamellae of Swollen Phopholipids. Journal of Molecular Biology 1965, 13 (1), 238-252.

[8] Mallick, S.; Choi, J. S. Liposomes: Versatile and Biocompatible Nanovesicles for Efficient Biomolecules Delivery. Journal of Nanoscience and Nanotechnology 2014, 14 (1), 755-765.

[9] Marqués-Gallego, P.; De Kroon, A. I. P. M. Ligation Strategies for Targeting Liposomal Nanocarriers. BioMed Research International 2014.

[10] Weinstein, J. N.; Magin, R. L.; Yatvin, M. B.; Zaharko, D. S. Liposomes and Local Hyperthermia: Selective Delivery of Methotrexate to Heated Tumors. Science 1979, 204 (4389), 188-191.

[11] Allen, T. M.; Cullis, P. R. Liposomal Drug Delivery Systems: From Concept to Clinical Applications. Advanced Drug Delivery Reviews 2013, 65 (1), 36-48.

[12] Bozzuto, G.; Molinari, A. Liposomes as Nanomedical Devices. International Journal of Nanomedicine 2015, 1O, 975-999.

[13] Gabizon, A.; Peretz, T.; Sulkes, A.; Amselem, S.; Ben-Yosef, R.; Ben-Baruch, N.; Catane, R.; Biran, S.; Barenholz, Y. Systemic Administration of Doxorubicin-Containing Liposomes in Cancer Patients: A Phase I Study. European Journal of Cancer and Clinical Oncology 1989, 25 (12), 1795-1803.

[14] Gabizon, A. A. Pegylated Liposomal Doxorubicin: Metamorphosis of an Old Drug into a New Form of Chemotherapy. Cancer Investigation 2001, 19 (4), 424-436.

[15] Barenholz, Y. Doxil ${ }^{\circledR}$ - The First FDA-Approved Nano-Drug: Lessons Learned. Journal of Controlled Release 2012, 160 (2), 117-134.

[16] Lopez-Berestein, G.; Fainstein, V.; Hopfer, R.; Mehta, K.; Sulllivan, M. P.; Keating, M.; Rosenblum, M. G.; Mehta, R.; Luna, M.; Hersh, E. M.; Reuben, J.; Juliano, R. L.; Bodey, G. P. Liposomal Amphotericin B for the Treatment of Systemic Fungal Infections in Patients with Cancer: A Preliminary Study. The Journal of Infectious Diseases 1985, 151 (4), 704-710.

[17] Hann, I. M.; Prentice, H. G. Lipid-Based Amphotericin B: A Review of the Last 10 Years of Use. International Journal of Antimicrobial Agents 2001, 17 (3), 161-169. 
[18] Harrington, K. J.; Lewanski, C. R.; Northcote, a D.; Whittaker, J.; Wellbank, H.; Vile, R. G.; Peters, a M.; Stewart, J. S. W. Phase I-II Study of Pegylated Liposomal Cisplatin (SPI-O77 ${ }^{\mathrm{TM}}$ ) in Patients with Inoperable Head and Neck Cancer. Annals of Oncology 2001, 12 (4), 493-496.

[19] Whitford, D. Proteins: Structure and Function; John Wiley \& Sons: West Sussex, United Kingdom, 2005 .

[20] Guidotti, G.; Brambilla, L.; Rossi, D. Cell-Penetrating Peptides: From Basic Research to Clinics. Trends in pharmacological sciences $\mathbf{2 0 1 7}, 38$ (4), 406-424.

[21] Nir, S.; Nieva, J. L. Interactions of Peptides with Liposomes: Pore Formation and Fusion. Progress in Lipid Research 2ooo, 39 (2), 181-206.

[22] Brogden, K. A. Antimicrobial Peptides: Pore Formers or Metabolic Inhibitors in Bacteria? Nature Reviews Microbiology 2005, 3 (3), 238-250.

[23] Sani, M. A.; Gagne, E.; Gehman, J. D.; Whitwell, T. C.; Separovic, F. Dye-release Assay for Investigation of Antimicrobial Peptide Activity in a Competitive Lipid Environment. European Biophysics Journal 2014, 43 (8-9), 445-450.

[24] Urban, a S.; Fedoruk, M.; Horton, M. R.; Rädler, J. O.; Stefani, F. D.; Feldmann, J. Controlled Nanometric Phase Transitions of Phospholipid Membranes by Plasmonic Heating of Single Gold Nanoparticles. Nano letters 2oo9, 9 (8), 2903-2908.

[25] Hirn, S.; Semmler-Behnke, M.; Schleh, C.; Wenk, A.; Lipka, J.; Schäffler, M.; Takenaka, S.; Möller, W.; Schmid, G.; Simon, U.; Kreyling, W. G. Particle Size-Dependent and Surface Charge-Dependent Biodistribution of Gold Nanoparticles after Intravenous Administration. European Journal of Pharmaceutics and Biopharmaceutics 2011, 77 (3), 407-416.

[26] Zhang, X. D.; Wu, D.; Shen, X.; Liu, P. X.; Fan, F. Y.; Fan, S. J. In Vivo Renal Clearance, Biodistribution, Toxicity of Gold Nanoclusters. Biomaterials 2012, 33 (18), 4628-4638.

[27] Pashley, R. M.; Karaman, M. E. Applied Colloid and Surface Chemistry; John Wiley \& Sons: West Sussex, United Kingdom, 2004.

[28] Gudlur, S.; Sukthankar, P.; Gao, J.; Avila, L. A.; Hiromasa, Y.; Chen, J.; Iwamoto, T.; Tomich, J. M. Peptide Nanovesicles Formed by the Self-Assembly of Branched Amphiphilic Peptides. PLoS ONE 2012, 7 (9), e45374.

[29] Sukthankar, P.; Gudlur, S.; Avila, L. A.; Whitaker, S. K.; Katz, B. B.; Hiromasa, Y.; Gao, J.; Thapa, P.; Moore, D.; Iwamoto, T.; Chen, J.; Tomich, J. M. Branched Oligopeptides Form Nanocapsules with Lipid Vesicle Characteristics. Langmuir 2013, 29 (47), 14648-14654.

[30] Meng, F.; Zhong, Z.; Feijen, J. Stimuli-Responsive Polymersomes for Programmed Drug. Biomacromolecules 2009, 10 (2), 197-209.

[31] Lim, S. K.; de Hoog, H. P.; Parikh, A. N.; Nallani, M.; Liedberg, B. Hybrid, Nanoscale Phospholipid/Block Copolymer Vesicles. Polymers 2013, 5 (3), 1102-1114.

[32] Gormley, A. J.; Chandrawati, R.; Christofferson, A. J.; Loynachan, C.; Jumeaux, C.; Artzy-Schnirman, A.; Aili, D.; Yarovsky, I.; Stevens, M. M. Layer-by-Layer Self-Assembly of Polymer Films and Capsules through Coiled-Coil Peptides. Chemistry of Materials 2015, 27 (16), 5820-5824.

[33] Yasuda, T.; Naito, Y.; Tsumita, T.; Tadakuma, T. A Simple Method to Measure Anti-Glycolipid Antibody by Using Complement-Mediated Immune Lysis of Fluorescent Dye-Trapped Liposomes. Journal of Immunological methods 1981, 44 (2), 153-158.

[34] Franzé, S.; Marengo, A.; Stella, B.; Minghetti, P.; Arpicco, S.; Cilurzo, F. Hyaluronan-Decorated Liposomes as Drug Delivery Systems for Cutaneous Administration. International Journal of Pharmaceutics 2018, 535 (1-2), 333-339.

[35] Torchilin, V. Tumor Delivery of Macromolecular Drugs Based on the EPR Effect. Advanced Drug Delivery Reviews 2011, 63 (3), 131-135. 
[36] Klibanov, A. L.; Maruyama, K.; Torchilin, V. P.; Huang, L. Amphipathic Polyethyleneglycols Effectively Prolong the Circulation Time of Liposomes. FEBS Letters 1990, 268 (1), 235-237.

[37] Allen, T. M.; Hansen, C.; Martin, F.; Redemann, C.; Yau-Young, A. Liposomes Containing Synthetic Lipid Derivatives of Poly(Ethylene Glycol) Show Prolonged Circulation Half-Lives in Vivo. Biochimica et Biophysica Acta - Biomembranes 1991, 1066 (1), 29-36.

[38] Yatvin, M. B.; Weinstein, J. N.; Dennis, W. H.; Blumenthal, R. Design of Liposomes for Enhanced Local Release of Drugs by Hyperthermia. Science 1978, 202 (4374), 1290-1293.

[39] Heath, T. D.; Fraley, R. T.; Papahadjopoulos, D. Antibody Targeting of Liposomes: Cell Specificity Obtained by Conjugation of F(Ab')2 to Vesicle Surface. Science 1980, 210 (4469), 539-541.

[40] Ponce, A. M.; Vujaskovic, Z.; Yuan, F.; Needham, D.; Dewhirst, M. W. Hyperthermia Mediated Liposomal Drug Delivery. International Journal of Hyperthermia 2006, 22 (3), 205-213.

[41] Grüll, H.; Langereis, S. Hyperthermia-Triggered Drug Delivery from Temperature-Sensitive Liposomes Using MRI-Guided High Intensity Focused Ultrasound. Journal of Controlled Release 2012, 161 (2), $317-327$.

[42] Kaneda, Y. Virosomes: Evolution of the Liposome as a Targeted Drug Delivery System. Advanced Drug Delivery Reviews 2000, 43 (2-3), 197-205.

[43] Huang, S. L.; MacDonald, R. C. Acoustically Active Liposomes for Drug Encapsulation and UltrasoundTriggered Release. Biochimica et Biophysica Acta - Biomembranes 2004, 1665 (1-2), 134-141.

[44] Al-Ahmady, Z. S.; Al-Jamal, W. T.; Bossche, J. V.; Bui, T. T.; Drake, A. F.; Mason, A. J.; Kostarelos, K. Lipid-Peptide Vesicle Nanoscale Hybrids for Triggered Drug Release by Mild Hyperthermia in Vitro and in Vivo. ACS Nano 2012, 6 (10), 9335-9346.

[45] Paasonen, L.; Laaksonen, T.; Johans, C.; Yliperttula, M.; Kontturi, K.; Urtti, A. Gold Nanoparticles Enable Selective Light-Induced Contents Release from Liposomes. Journal of Controlled Release 2007, $122(1), 86-93$.

[46] Amstad, E.; Kohlbrecher, J.; Müller, E.; Schweizer, T.; Textor, M.; Reimhult, E. Triggered Release from Liposomes through Magnetic Actuation of Iron Oxide Nanoparticle Containing Membranes. Nano Letters 2011, 11 (4), 1664-1670.

[47] Yatvin, M. B.; Kreutz, W.; Horwitz, B. A.; Shinitzky, M. PH-Sensitive Liposomes: Possible Clinical Implications. Science 1980, 210 (4475), 1253-1255.

[48] Sarkar, N. R.; Rosendahl, T.; Krueger, A. B.; Banerjee, A. L.; Benton, K.; Mallik, S.; Srivastava, D. K. "Uncorking" of Liposomes by Matrix Metalloproteinase-9. Chemical Communications 2005, 8, 9991001.

[49] Sarkar, N.; Banerjee, J.; Hanson, A. J.; Elegbede, A. I.; Rosendahl, T.; Krueger, A. B.; Banerjee, A. L.; Tobwala, S.; Wang, R.; Lu, X.; Mallik, S.; Srivastava, D. K. Matrix Metalloproteinase-Assisted Triggered Release of Liposomal Contents. Bioconjugate Chemistry 2008, 19 (1), 57-64.

[50] Banerjee, J.; Hanson, A. J.; Gadam, B.; Elegbede, A. I.; Tobwala, S.; Ganguly, B.; Wagh, A. V.; Muhonen, W. W.; Law, B.; Shabb, J. B.; Srivastava, D. K.; Mallik, S. Release of Liposomal Contents by Cell-Secreted Matrix Metalloproteinase-9. Bioconjugate Chemistry 2oo9, 20 (7), 1332-1339.

[51] Berg, J. M.; Tymoczko, J. L.; Stryer, L. Lipids and Cell Membranes. In Biochemistry; W. H. Freeman and Company: New York, 2002; pp 319-344.

[52] Sud, M.; Fahy, E.; Cotter, D.; Brown, A.; Dennis, E. a; Glass, C. K.; Merrill, A. H.; Murphy, R. C.; Raetz, C. R. H.; Russell, D. W.; Subramaniam, S. LMSD: Lipid Maps Structure Database. Nucleic acids research $\mathbf{2 0 0 7}, 35$, D527-532.

[53] van Meer, G.; Voelker, D. R.; Feigenson, G. W. Membrane Lipids: Where They Are and How They Behave. Nature Reviews Molecular Cell Biology 2008, 9 (2), 112-124. 
[54] Steed, J. W.; Atwood, J. L. Supramolecular Chemistry, 2nd ed.; John Wiley \& Sons: West Sussex, United Kingdom, 2009.

[55] Liu, J.; Conboy, J. C. Direct Measurement of the Transbilayer Movement of Phospholipids by SumFrequency Vibrational Spectroscopy. Journal of the American Chemical Society 2004, 126 (27), $8376-$ 8377 .

[56] Parasassi, T.; De Stasio, G.; d’Ubaldo, a; Gratton, E. Phase Fluctuation in Phospholipid Membranes Revealed by Laurdan Fluorescence. Biophysical journal 1990, 57 (6), 1179-1186.

[57] Mabrey, S.; Sturtevant, J. M. Investigation of Phase Transitions of Lipids and Lipid Mixtures by High Sensitivity Differential Scanning Calorimetry. Proc. Natl. Acad. Sci. USA 1976, 73 (11), 3862-3866.

[58] Cevc, G. How Membrane Chain-Melting Phase-Transition Temperature Is Affected by the Lipid Chain Asymmetry and Degree of Unsaturation: An Effective Chain-Length Model. Biochemistry 1991, 30 (29), 7186-7193.

[59] Szoka, F.; Papahadjopoulos, D. Procedure for Preparation of Liposomes with Large Internal Aqueous Space and High Capture by Reverse-Phase Evaporation. Proceedings of the National Academy of Sciences 1978, 75 (9), 4194-4198.

[6o] Castile, J. D.; Taylor, K. M. G. Factors Affecting the Size Distribution of Liposomes Produced by FreezeThaw Extrusion. International Journal of Pharmaceutics 1999, 188 (1), 87-95.

[61] Schubert, M. A.; Müller-Goymann, C. C. Solvent Injection as a New Approach for Manufacturing Lipid Nanoparticles - Evaluation of the Method and Process Parameters. European Journal of Pharmaceutics and Biopharmaceutics 2003, 55 (1), 125-131.

[62] Zumbuehl, O.; Weder, H. G. Liposomes of Controllable Size in the Range of 40 to 180 Nm by Defined Dialysis of Lipid/Detergent Mixed Micelles. Biochimica et Biophysica Acta - Biomembranes 1981, 640 (1), 252-262.

[63] Bangham, A. D.; Hill, M. W.; Miller, N. G. A. Preparation and Use of Liposomes as Models of Biological Membranes. In Methods in membrane biology; Springer: Boston, 1974; pp 1-68.

[64] Olson, F.; Hunt, C. A.; Szoka, F. C.; Vail, W. J.; Papahadjopoulos, D. Preparation of Liposomes of Defined Size Distribution by Extrusion through Polycarbonate Membranes. Biochimica et Biophysica Acta - Biomembranes 1979, 557 (1), 9-23.

[65] Mayer, L. D.; Hope, M. J.; Cullis, P. R. Vesicles of Variable Sizes Produced by a Rapid Extrusion Procedure. Biochimica et Biophysica Acta 1986, 858, 161-168.

[66] Barnes, G. T.; Gentle, I. R. Biological Interfaces. In Interfacial science: an introduction; Oxford university press: Oxford, 2011; pp 289-319.

[67] Rosilio, V. How Can Artificial Lipid Models Mimic the Complexity of Molecule-Membrane Interactions? In Advances in Biomembranes and Lipid Self-Assembly; Academic Press, 2018; pp 107146.

[68] Madigan, M. T.; Martinko, J. M. Cell Structure/Function. In Brock Biology of Microorganisms; Pearson Education: Upper Saddle River, 2006; pp 55-100.

[69] Matsuzaki, K.; Sugishita, K.; Miyajima, K. Interactions of an Antimicrobial Peptide, Magainin 2, Lipopolysaccaride-Containing Liposomes as a Model for Outer Membranes of Gram-Negative Bacteria. FEBS Letters 1999, 449 (2-3), 221-224.

[70] Shang, D.; Zhang, Q.; Dong, W.; Liang, H.; Bi, X. The Effects of LPS on the Activity of Trp-Containing Antimicrobial Peptides against Gram-Negative Bacteria and Endotoxin Neutralization. Acta Biomaterialia 2016, 33, 153-165.

[71] Manhong, W.; Hancock, R. E. W. Interaction of the Cyclic Antimicrobial Cationic Peptide Bactenecin with the Outer and Cytoplasmic Membrane. The Journal of biological chemistry 1999, 274 (1), 29-35. 
[72] Nielsen, S. B.; Otzen, D. E. Impact of the Antimicrobial Peptide Novicidin on Membrane Structure and Integrity. Journal of Colloid and Interface Science 2010, 345 (2), 248-256.

[73] Oren, Z.; Lerman, J. C.; Gudmundsson, G. H.; Agerberth, B.; Shai, Y. Structure and Organization of the Human Antimicrobial Peptide LL-37 in Phospholipid Membranes: Relevance to the Molecular Basis for Its Non-Cell-Selective Activity. Biochemical Journal 1999, 341 (3), 501.

[74] Matsuzaki, K.; Sugishita, K. I.; Fujii, N.; Miyajima, K. Molecular Basis for Membrane Selectivity of an Antimicrobial Peptide, Magainin 2. Biochemistry 1995, 34 (10), 3423-3429.

[75] Cabiaux, V.; Agerberth, B.; Johansson, J.; Homble, F.; Goormaghtigh, E.; Ruysschaert, J. M. Secondary Structure and Membrane Interaction of PR-39, a Pro+Arg-Rich Antibacterial Peptide. European Journal of Biochemistry 1994, 224 (3), 1019-1027.

[76] He, J.; Krauson, A. J.; Wimley, W. C. Toward the de Novo Design of Antimicrobial Peptides: Lack of Correlation between Peptide Permeabilization of Lipid Vesicles and Antimicrobial, Cytolytic, or Cytotoxic Activity in Living Cells. Peptide Science 2014, 102 (1), 1-6.

[77] Zhou, L.; Srisatjaluk, R.; Justus, D. E.; Doyle, R. J. On the Origin of Membrane Vesicles in GramNegative Bacteria. FEMS Microbiology Letters 1998, 163 (2), 223-228.

[78] Gursky, O.; Aleshkov, S. Temperature-Dependent $\beta$-Sheet Formation in $\beta$-Amyloid A $\beta(1-40)$ Peptide in Water: Uncoupling $\beta$-Structure Folding from Aggregation. Biochimica et biophysica acta 2000, 1476, 93-102.

[79] Ghosh, A.; Haverick, M.; Stump, K.; Yang, X.; Tweedle, M. F.; Goldberger, J. E. Fine-Tuning the PH Trigger of Self-Assembly. Journal of the American Chemical Society 2012, 134 (8), 3647-3650.

[8o] Ozbas, B.; Kretsinger, J.; Rajagopal, K.; Schneider, J. P.; Pochan, D. J. Salt-Triggered Peptide Folding and Consequent Self-Assembly into Hydrogels with Tunable Modulus. Macromolecules 2004, 37 (19), $7331-7337$.

[81] Aili, D.; Enander, K.; Rydberg, J.; Nesterenko, I.; Björefors, F.; Baltzer, L.; Liedberg, B. Folding Induced Assembly of Polypeptide Decorated Gold Nanoparticles. Journal of the American Chemical Society 2008, 130 (17), 5780-5788.

[82] Selegård, R.; Rouhbakhsh, Z.; Shirani, H.; Johansson, L. B. G.; Norman, P.; Linares, M.; Aili, D.; Nilsson, K. P. R. Distinct Electrostatic Interactions Govern the Chiro-Optical Properties and Architectural Arrangement of Peptide-Oligothiophene Hybrid Materials. Macromolecules 2017, 50 (18), 7102-7110.

[83] Rydberg, J.; Baltzer, L.; Sarojini, V. Intrinsically Unstructured Proteins by Design-Electrostatic Interactions Can Control Binding, Folding, and Function of a Helix-Loop-Helix Heterodimer. Journal of peptide science $\mathbf{2 0 1 3}, 19$ (8), 461-469.

[84] Aronsson, C.; Dånmark, S.; Zhou, F.; Öberg, P.; Enander, K.; Su, H.; Aili, D. Self-Sorting Heterodimeric Coiled Coil Peptides with Defined and Tunable Self-Assembly Properties. Scientific Reports 2015, 5 , 14063 .

[85] Thomas, F.; Boyle, A. L.; Burton, A. J.; Woolfson, D. N. A Set of de Novo Designed Parallel Heterodimeric Coiled Coils with Quantified Dissociation Constants in the Micromolar to SubNanomolar Regime. Journal of the American Chemical Society 2013, 135 (13), 5161-5166.

[86] Lundqvist, M.; Nygren, P.; Jonsson, B. H.; Broo, K. Induction of Structure and Function in a Designed Peptide upon Adsorption on a Silica Nanoparticle. Angewandte Chemie 2oo6, 45 (48), 8169-8173.

[87] Nygren, P.; Lundqvist, M.; Liedberg, B.; Jonsson, B.; Ederth, T. Secondary Structure in de Novo Designed Peptides Induced by Electrostatic Interaction with a Lipid Bilayer Membrane. Langmuir 2010, 26 (9), 6437-6448

[88] Merrifield, R. B. Automated Synthesis of Peptides. Science 1965, 150 (3693), 178-185.

[89] Banner, D. W.; Kokkinidis, M.; Tsernoglou, D. Structure of the ColE1 Rop Protein at 1.7 Å Resolution. Journal of Molecular Biology 1987, 196 (3), 657-675. 
[90] Mathews, F. S.; Bethge, P. H.; Czerwinskis, E. W. The Structure of Cytochrome B562 from Escherichia Coli at 2.5 Å Resolution. Journal of Biological Chemistry 1979, 254 (5), 1699-1706.

[91] Brandhuber, B. J.; Boone, T.; Kenney, W. C.; McKay, D. B. Three-Dimensional Structure of Interleukin2. Science 1987, 238 (4834), 1707-1709.

[92] Conway, J. F.; Cheng, N.; Zlotnick, A.; Wingfield, P. T.; Stahl, S. J.; Steven, A. C. Visualization of a 4Helix Bundle in the Hepatitis B Virus Capsid by Cryo-Electron Microscopy. Nature 1997, 386 (6620), 91-94.

[93] Enander, K.; Aili, D.; Baltzer, L.; Lundström, I.; Liedberg, B. Alpha-Helix-Inducing Dimerization of Synthetic Polypeptide Scaffolds on Gold. Langmuir 2005, 21 (6), 2480-2487.

[94] Aili, D.; Enander, K.; Rydberg, J.; Lundström, I.; Baltzer, L.; Liedberg, B. Aggregation-Induced Folding of a de Novo Designed Polypeptide Immobilized on Gold Nanoparticles. Journal of the American Chemical Society 2006, 128 (7), 2194-2195.

[95] Eberle, W.; Pastore, A.; Sander, C.; Rösch, P. The Structure of ColE1 Rop in Solution. Journal of Biomolecular NMR 1991, 1 (1), 71-82.

[96] Berman, H. M.; Westbrook, J.; Feng, Z.; Gilliland, G.; Bhat, T. N.; Weissig, H.; Shindyalov, I. N.; Bourne, P. E. The Protein Data Bank. Nucleic acids research 2ooo, 28 (1), 235-242.

[97] Rose, A. S.; Hildebrand, P. W. NGL Viewer: A Web Application for Molecular Visualization. Nucleic Acids Research 2015, 43 (W1), W576-W579.

[98] Rose, A. S.; Bradley, A. R.; Valasatava, Y.; Duarte, J. M.; Prlić, A.; Rose, P. W. Web-Based Molecular Graphics for Large Complexes. Proceedings of the 21st International Conference on Web3D Technology (Web3D '16) 2016, No. 1, 185-186.

[99] Woolfson, D. N. The Design of Coiled-Coil Structures and Assemblies. In Advances in protein chemistry; Academic Press, 2oo5; Vol. 70, pp 79-112.

[100] McLachlan, A. D.; Stewart, M. Tropomyosin Coiled-Coil Interactions: Evidence for an Unstaggered Structure. Journal of Molecular Biology 1975, 98 (2), 293-304.

[101] Paulsson, M.; Deutzmann, R.; Timpl, R.; Dalzoppo, D.; Odermatt, E.; Engel, J. Evidence for Coiled-Coil Alpha-Helical Regions in the Long Arm of Laminin. The EMBO journal 1985, 4 (2), 309-316.

[102] Deisenhofer, J.; Jones, T. A.; Huber, R.; Sjödahl, J.; Sjöquist, J. Crystallization, Crystal Structure Analysis and Atomic Model of the Complex Formed by a Human Fc Fragment and Fragment B of Protein A from Staphylococcus Aureus. Hoppe-Seyler's Zeitschrift für physiologische Chemie 1978, 359 (2), 975-986.

[103] Brown, J. H.; Kim, K.-H.; Jun, G.; Greenfield, N. J.; Dominguez, R.; Volkmann, N.; HitchcockDeGregori, S. E.; Cohen, C. Deciphering the Design of the Tropomyosin Molecule. Proceedings of the National Academy of Sciences 2001, 98 (15), 8496-8501.

[104] Litowski, J. R.; Hodges, R. S. Designing Heterodimeric Two-Stranded a-Helical Coiled-Coils: Effects of Hydrophobicity and $\alpha$-Helical Propensity on Protein Folding, Stability, and Specificity. Journal of Biological Chemistry 2002, 277 (40), 37272-37279.

[105] Dånmark, S.; Aronsson, C.; Aili, D. Tailoring Supramolecular Peptide-Poly(Ethylene Glycol) Hydrogels by Coiled Coil Self-Assembly and Self-Sorting. Biomacromolecules 2016, 17 (6), 2260-2267.

[106] Nick Pace, C.; Martin Scholtz, J. A Helix Propensity Scale Based on Experimental Studies of Peptides and Proteins. Biophysical Journal 1998, 75 (1), 422-427.

[107] Cotter, P. D.; Ross, R. P.; Hill, C. Bacteriocins-a Viable Alternative to Antibiotics? Nature Reviews Microbiology 2013, 11 (2), 95-105. 
[108] Bush, K.; Courvalin, P.; Dantas, G.; Davies, J.; Eisenstein, B.; Huovinen, P.; Jacoby, G. A.; Kishony, R.; Kreiswirth, B. N.; Kutter, E.; Lerner, S. A.; Levy, S.; Lewis, K.; Lomovskaya, O.; Miller, J. H.; Mobashery, S.; Piddock, L. J. V.; Projan, S.; Thomas, C. M. et al. Tackling Antibiotic Resistance. Nature Reviews Microbiology 2011, 9 (12), 894-896.

[109] Peschel, A.; Sahl, H. G. The Co-Evolution of Host Cationic Antimicrobial Peptides and Microbial Resistance. Nature Reviews Microbiology 2006, 4 (7), 529-536.

[110] Ahrné, S.; Nobaek, S.; Jeppsson, B.; Adlerberth, I.; Wold, A. E.; Molin, G. The Normal Lactobacillus Flora of Healthy Human Rectal and Oral Mucosa. Journal of Applied Microbiology 1998, 85 (1), 88 94.

[111] Maldonado, A.; Ruiz-Barba, J. L.; Jiménez-Díaz, R. Purification and Genetic Characterization of Plantaricin NC8, a Novel Coculture-Inducible Two-Peptide Bacteriocin from Lactobacillus Plantarum NC8. Applied and environmental microbiology 2003, 69 (1), 383-389.

[112] Kyte, J.; Doolittle, R. F. A Simple Method for Displaying the Hydropathic Character of a Protein. Journal of Molecular Biology 1982, 157 (1), 105-132.

[113] Zasloff, M. Antimicrobial Peptides of Multicellular Organisms. Nature 2oo2, 415 (6870), 389-395.

[114] Fjell, C. D.; Hiss, J. A.; Hancock, R. E. W.; Schneider, G. Designing Antimicrobial Peptides: Form Follows Function. Nature Reviews Drug Discovery 2012, 11 (1), 37-51.

[115] Park, Y.; Lee, D. G.; Jang, S. H.; Woo, E. R.; Jeong, H. G.; Choi, C. H.; Hahm, K. S. A Leu-Lys-Rich Antimicrobial Peptide: Activity and Mechanism. Biochimica et Biophysica Acta - Proteins and Proteomics 2003, 1645 (2), 172-182.

[116] Som, A.; Tezgel, A. O.; Gabriel, G. J.; Tew, G. N. Self-Activation in de Novo Designed Mimics of CellPenetrating Peptides. Angewandte Chemie 2011, 50 (27), 6147-6150.

[117] Blondelle, S. E.; Forood, B.; Houghten, R. A.; Perez-Paya, E. Secondary Structure Induction in Aqueous vs Membrane-like Environments. Biopolymers 1997, 42 (4), 489-498.

[118] Datrie, M.; Schumann, M.; Wieprecht, T.; Winkler, A.; Beyermann, M.; Krause, E.; Matsuzaki, K.; Murase, O.; Bienert, M. Peptide Helicity and Membrane Surface Charge Modulate the Balance of Electrostatic and Hydrophobic Interactions with Lipid Bilayers and Biological Membranes. Biochemistry 1996, 35 (38), 12612-12622.

[119] Berg, J.; Tymoczko, J. L.; Stryer, L. Protein Structure and Function. In Biochemistry; W. H. Freeman and Company: New York, 2oo2; pp 41-76.

[120] Sevcsik, E.; Pabst, G.; Jilek, A.; Lohner, K. How Lipids Influence the Mode of Action of MembraneActive Peptides. Biochimica et Biophysica Acta - Biomembranes 2007, 1768 (10), 2586-2595.

[121] Kumar, P.; Kizhakkedathu, J. N.; Straus, S. K. Antimicrobial Peptides: Diversity, Mechanism of Action and Strategies to Improve the Activity and Biocompatibility in Vivo. Biomolecules 2o18, 8 (1), 4.

[122] Bechinger, B.; Lohner, K. Detergent-like Actions of Linear Amphipathic Cationic Antimicrobial Peptides. Biochimica et Biophysica Acta - Biomembranes 2oo6, 1758 (9), 1529-1539.

[123] Matsuzaki, K.; Yoneyama, S.; Miyajima, K. Pore Formation and Translocation of Melittin. 1997, 73 (August), 831-838.

[124] Ladokhin, A. S. .; White, S. H. . Folding of Amphipathic a-Helices on Membranes: Energetics of Helix Formation by Melittin. Journal of Molecular Biology 1999, 285 (4), 1363-1369.

[125] Marion, D.; Zasloff, M.; Bax, A. A Two-Dimensional NMR Study of the Antimicrobial Peptide Magainin 2. FEBS Lett 1988, 227 (1), 21-26.

[126] Matsuzaki, K.; Murase, O.; Fujii, N.; Miyajima, K. Translocation of a Channel-Forming Antimicrobial Peptide, Magainin 2, across Lipid Bilayers by Forming a Pore. Biochemistry 1995, 34 (19), 6521-6526. 
[127] Sciences, M. The Peptide Antibiotic LL-37 7CAP-18 Is Expressed in Epithelia of the Human Lung Where It Has Broad Antimicrobial Activity at the Airway Surface. 1998, 95 (August), 9541-9546.

[128] Henzler Wildman, K. A.; Lee, D.-K.; Ramamoorthy, A. Mechanism of Lipid Bilayer Disruption by the Human Antimicrobial Peptide, LL-37. Biochemistry 2oo3, 42, 6545-6558.

[129] Rabe, M.; Zope, H. R.; Kros, A. Interplay between Lipid Interaction and Homo-Coiling of MembraneTethered Coiled-Coil Peptides. Langmuir 2015, 31 (36), 9953-9964.

[130] Versluis, F.; Voskuhl, J.; Van Kolck, B.; Zope, H.; Bremmer, M.; Albregtse, T.; Kros, A. In Situ Modification of Plain Liposomes with Lipidated Coiled Coil Forming Peptides Induces Membrane Fusion. Journal of the American Chemical Society 2013, 135 (21), 8057-8062.

[131] Robson Marsden, H.; Korobko, A. V.; Zheng, T.; Voskuhl, J.; Kros, A. Controlled Liposome Fusion Mediated by SNARE Protein Mimics. Biomaterials Science 2013, 1 (10), 1046-1054.

[132] Futaki, S.; Ohashi, W.; Suzuki, T.; Niwa, M.; Tanaka, S.; Ueda, K.; Harashima, H.; Sugiura, Y. Stearylated Arginine-Rich Peptides: A New Class of Transfection Systems. Bioconjugate Chemistry 2001, 12 (6), 1005-1011.

[133] Datta, A.; Kundu, P.; Bhunia, A. Designing Potent Antimicrobial Peptides by Disulphide Linked Dimerization and N-Terminal Lipidation to Increase Antimicrobial Activity and Membrane Perturbation: Structural Insights into Lipopolysaccharide Binding. Journal of Colloid and Interface Science 2016, 461, 335-345.

[134] Northrop, B. H.; Frayne, S. H.; Choudhary, U. Thiol-maleimide "Click" Chemistry: Evaluating the Influence of Solvent, Initiator, and Thiol on the Reaction Mechanism, Kinetics, and Selectivity. Polymer Chemistry 2015, 6 (18), 3415-3430.

[135] Okada, A.; Wakamatsu, K.; Miyazawa, T.; Higashijima, T. Vesicle-Bound Conformation of Melittin: Transferred Nuclear Overhauser Enhancement Analysis in the Presence of Perdeuterated Phosphatidylcholine Vesicles. Biochemistry 1994, 33 (32), 9438-9446.

[136] Wang, W.; Smith, D. K.; Moulding, K.; Min Chen, H. The Dependence of Membrane Permeability by the Antibacterial Peptide Cecropin B and Its Analogs, CB-1 and CB-3, on Liposomes of Different Composition. J.of Biol. Chemistry 1998, 273 (42), 27438-27448.

[137] Wiradharma, N.; Khoe, U.; Hauser, C. A. E.; Seow, S. V.; Zhang, S.; Yang, Y. Y. Synthetic Cationic Amphiphilic a-Helical Peptides as Antimicrobial Agents. Biomaterials 2011, 32 (8), 2204-2212.

[138] Mechler, A.; Praporski, S.; Atmuri, K.; Boland, M.; Separovic, F.; Martin, L. L. Specific and Selective Peptide-Membrane Interactions Revealed Using Quartz Crystal Microbalance. Biophysical journal 2007, 93 (11), 3907-3916.

[139] Mccubbin, G. A.; Praporski, S.; Piantavigna, S.; Knappe, D.; Hoffmann, R.; Bowie, J. H.; Separovic, F.; Martin, L. L. QCM-D Fingerprinting of Membrane-Active Peptides. European Biophysics Journal 2011, $40(4), 437-446$.

[140] Lu, N. Y.; Yang, K.; Li, J. L.; Yuan, B.; Ma, Y. Q. Vesicle Deposition and Subsequent Membrane-Melittin Interactions on Different Substrates: A QCM-D Experiment. Biochimica et Biophysica Acta Biomembranes 2013, 1828 (8), 1918-1925.

[141] Ii, M.; Yamamoto, H.; Adachi, Y.; Maruyama, Y.; Shinomura, Y. Role of Matrix Metalloproteinase-7 (Matrilysin) in Human Cancer Invasion, Apoptosis, Growth, and Angiogenesis. Experimental biology and medicine 2006, 231 (1), 20-27.

[142] Chen, P.; Selegård, R.; Aili, D.; Liedberg, B. Peptide Functionalized Gold Nanoparticles for Colorimetric Detection of Matrilysin (MMP-7) Activity. Nanoscale 2013, 5 (19), 8973-8976.

[143] Wang, F. Q.; So, J.; Reierstad, S.; Fishman, D. A. Matrilysin (MMP-7) Promotes Invasion of Ovarian Cancer Cells by Activation of Progelatinase. International Journal of Cancer 2oo5, 114 (1), 19-31. 
[144] Litowski, J. R.; Hodges, R. S. Designing Heterodimeric Two-Stranded a-Helical Coiled-Coils: Effects of Hydrophobicity and a-Helical Propensity on Protein Folding, Stability, and Specificity. Journal of Biological Chemistry 2002, 277 (40), 37272-37279.

[145] De Planque, M. R. R.; Bonev, B. B.; Demmers, J. A. A.; Greathouse, D. V.; Koeppe, R. E.; Separovic, F.; Watts, A.; Killian, J. A. Interfacial Anchor Properties of Tryptophan Residues in Transmembrane Peptides Can Dominate over Hydrophobic Matching Effects in Peptide-Lipid Interactions. Biochemistry 2003, 42 (18), 5341-5348.

[146] Kučerka, N.; Nieh, M. P.; Katsaras, J. Fluid Phase Lipid Areas and Bilayer Thicknesses of Commonly Used Phosphatidylcholines as a Function of Temperature. Biochimica et Biophysica Acta Biomembranes 2011, 1808 (11), 2761-2771.

[147] Dietz, H.; Rief, M. Protein Structure by Mechanical Triangulation. Proceedings of the National Academy of Sciences 2006, 103 (5), 1244-1247.

[148] Perutz, M. F. New X-Ray Evidence on the Configuration of Polypeptide Chains: Polypeptide Chains in Poly- $\gamma$-Benzyl-l-Glutamate, Keratin and Hæmoglobin. Nature 1951, 167 (4261), 1053-1054.

[149] Rabe, M.; Aisenbrey, C.; Pluhackova, K.; de Wert, V.; Boyle, A. L.; Bruggeman, D. F.; Kirsch, S. A.; Böckmann, R. A.; Kros, A.; Raap, J.; Bechinger, B. A Coiled-Coil Peptide Shaping Lipid Bilayers upon Fusion. Biophysical Journal 2016, 111 (10), 2162-2175.

[150] Oppegård, C.; Rogne, P.; Emanuelsen, L.; Kristiansen, P. E.; Fimland, G.; Nissen-Meyer, J. The TwoPeptide Class II Bacteriocins: Structure, Production, and Mode of Action. Journal of Molecular Microbiology and Biotechnology 2007, 13 (4), 210-219.

[151] Maldonado, A.; Ruiz-Barba, J. L.; Jiménez-Díaz, R. Production of Plantaricin NC8 by Lactobacillus Plantarum NC8 Is Induced in the Presence of Different Types of Gram-Positive Bacteria. Archives of Microbiology 2004, 181 (1), 8-16.

[152] Mock, J. J.; Barbic, M.; Smith, D. R.; Schultz, D. A.; Schultz, S. Shape Effects in Plasmon Resonance of Individual Colloidal Silver Nanoparticles. Journal of Chemical Physics 2002, 116 (15), 6755-6759.

[153] Cortie, M. B. The Weird World of Nanoscale Gold. Gold Bulletin 2004, 37 (1-2), 12-19.

[154] Willets, K. a; Van Duyne, R. P. Localized Surface Plasmon Resonance Spectroscopy and Sensing. Annual review of physical chemistry $\mathbf{2 0 0 7}, 58,267-297$.

[155] Link, S.; El-Sayed, M. a. Size and Temperature Dependence of the Plasmon Absorption of Colloidal Gold Nanoparticles. The Journal of Physical Chemistry B 1999, 103 (21), 4212-4217.

[156] Burda, C.; Chen, X.; Narayanan, R.; El-Sayed, M. a. Chemistry and Properties of Nanocrystals of Different Shapes. Chemical reviews 2005, 105 (4), 1025-1102.

[157] Ghosh, S. K.; Pal, T. Interparticle Coupling Effect on the Surface Plasmon Resonance of Gold Nanoparticles: From Theory to Applications. Chemical reviews 2007, 107 (11), 4797-4862.

[158] Mirkin, C. a; Letsinger, R. L.; Mucic, R. C.; Storhoff; J, J. A DNA-Based Method for Rationally Assembling Nanoparticles into Macroscopic Materials. Nature 1996, 382, 607-609.

[159] Aili, D.; Selegård, R.; Baltzer, L.; Enander, K.; Liedberg, B. Colorimetric Protein Sensing by Controlled Assembly of Gold Nanoparticles Functionalized with Synthetic Receptors. Small (Weinheim an der Bergstrasse, Germany) 2009, 5 (21), 2445-2452.

[160] de la Rica, R.; Stevens, M. M. Plasmonic ELISA for the Ultrasensitive Detection of Disease Biomarkers with the Naked Eye. Nature nanotechnology 2012, 7 (12), 821-824.

[161] Chen, P.; Selegård, R.; Aili, D.; Liedberg, B. Peptide Functionalized Gold Nanoparticles for Colorimetric Detection of Matrilysin (MMP-7) Activity. Nanoscale 2013, 5 (19), 8973-8976.

[162] Govorov, A. O.; Richardson, H. H. Generating Heat with Metal Nanoparticles. Nano Today 2007, 2 (1), 30-38. 
[163] O’Neal, D. P.; Hirsch, L. R.; Halas, N. J.; Payne, J. D.; West, J. L. Photo-Thermal Tumor Ablation in Mice Using near Infrared-Absorbing Nanoparticles. Cancer letters 2oo4, 209 (2), 171-176.

[164] Agarwal, A.; Mackey, M. A.; El-Sayed, M. A.; Bellamkonda, R. V. Remote Triggered Release of Doxorubicin in Tumors by Synergistic Application of Gold Nanorods. ACS nano 2o11, 5 (6), 4919-4926.

[165] Murillo, L. E.; Viera, O.; Vicuña, E.; Briano, J. G.; Castro, M.; Ishikawa, Y.; Irizarry, R.; Solá, L. Growth Kinetics of Gold Nanoparticles. Comput. Nanosci. Nanotechnology 2oo2, 435-438.

[166] Turkevich, J.; Stevenson, P. C.; Hillier, J. A Study of the Nucleation and Growth Processes in the Synthesis of Collidal Gold. Discussions of the Faraday Society 1951, 11, 55-75.

[167] Frens, G. Controlled Nucleation for the Regulation of the Particle Size in Monodisperse Gold Suspensions. Nature Physical Science 1973, 241 (105), 20-22.

[168] Hill, H. D.; Mirkin, C. a. The Bio-Barcode Assay for the Detection of Protein and Nucleic Acid Targets Using DTT-Induced Ligand Exchange. Nature protocols 2oo6, 1 (1), 324-336.

[169] McGilvray, K. L.; Decan, M. R.; Wang, D.; Scaiano, J. C. Facile Photochemical Synthesis of Unprotected Aqueous Gold Nanoparticles. Journal of the American Chemical Society 2oo6, 128 (50), 15980-15981.

[170] Rahman, M.; Rebrov, E. Microreactors for Gold Nanoparticles Synthesis: From Faraday to Flow. Processes 2014, 2 (2), 466-493.

[171] Alric, C.; Miladi, I.; Kryza, D.; Taleb, J.; Lux, F.; Bazzi, R.; Billotey, C.; Janier, M.; Perriat, P.; Roux, S.; Tillement, O. The Biodistribution of Gold Nanoparticles Designed for Renal Clearance. Nanoscale 2013, 5 (13), 5930-5939.

[172] Tsunoyama, H.; Ichikuni, N.; Tsukuda, T. Microfluidic Synthesis and Catalytic Application of PVPStabilized, Approximately 1 Nm Gold Clusters. Langmuir 2oo8, 24 (20), 11327-11330.

[173] Shang, L.; Dong, S.; Nienhaus, G. U. Ultra-Small Fluorescent Metal Nanoclusters: Synthesis and Biological Applications. Nano Today 2011, 6 (4), 401-418.

[174] Link, S.; El-Sayed, M. A. M. Size and Temperature Dependence of the Plasmon Absorption of Colloidal Gold Nanoparticles. The Journal of Physical Chemistry B 1999, 103 (21), 4212-4217.

[175] Zuber, A.; Purdey, M.; Schartner, E.; Forbes, C.; Van Der Hoek, B.; Giles, D.; Abell, A.; Monro, T.; Ebendorff-Heidepriem, H. Detection of Gold Nanoparticles with Different Sizes Using Absorption and Fluorescence Based Method. Sensors and Actuators, B: Chemical 2016, 227, 117-127.

[176] Cottancin, E.; Celep, G.; Lermé, J.; Pellarin, M.; Huntzinger, J. R.; Vialle, J. L.; Broyer, M. Optical Properties of Noble Metal Clusters as a Function of the Size: Comparison between Experiments and a Semi-Quantal Theory. In Theoretical Chemistry Accounts; Springer: Berlin Heidelberg, 20o6; Vol. 116 , pp 514-523.

[177] Lakowicz, J. R. Principles of Fluorescence Spectroscopy, 3rd ed.; Springer: New York, 2006.

[178] Chen, R. F.; Knutson, J. R. Mechanism of Fluorescence Concentration Quenching of Carboxyfluorescein in Liposomes: Energy Transfer to Nonfluorescent Dimers. Analytical Biochemistry 1988, 172 (1), 6177 .

[179] Sun, W. Q.; Leopold, A. C.; Crowe, L. M.; Crowe, J. H. Stability of Dry Liposomes in Sugar Glasses. Biophysical Journal 1996, 70 (4), 1769-1776.

[180] de la Maza, A.; Parra, J. L.; Sanchez Leal, J. Alteration of Permeability of Neutral and Electronegatively Charged Liposomes by Alkyl Sulfate Surfactants. Langmuir 1992, 8 (10), 2422-2426.

[181] Goldburg, W. I. Dynamic Light Scattering. American Journal of Physics 1999, 67 (12), 1152-1160.

[182] Provencher, S. W. CONTIN : A General Purpose Constrained Regularization Program for Inverting Noisy Linear Algebraic and Integral Equations. Computer Physics Communications 1982, 27, 229242. 
[183] Hallett, F. R.; Watton, J.; Krygsman, P. Vesicle Sizing: Number Distributions by Dynamic Light Scattering. Biophysical Journal 1991, 59 (2), 357-362.

[184] Bhattacharjee, S. DLS and Zeta Potential - What They Are and What They Are Not? Journal of Controlled Release 2016, 235, 337-351.

[185] Harris, D. C. Quantitative Chemical Analysis, 7th ed.; W. H. Freeman and Company: New York, 2007.

[186] Gill, S. C.; von Hippel, P. H. Calculation of Protein Extinction Coefficients from Amino Acid Sequence Data. Analytical biochemistry 1989, 182 (2), 319-326.

[187] Greenfield, N.; Fasman, G. D. Computed Circular Dichroism Spectra for the Evaluation of Protein Conformation. Biochemistry 1969, 8 (10), 4108-4116.

[188] Kelly, S. M.; Price, N. C. The Use of Circular Dichroism in the Investigation of Protein Structure and Function. Current protein \& peptide science 2ooo, 1 (4), 349-384.

[189] Dixon, M. C. Quartz Crystal Microbalance with Dissipation Monitoring: Enabling Real-Time Characterization of Biological Materials and Their Interactions. Journal of Biomolecular Techniques 2008, 19 (3), 151-158.

[190] Rodahl, M.; Höök, F.; Krozer, A.; Brzezinski, P.; Kasemo, B. Quartz Crystal Microbalance Setup for Frequency and Q-Factor Measurements in Gaseous and Liquid Environments. Review of Scientific Instruments 1995, 66 (7), 3924-3930.

[191] Keller, C. A.; Kasemo, B. Surface Specific Kinetics of Lipid Vesicle Adsorption Measured with a Quartz Crystal Microbalance. Biophysical Journal 1998, 75 (3), 1397-1402.

[192] Cho, N.-J.; Frank, C. W.; Kasemo, B.; Höök, F. Quartz Crystal Microbalance with Dissipation Monitoring of Supported Lipid Bilayers on Various Substrates. Nature protocols 2010, 5 (6), 1096-1106.

[193] Wieprecht, T.; Beyermann, M.; Seelig, J. Thermodynamics of the Coil-a-Helix Transition of Amphipathic Peptides in a Membrane Environment: The Role of Vesicle Curvature. Biophysical Chemistry 2002, 96 (2-3), 191-201.

[194] Lewis, E. A.; Murphy, K. P. Isothermal Titration Calorimetry. In Protein-Ligand Interactions, Methods and Applications; Nienhaus, G. U., Ed.; Humana Press: Totowa, New Jersey, 2005; pp 1-16.

[195] Liedberg, B.; Nylander, C.; Lunström, I. Surface Plasmon Resonance for Gas Detection and Biosensing. Sensors and actuators 1983, 4, 299-304.

[196] Homola, J. Surface Plasmon Resonance Sensors for Detection of Chemical and Biological Species. Chemical Reviews 2008, 108 (2), 462-493.

[197] Löfås, S.; Johnsson, B. A Novel Hydrogel Matrix on Gold Surfaces in Surface Plasmon Resonance Sensors for Fast and Efficient Covalent Immobilization of Ligands. Journal of the Chemical Society, Chemical Communications 1990, 21, 1526-1528.

[198] Cooper, M. A.; Hansson, A.; Löfås, S.; Williams, D. H. A Vesicle Capture Sensor Chip for Kinetic Analysis of Interactions with Membrane-Bound Receptors. Analytical Biochemistry 2000, 277 (2), 196-205.

[199] Anderluh, G.; Beseničar, M.; Kladnik, A.; Lakey, J. H.; Maček, P. Properties of Nonfused Liposomes Immobilized on an L1 Biacore Chip and Their Permeabilization by a Eukaryotic Pore-Forming Toxin. Analytical Biochemistry 2oo5, 344 (1), 43-52.

[200] Erb, E.-M.; Chen, X.; Allen, S.; Roberts, C. J.; Tendler, S. J. B.; Davies, M. C.; Forsén, S. Characterization of the Surfaces Generated by Liposome Binding to the Modified Dextran Matrix of a Surface Plasmon Resonance Sensor Chip. Analytical Biochemistry 200o, 280 (1), 29-35.

[201] Mozsolits, H.; Aguilar, M. I. Surface Plasmon Resonance Spectroscopy: An Emerging Tool for the Study of Peptide-Membrane Interactions. Peptide Science 2002, 66 (1), 3-18. 
[202] Williams, D. B.; Carter, B. C. Transmission Electron Microscopy, 2nd ed.; Springer Science: New York, 2009. 


\section{Papers}

The papers associated with this thesis have been removed for copyright reasons. For more details about these see:

http://urn.kb.se/resolve?urn=urn:nbn:se:liu:diva-150419 